\title{
Um sistema de rastreamento de olhar tolerante a movimentações da face
}

\author{
Flávio Luiz Coutinho \\ DISSERTAÇÃO APRESENTADA \\ $\mathrm{AO}$ \\ INSTITUTO DE MATEMÁTICA E ESTATÍSTICA \\ DA \\ UNIVERSIDADE DE SÃO PAULO \\ PARA \\ OBTENÇÃO DO TÍTULO DE MESTRE \\ EM \\ CIÊNCIAS \\ Área de Concentração: Ciência da Computação \\ Orientador: Prof. Dr. Carlos Hitoshi Morimoto
}

São Paulo, maio de 2006 


\title{
Um sistema de rastreamento de olhar tolerante a movimentações da face
}

\author{
Este exemplar corresponde à redação final da dis- \\ sertação devidamente corrigida e defendida por \\ Flávio Luiz Coutinho e aprovada pela Comissão \\ Julgadora.
}

São Paulo, 5 de maio de 2006.

Banca Examinadora :

Prof. Dr. Carlos Hitoshi Morimoto (orientador) - IME/USP

Prof. Dr. Ronaldo Fumio Hashimoto - IME/USP

Profa. Dra. Maria Cristina Ferreira de Oliveira - ICMC/USP 


\section{Agradecimentos}

A Deus, por todos os dias me iluminar.

Ao meu orientador, Carlos Hitoshi Morimoto, pelo apoio, paciência e oportunidade de trabalhar neste projeto, além do contínuo incentivo, sempre mostrando o melhor caminho a seguir nos momentos difíceis. Agradeço também pela confiança depositada no meu trabalho.

Aos amigos e colegas do IME com os quais pude trocar informações e experiências, em especial àqueles que participaram dos testes do rastreador de olhar aqui apresentado.

Por fim, agradeço aos meus pais, Liane e Walter, aos meus irmãos Audrey e Walter, a minha noiva, Monete, e a toda minha família pelo apoio, não só durante a realização deste trabalho, mas durante todas as etapas percorridas para chegar até aqui. 


\section{Resumo}

A crescente capacidade do poder computacional e a proliferação de dispositivos ao nosso redor vem permitindo o desenvolvimento de novas e sofisticadas interfaces para interação humano-computador que reagem à presença e ao estado de seus usuários. Como o olhar tem a capacidade de transmitir muitas informações sobre o usuário, rastreadores de olhar, dispositivos que estimam a direção para onde uma pessoa olha, tem papel importante no desenvolvimento de tais interfaces. Entre suas aplicações temos o auxílio a pessoas com dificuldades motoras, que podem utilizar um rastreador de olhar como substituto ao mouse, aplicações de diagnóstico, que estudam evidências do comportamento humano, ou ainda o desenvolvimento de interfaces que utilizem a informação sobre o olhar como um canal a mais de comunicação com o usuário para perceber suas intenções. Muitas técnicas para atingir tal objetivo foram desenvolvidas mas as tradicionais ainda oferecem certas dificuldades de uso para seus usuários como a intolerância a movimentos de cabeça e a necessidade de calibração por sessão de uso. Neste trabalho fizemos um levantamento de uma série de técnicas de rastreamento de olhar, indo das mais tradicionais até algumas mais recentes que visam melhorar a facilidade de uso destes sistemas. Uma das técnicas mais promissoras utiliza múltiplas fontes de luz fixadas nos cantos do monitor do computador. Através da análise da posição dos reflexos gerados por essas fontes de luz sobre a córnea, juntamente com a informação da posição da pupila, presentes em imagens capturadas do olho, 
é possível estimar o ponto observado no monitor. Devido às suas vantagens ela foi escolhida para estudo mais detalhado e implementação. Extensos testes utilizando simulações foram realizados para avaliar seu desempenho. Foi também desenvolvida uma extensão dessa técnica, utilizando um modelo mais preciso do olho, visando melhorar sua precisão. Ao final apresentamos nossa implementação, baseada nessa extensão da técnica original, que é tolerante a movimentação da face e mostramos os resultados obtidos em testes realizados com um grupo de usuários. 


\section{Abstract}

Recent advances in computing power and the proliferation of computing devices around us allowed the development of new computer interfaces which can react to the presence and state of its users. Since gaze can transmit a lot of information about the user, gaze trackers, devices that can estimate the direction which a person is looking at, have an important role in the development of such interfaces. Among gaze tracking applications, we have aid for people with limited motor skills, human behavior studies, and the development of interfaces that can take gaze information as an additional communication channel with the user. Lots of techniques have been developed to reach this goal, but they have some problems that make them hard to be widely used. These problems are the need of calibration for each use session and the need to keep the user's head still. In this work we studied some of the existing gaze tracking techniques, from the more traditional ones to more recent ones. One of the most interesting techniques makes use of multiple light sources fixed at the monitor's corners. By analyzing the positions of corneal reflections and the pupil present in captured images of the eye, it is possible to estimate the gaze point on the monitor screen. Due to its advantages this technique was chosen for a deeper study and implementation. Lots of experiments using simulated data have been carried out to validate the technique. Using a more accurate model of the eye, an extension for this technique was also developed 
to increase its precision. Finally, we present our implementation, that allows for large head movement, as well as test results obtained from real users. 


\section{Sumário}

1 Introdução 1

2 Técnicas de estimação do olhar $\quad 7$

2.1 Estrutura e modelo do olho . . . . . . . . . . . . . . . . . . 8

2.2 Técnicas intrusivas . . . . . . . . . . . . . . . . . . 12

2.3 Técnicas remotas tradicionais . . . . . . . . . . . . . . . . . . 14

2.4 Técnicas robustas a movimentos de cabeça . . . . . . . . . . . . . . . . 20

2.4.1 Uma câmera . . . . . . . . . . . . . . . . . . . . 21

2.4.2 Múltiplas Câmeras . . . . . . . . . . . . . . . . . . . 24

2.4.3 Projeção de padrão de luz . . . . . . . . . . . . . . . . . . . . 28

3 Análise exploratória $\quad 41$

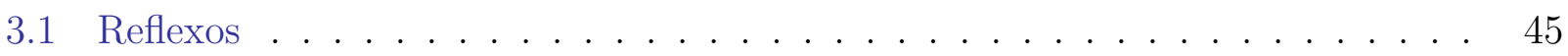

3.2 Sem calibração do $\alpha \ldots \ldots$. . . . . . . . . . . . . . . . . . . . . . 48

3.3 Com calibração . . . . . . . . . . . . . . . . . . . . 53

3.4 Conclusão . . . . . . . . . . . . . . . . . . . . . . 57

4 Novo Método $\quad 61$ 
5 Implementação $\quad 69$

5.1 Hardware ............................. . . . 69

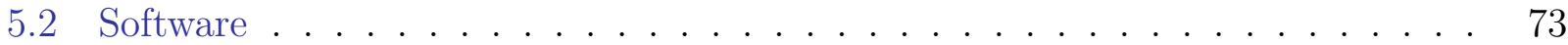

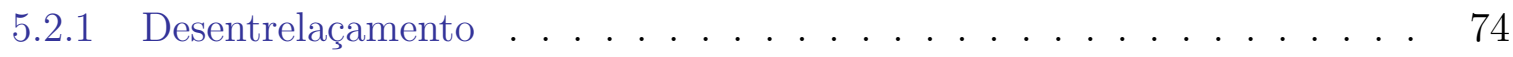

5.2 .2 Detecção inicial da pupila . . . . . . . . . . . . . . . . . . 74

5.2.3 Procura dos reflexos sobre a córnea . . . . . . . . . . . . . 76

5.2.4 Procura detalhada da pupila . . . . . . . . . . . . . . . 79

5.2.5 Estimando a direção do olhar ... . . . . . . . . . . . . 81

6 Resultados $\quad 83$

$\begin{array}{llr}7 & \text { Conclusão } & 91\end{array}$ 


\section{Capítulo 1}

\section{Introdução}

O avanço da tecnologia de computadores tem mudado a maneira como nos relacionamos com essas máquinas. Nas últimas décadas vimos a mudança da era do mainframe (onde muitos usuários compartilhavam uma única máquina) para a era do computador pessoal onde cada usuário possui sua própria máquina. Hoje em dia nos vemos cada vez mais rodeados de múltiplos dispositivos computacionais. Apesar dessa tendência proporcionar um aumento de produtividade nas atividades das pessoas, tal beneficio tem um custo associado: a exigência de se estar constantemente disponível para atender as notificações emitidas por tais aparelhos que disputam a atenção do usuário entre si [Ver03]. Como exemplo podemos citar um cliente de correio eletrônico que soa um alarme sempre que chega uma nova mensagem. Embora possa ser útil para chamar a atenção do usuário, é bastante provável que o alarme acabe distraindo o usuário da sua atividade prejudicando sua produtividade. Entretanto, se fosse possível notificar a chegada de novas mensagens apenas nos momentos em que o usuário olha para um ícone específico da sua área de trabalho, evitaria-se essa dispersão da sua atenção.

Cientes desse custo, pesquisadores da área de Interação Humano Computador (IHC) estão desenvolvendo novas maneiras para a interação de dispositivos computacionais com seus 
usuários que visam conservar a atenção destes ao invés de distraí-los. Para isso é preciso que os novos sistemas tenham a capacidade de obter informações sobre seus usuários por canais de comunicação adicionais. Essas interfaces sensíveis a contexto, onde este é definido pela atenção do usuário, são chamadas interfaces prestativas.

Como nosso corpo e, em especial, a face e os olhos são eficientes comunicadores da nossa atenção, técnicas e ferramentas de Visão Computacional vem sendo bastante exploradas pela área de IHC a fim de criar interfaces que possam reagir de forma mais adequada à presença e ao estado do usuário. Tópicos como detecção e rastreamento de faces, reconhecimento de gestos, e rastreamento do olhar são alguns temas bastante estudados e aplicados.

Neste trabalho tratamos o problema de rastreamento (ou estimação) do olhar. Sistemas de rastreamento de olhar permitem estimar a direção para onde uma pessoa está olhando. A estimação pode ser tanto no espaço 3D, determinando a linha de visão do usuário, quanto no espaço 2D. Neste último caso determina-se o ponto observado sobre um plano de interesse (por exemplo a tela do monitor).

As técnicas de rastreamento de olhar existentes podem ser classificadas em dois grupos: técnicas intrusivas e técnicas não intrusivas. São consideradas técnicas intrusivas aquelas que exigem para seu uso a utilização de algum tipo de equipamento em contato físico com o usuário como, por exemplo, capacetes, eletrodos ou lentes de contato especiais. Essas técnicas não são interessantes para aplicações interativas pois requerem um tempo de preparação elevado e o uso prolongado desses equipamentos pode se tornar desconfortável para o usuário. Nas técnicas não intrusivas (também chamadas de técnicas remotas) o uso de tais equipamentos é dispensado e, normalmente, utiliza-se técnicas de visão computacional para processar imagens do usuário obtidas por meio de câmeras (a quantidade de câmeras pode variar conforme a técnica). As técnicas remotas oferecem maior conforto, permitindo um maior tempo de uso por parte das pessoas, mesmo que a precisão no rastreamento seja, em geral, menor do que 
a obtida pelas técnicas intrusivas mais precisas. Tipicamente, essas técnicas procuram, nas imagens, por pontos característicos do olho como a pupila, a íris e reflexos gerados por fontes de luz. Em seguida, a partir dos pontos detectados, aplica-se algum algoritmo que converta essas informações no ponto observado pelo usuário.

Para fins de usabilidade, as técnicas de rastreamento de olhar podem ainda ser classificadas em: técnicas que exigem calibração e técnicas que não exigem calibração. Apesar das técnicas do primeiro grupo apresentarem bons resultados, a obtenção da calibração pode ser um processo incômodo ao usuário quando é necessário ser feita freqüentemente. Devido ao fato da função de calibração normalmente estar associada a um posicionamento do usuário, a precisão dessas técnicas são afetadas com a movimentação da pessoa. Esses problemas, isto é, a constante necessidade de recalibrar o sistema e restrições à movimentos da cabeça, limitam a usabilidade dessas técnicas, dificultando a ampla difusão e utilização das mesmas para uso cotidiano fora de ambientes controlados e de experiências. As técnicas que não requerem calibração correspondem a trabalhos mais recentes. Essas técnicas substituem o processo de calibração por um processo de medição de características do usuário que podem ser armazenadas, e que, portanto, pode ser realizado apenas uma vez. Por usarem modelos geométricos mais avançados, elas também apresentam maior robustez a movimentos da cabeça, oferecendo uma usabilidade ainda melhor.

Andrew T. Duchowski [Duc02], fez um levantamento de aplicações do rastreamento do olhar dividindo-as em dois grupos: aplicações de diagnóstico e aplicações interativas. As aplicações de diagnóstico são aquelas que utilizam dados obtidos pelo rastreador como evidência do comportamento visual e da atenção de um indivíduo. Já as aplicações interativas usam dados obtidos via rastreador para responder ou interagir com o usuário conforme o movimento observado do olhar.

Exemplos de aplicações de diagnóstico incluem estudos neurológicos que relacionam da- 
dos obtidos pelo rastreamento com a atividade cerebral e estudos psicológicos que analisam informações obtidas via rastreador e as cruzam com outras informações como a atividade realizada. Exemplos de atividades estudadas com o auxílio de rastreamento do olhar seriam leitura, direção de veículos, ou mesmo atividades mais específicas como inspeção visual realizada por pessoas em fábricas. Os pontos de fixação do olhar, o tempo de fixação, número de fixações durante uma atividade e a distribuição espacial entre elas são alguns parâmetros relevantes do movimento do olho que um rastreador de olhar ajudaria a obter, daí a sua utilidade para esse tipo de estudo.

No caso das aplicações interativas, o uso mais comum talvez seja a utilização dos rastreadores como dispositivos apontadores alternativos, auxiliando pessoas portadoras de deficiências físicas e permitindo o desenvolvimento de aplicações mais naturais e intuitivas. Nem sempre, contudo, o objetivo é utilizar rastreadores como substitutos diretos do mouse. O simples reconhecimento de gestos do olho como piscadas, fixações e movimentação (sem fazer o rastreamento do ponto observado) pode fornecer informações para serem aplicadas em uma interface prestativa [Sel04]. Até mesmo o simples reconhecimento da presença de olho pode ser utilizado para promover a interação do usuário com aplicativos [SVS03]. O trabalho desenvolvido por Zhai et al. [ZMI99] e estendido por Barcelos [Bar05] são exemplos onde um rastreador de olhar é aplicado de forma indireta. Através da combinação do rastreador e da manipulação do mouse, permite-se fazer seleções finas de forma manual sobre uma região de interesse da tela que por sua vez é definida pelo olhar do usuário.

Este trabalho foi realizado no Laboratório de Tecnologias para Interação (LaTIn) do Instituto de Matemática e Estatística da Universidade de São Paulo, que tem desenvolvido pesquisas e tecnologias para IHC que utilizam técnicas de visão computacional. Como exemplo de trabalhos desenvolvidos no LaTIn temos: rastreadores de faces [Bar06], interfaces baseadas em gestos [CMZ05] e rastreadores de olhar baseados na técnica de reflexão sobre a córnea 
[Bar05, MM05], uma técnica tradicional, utilizando porém um detector e rastreador mais robusto de olhos.

Nosso objetivo com este trabalho foi desenvolver um sistema rastreador de olhar que minimizasse os problemas dos rastreadores remotos tradicionais, ou seja, que minimizasse as exigências de calibração e restrições sobre a movimentação da cabeça. Também era desejável que o rastreador possuísse uma configuração de hardware simples, de fácil manipulação e que não utilizasse qualquer equipamento em contato físico com seus usuários a fim de prover maior conforto. Para alcançar tais objetivos, foi feito um levantamento bibliográfico das principais técnicas de rastreamento de olhar existentes a fim de escolher aquela que melhor atendia nossas exigências. Em seguida, foram feitos testes a partir simulações para avaliar o desempenho da técnica escolhida para finalmente implementar o rastreador. Como contribuição deste trabalho temos o desenvolvimento de um rastreador de olhar mais acessível para pessoas em geral no que diz respeito à facilidade e praticidade de uso.

Nos próximos capítulos discutimos em maiores detalhes as técnicas estudadas, as implementações realizadas e os resultados experimentais obtidos. O capítulo 2 apresenta a revisão bibliográfica das técnicas de rastreamento de olhar, passando por todos os tipos de técnicas, mas dando maior atenção às técnicas mais recentes. Descrevemos também brevemente a estrutura do olho humano, para melhor entendimento dos princípios de funcionamento dessas técnicas. Por fim veremos, ainda nesse capítulo, a técnica escolhida para nossa implementação do rastreador de forma mais detalhada. Na seqüência, no capítulo 3, detalhamos algumas simulações conduzidas para verificar a eficácia da técnica escolhida e, a partir dos resultados obtidos, apresentamos uma extensão para ela no capítulo 4 a fim de contornar limitações encontradas. No capítulo 5 descrevemos como foi feita a implementação do rastreador e os resultados obtidos em testes feitos por um grupo de usuários são apresentados no capítulo 6. Finalmente, o capítulo 7 apresenta conclusões e caminhos futuros para dar continuidade a 
nossa pesquisa. 


\section{Capítulo 2}

\section{Técnicas de estimação do olhar}

A estimação (ou rastreamento) de olhar consiste em determinar a direção para onde uma pessoa está olhando. Havendo informações sobre o ambiente cercando o usuário é possível também estimar qual o ponto observado.

Como já discutido, as técnicas de estimação do olhar podem ser classificadas em intrusivas e não intrusivas. As intrusivas são aquelas que exigem o uso de algum equipamento em contato direto com o usuário (como lentes de contato, capacetes e eletrodos), o que não é interessante quando visamos a utilização de rastreadores de olhar em aplicações interativas. As técnicas não intrusivas são em geral baseadas em visão computacional e também são conhecidas como técnicas remotas. Apesar de oferecer maior conforto de uso do que as técnicas intrusivas, as técnicas remotas tradicionais ainda possuem duas limitações que dificultam a sua popularização, que são:

- a necessidade freqüente de calibração;

- a necessidade de restringir a movimentação da cabeça.

Dessa forma, a eliminação ou pelo menos a minimização dessas limitações é algo bastante 


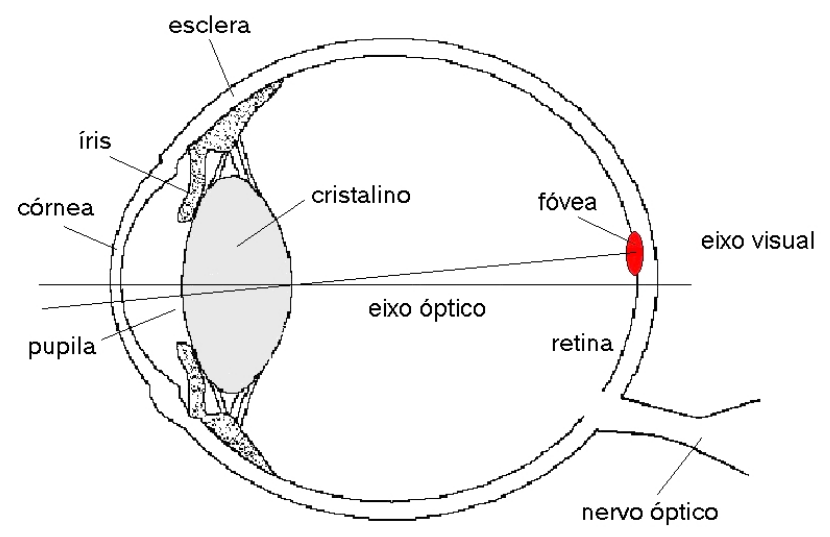

Figura 2.1: Diagrama da estrutura do olho humano.

desejável.

Revisões bibliográficas sobre rastreamento de olhar podem ser encontradas em [YS75], [GEN95], [Duc03] e [MM05]. Neste capítulo serão apresentadas rapidamente algumas das técnicas tradicionais mais relevantes e daremos maior ênfase para técnicas mais recentes que sugerem novos modelos geométricos para permitir maior tolerância à movimentos de cabeça e eliminar a necessidade freqüente de calibração. Antes de introduzi-las, vamos descrever brevemente a anatomia do olho e definir um modelo geométrico criado para representar sua estrutura. O conhecimento sobre a anatomia do olho e seu funcionamento facilitará a descrição do princípio de funcionamento de cada técnica e permitirá uma discussão sobre seu desempenho e precisão.

\subsection{Estrutura e modelo do olho}

A figura 2.1 ilustra a estrutura do olho humano. O olho possui uma forma aproximadamente esférica que é envolta por um tecido esbranquiçado, chamado esclera [WS82]. A esclera cobre 
praticamente toda a superfície do globo ocular com exceção da parte anterior por onde incidem os raios de luz. O orifício por onde entram esses raios é chamado pupila. A musculatura do olho que define a pupila é chamada de íris, que consiste na parte colorida do olho e atua como um diafragma que aumenta ou diminui a abertura da pupila, regulando a quantidade de luz no interior do olho. A fronteira da esclera com a íris é chamada de limbus. A córnea é uma membrana transparente que cobre a íris, e possui uma curvatura mais acentuada que o globo ocular em si.

Atrás da íris, localiza-se o cristalino, que é uma lente que atua no processo de formação das imagens sobre o fundo do olho. A região entre o cristalino e a córnea é preenchida por um fluido chamado humor aquoso. O cristalino possui a capacidade de se deformar para ajustar o foco conforme a distância do objeto sendo observado. O fundo da região interna do olho, onde são formadas as imagens, é chamado de retina. Nela existem 2 tipos de células foto receptoras chamadas de cones e bastonetes, que captam informações sobre cor e luminosidade. Sobre a retina existe uma pequena região chamada fóvea, com grande concentração de cones, que é de especial interesse pois é responsável pela visão de detalhes. A região interna do olho compreendida entre o cristalino e a retina é preenchida pelo humor vítreo.

Assim como uma câmera, o olho é um dispositivo de captura de imagem e seus principais elementos ópticos são a córnea, a pupila e o cristalino. Como esses elementos não são perfeitamente alinhados, o eixo óptico do olho é definido como o eixo aproximado conectando os centros de curvatura de tais elementos. Porém, o eixo que define a linha de visão real é o eixo visual, definido pela linha conectando o ponto observado e a fóvea e que passa pelos pontos nodais do olho. Tipicamente a diferença angular entre esses eixos tem um valor médio de $5^{\circ}$, em um intervalo que varia de 4-8 [WS82]. Essa diferença de eixos é uma característica importante na estimação do olhar pois computar apenas o eixo óptico não significa que a estimação do olhar esteja de acordo com o ponto real observado pelo usuário. 
Para testar algoritmos e técnicas de rastreamento de olhar, a utilização de modelos que representem o olho adequadamente se faz necessário. O modelo que utilizamos em nosso trabalho é o modelo de olho de Gullstrand [Lon74]. Nesse modelo, o olho é representado através de superfícies esféricas, juntamente com os valores médios das dimensões de cada estrutura e os índices de refração de cada meio atravessado pela luz. Esses valores são mostrados na tabela 2.1, que mostra o caminho percorrido pela luz até a retina, e a figura 2.2 ilustra esse modelo, destacando as estruturas mais importantes para o nosso estudo. Morimoto e Mimica [MM05] também utilizaram esse modelo para gerar imagens sintéticas de um olho típico usando a técnica de traçamento de raios (ray tracing) para estudar o comportamento de funções de calibração em rastreadores de olhar. Um exemplo de imagem gerada por esse modelo pode ser vista na figura 2.3.

\begin{tabular}{|l|c|c|c|}
\hline & Posição $(\mathbf{m m})$ & Raio $(\mathbf{m m})$ & Índice de refração após a superfície \\
\hline Córnea & 0 & 7.7 & 1.376 \\
\hline & 0.5 & 6.8 & 1.336 \\
\hline Cristalino & 3.2 & 5.33 & 1.385 \\
\hline & 3.8 & 2.65 & 1.406 \\
\hline & 6.6 & -2.65 & 1.385 \\
\hline & 7.2 & -5.33 & 1.336 \\
\hline Retina & 24.0 & -11.5 & \\
\hline
\end{tabular}

Tabela 2.1: dimensões e índices de refração para as estruturas do olho percorridas por um raio de luz da córnea até a retina, segundo o modelo de Gullstrand.

O modelo de Gullstrand, apesar de simplificado, ilustra claramente que, quando um raio de luz incide sobre a córnea e penetra no olho, ele atravessa 4 camadas até incidir sobre a retina. A cada transição de meio material presente nessas camadas parte da luz é refletida gerando as chamadas imagens de Purkinje [YS75] (veja figura 2.4). A primeira imagem de Purkinje é o reflexo mais forte e brilhante gerado sobre a córnea, que é facilmente detectado por uma 


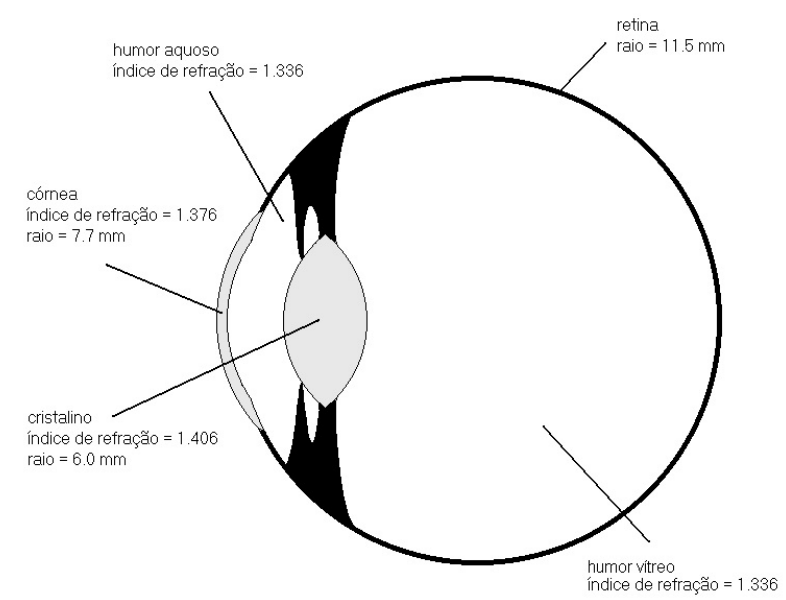

Figura 2.2: modelo do olho Gullstrand.

câmera e é utilizado por várias técnicas para rastreamento do olhar. Os demais reflexos são bem mais difíceis de se detectar, exigindo equipamentos especiais.

O uso de fontes de luz é também explorado em técnicas para detecção da pupila. Ebisawa [Ebi95] e Morimoto et al. [MKAF00, MF00] exploram uma propriedade fisiológica do olho pela qual a imagem de uma pupila iluminada por uma fonte de luz próxima do eixo óptico da câmera aparece brilhante (devido à luz refletida do interior do olho). Por outro lado, quando a fonte de luz está afastada do eixo óptico da câmera, a pupila aparece escura na imagem (veja figura 2.5). Uma vantagem da utilização desta característica do olho é que ela é bastante incomum em outros tipos de objetos. Dessa forma, para imagens obtidas sob estas duas condições de iluminação, as pupilas costumam ser os únicos pontos que apresentam grande contraste entre as imagens, facilitando sua localização. É importante notar que existe uma grande variação observada nesse efeito da pupila brilhante entre as pessoas [NWKF02], o que pode prejudicar o desempenho de sistemas de rastreamento baseados nessa característica. 


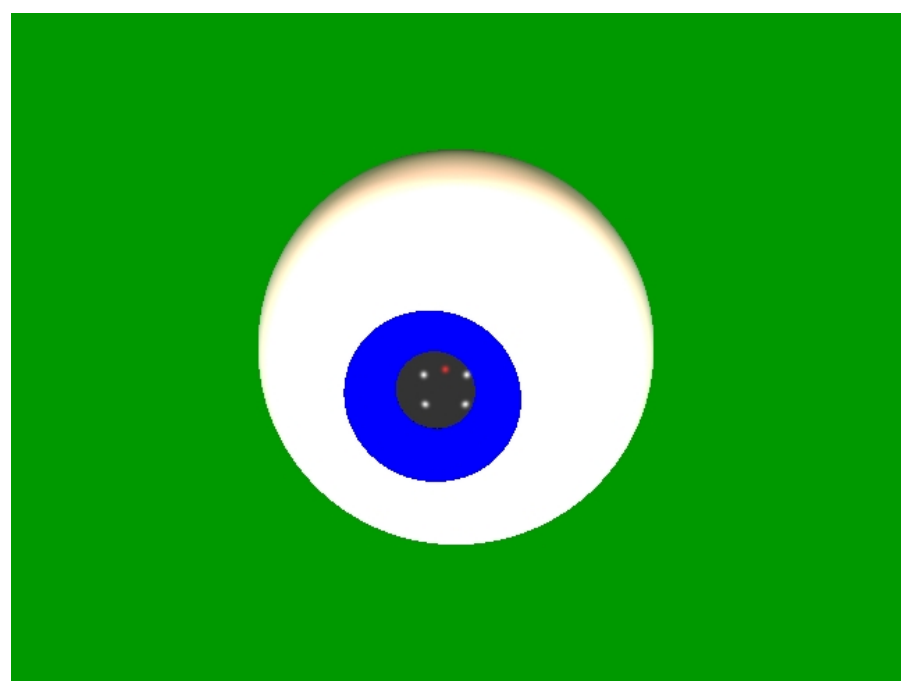

Figura 2.3: imagem gerada por traçamento de raios a partir do modelo de Gullstrand.

\subsection{Técnicas intrusivas}

Uma dos métodos mais tradicionais entre as técnicas intrusivas para detecção e rastreamento do olhar são as técnicas baseadas no uso de lentes de contato. Robinson [Rob63] usa uma pequena bobina embutida na lente de contato que é posicionada sobre a córnea. Uma pequena sucção é utilizada para manter a lente firme e evitar que ela se desloque devido a movimentos rápidos do olho. O usuário é então colocado dentro de um campo eletromagnético e, a partir da amplitude da corrente elétrica induzida sobre a bobina da lente, é possível determinar a direção do olhar. Apesar de ser um método altamente intrusivo, sua precisão é bastante alta (menor que $1^{\circ}$ ) e sua freqüência de captura também é bastante elevada (menos que 1 milisegundo), segundo estudo apresentado por Geest e Frens [GF02].

Outra técnica intrusiva mas de menor custo que a anterior, desenvolvida por Kaufman et al. [KBS93], utiliza a medida do potencial elétrico da pele. Através do posicionamento de eletrodos ao redor dos olhos é possível medir pequenas diferenças no potencial elétrico da pele 


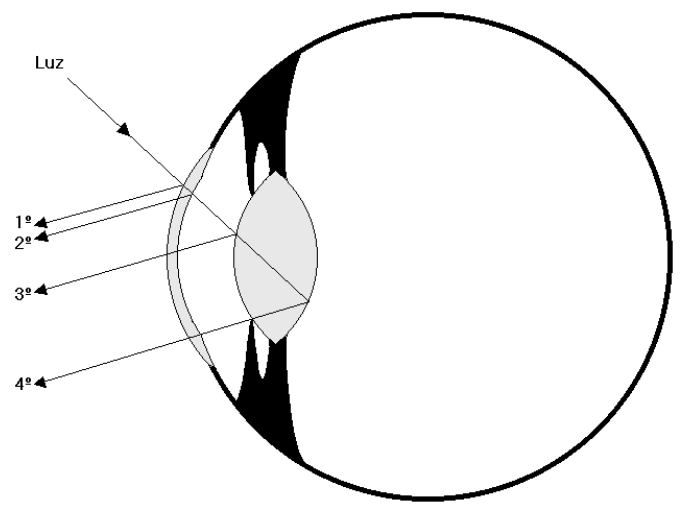

Figura 2.4: formação dos reflexos gerados por uma fonte de luz.
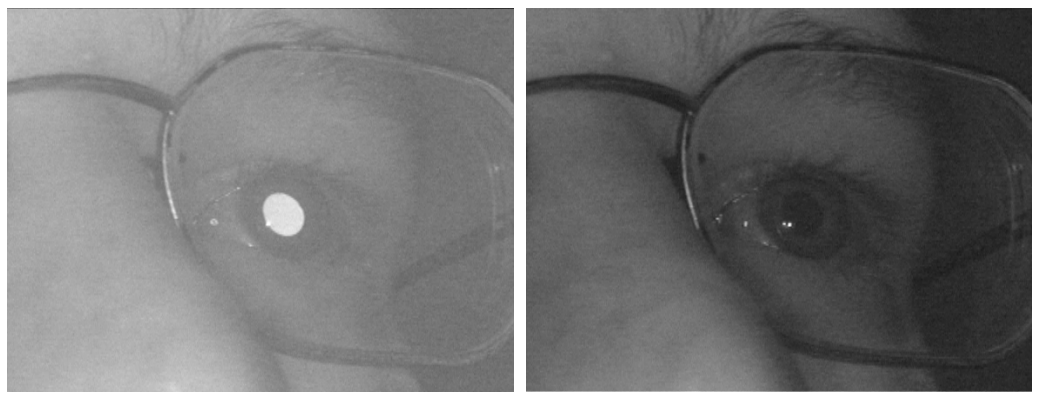

Figura 2.5: à esquerda, imagem da pupila brilhante iluminada por uma fonte de luz localizada no eixo óptico da câmera. À direita, imagem da pupila escura, iluminada por fonte de luz afastada do eixo óptico da câmera. 
que podem ser mapeadas aos movimentos dos olhos. A precisão deste método é da ordem de $2^{\circ}$. Esta é uma técnica bastante comum para a gravação dos movimentos dos olhos em aplicações clínicas devido a sua simplicidade. Contudo não é apropriada para utilização no dia a dia pelo desconforto decorrente da utilização de eletrodos fixados à pele.

Ruelen et al. [RMK $\left.{ }^{+} 88\right]$ utilizam fontes de luz infravermelhas e transistores foto-sensíveis posicionados sobre e abaixo do olho respectivamente. As luzes e os sensores são montados em um suporte similar a um óculos de modo que o limbus seja sempre iluminado. Os transistores foto-sensíveis transformam a luz refletida pelo olho em uma voltagem. A voltagem dos transistores localizados na região nasal da face é comparada à voltagem dos transistores localizados na região temporal da face e a diferença computada é proporcional aos desvios dos olhos. Este sistema possui uma alta precisão, em torno de 2'. Contudo, o uso do aparato também restringe o conforto para longos períodos de utilização.

\subsection{Técnicas remotas tradicionais}

Cornsweet e Crane [CC73] desenvolveram outro método bastante preciso para rastreamento do olhar que utiliza a $1^{\circ}$ e a $4^{\circ}$ imagem de Purkinje. O princípio de funcionamento utilizando esses dois reflexos é o seguinte: quando o olho translada no espaço ambos os reflexos se movimentam juntos, mas quando este rotaciona, os reflexos movem-se independentemente, modificando a posição relativa entre eles. Essa modificação da posição relativa entre os dois reflexos é utilizada para computar a orientação do olho. Este método possui uma alta precisão, da ordem de 1'.

Baluja e Pomerleau [BP94] utilizam redes neurais para rastrear o olhar. Nesta técnica, o sistema detecta o olho do usuário através da procura do reflexo especular gerado por uma fonte de luz fixa. A localização do reflexo é utilizada também para delimitar a janela de procura 
do olho no próximo quadro de vídeo a ser processado. Em seguida, uma janela em torno do reflexo localizado é extraída e a imagem resultante é utilizada como entrada para uma rede neural. Para coletar os dados de treinamento da rede neural, o usuário deve seguir um cursor em movimento que se move sobre um caminho definido. Neste processo de treinamento a imagem do olho é extraída e associada com a coordenada (x, y) do cursor observado pelo usuário. Um total de 2000 pontos de treinamento foram coletados e a precisão média obtida foi de $1.7^{\circ}$.

Stiefelhagen et al. [SYW97] também utilizaram redes neurais para estimar a direção do olhar, mas não necessitam de fontes de luz para gerar reflexos sobre a córnea. Neste trabalho a detecção da região do olho é feita detectando-se primeiramente a região da imagem correspondente à face do usuário (utilizando um modelo baseado em cores), e em seguida localizando duas regiões escuras correspondentes às pupilas. Uma vez detectadas, elas são rastreadas nos próximos quadros em janelas de procura em torno da posição inicial das mesmas. As regiões em torno das pupilas são então extraídas, equalizadas (para compensar variações nas condições de iluminação), e utilizadas como entrada para a rede neural. Os resultados obtidos são similares aos obtidos em [BP94], ficando em torno de $1.3^{\circ}$ a $1.9^{\circ}$. Como a entrada de dados para a rede neural consiste apenas de informação local, isto é, apenas imagens dos olhos, é esperado que os usuários não façam grandes movimentos de cabeça.

Kim e Ramakrishna propõem, em [KR99], uma técnica cujo foco é determinar a direção do olhar permitindo pequenos movimentos da cabeça. Esta técnica utiliza o centro da íris e um ponto de referência para estimar o olhar através de um modelo geométrico. O ponto de referência utilizado é uma pequena marca posicionada na haste que liga as duas lentes de um óculos. O propósito desse ponto de referência é obter informação a respeito da posição da face do usuário e tomar esse ponto como a origem dos movimentos da íris. Note que essa marca não fornece informação a respeito da orientação da face, uma vez que é apenas 


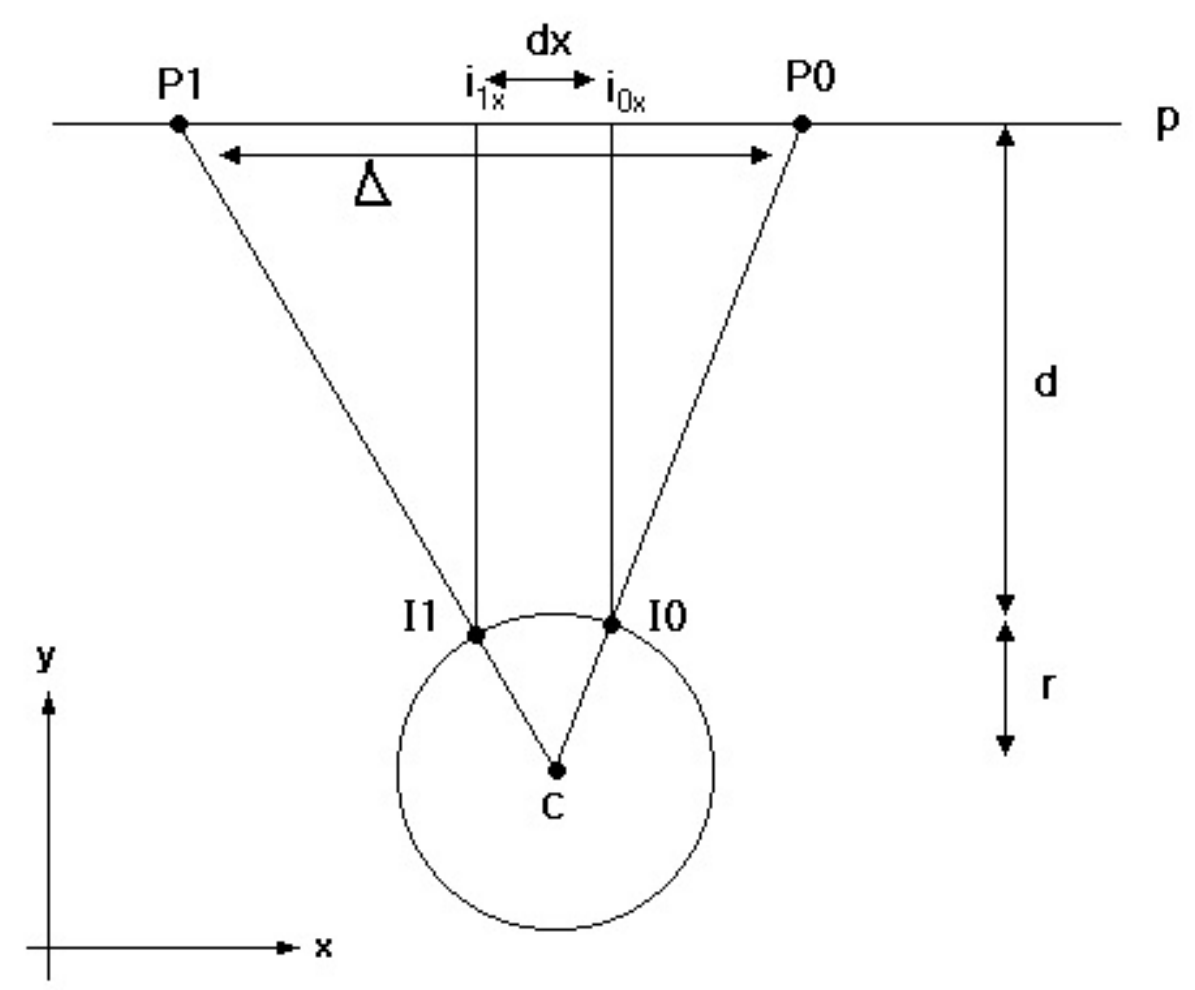

Figura 2.6: Geometria da análise para o caso 1D.

uma referência pontual, mas é útil para compensar pequenos movimentos da cabeça. Outras condições assumidas são: que o usuário mantenha a cabeça num plano paralelo ao monitor e que o eixo da câmera seja posicionado perpendicularmente ao plano do monitor.

Para entender melhor o modelo geométrico, vamos analisar como este funcionaria no caso 1D, isto é, só levando em conta o rastreamento do olhar na horizontal (ou ao longo de uma linha qualquer do monitor), como ilustra a figura 2.6. A extensão do método para o caso 2D (rastreamento na horizontal e vertical) é um passo simples.

Seja $p$ a linha horizontal do monitor considerada. Vamos assumir que essa linha é paralela ao eixo $x$, e que o eixo $y$ é perpendicular a $x$. Seja $d$ a distância do olho a essa linha, $C$ o 
centro do olho e $r$ o seu raio. Seja $P_{0}$ um ponto de referência sobre $p$. Quando o olho rotaciona apontando para $P_{1}$, temos um deslocamento $\Delta$ sobre $p$. Da mesma forma, nessa rotação do olho, o centro da íris se desloca de $I_{0}=\left(i x_{0}, i y_{0}\right)$ para $I_{1}=\left(i x_{1}, i y_{1}\right)$. Considera-se ainda que a diferença de $i y_{0}$ e $i y_{1}$ para o plano é sempre $d$, isto é, assume-se uma projeção ortográfica do centro da íris para o plano da imagem. Assim, $I_{0}$ e $I_{1}$ estão sempre sobre a reta paralela ao eixo $x$, distante $d$ da reta $p$. Com essas simplificações, é simples calcular o deslocamento $\Delta$ sobre a reta $p$ dada a diferença $d x=i x_{1}-i x_{0}$. Para isso basta utilizar a equação 2.1 .

$$
\Delta=\frac{d+r}{r} d x
$$

Utilizando este modelo geométrico, tendo-se o deslocamento do centro da íris ao longo do eixo $x$, podemos estimar o quanto essa variação representa no deslocamento real do ponto observado sobre a linha $p$ usando a equação 2.1 acrescida de um fator $k$. Este fator traduz o deslocamento em pixels do centro da íris para o deslocamento real da íris. Adicionando este fator $k$ à equação 2.1 obtemos a equação 2.2 .

$$
\Delta=k \frac{d+r}{r} d x
$$

Para calcular o valor de $k$ é necessário realizar uma calibração. A distância $d$ também pode ser obtida via calibração, ou então fixada com um valor que deve ser mantido pelo usuário. Para completar o modelo é necessário ainda considerar a movimentação da cabeça do usuário ao longo do plano paralelo ao monitor. Esse movimento pode ser compensado no cálculo de $\Delta$ através da marca de referência, da seguinte maneira:

$$
\Delta=k \frac{d+r}{r} d x+k d_{r e f}
$$

Onde $d_{r e f}$ é o deslocamento do ponto de referência na imagem em relação ao ponto inicial 
fixado (isto é, a posição da marca de referência quando o usuário estava olhando para $I_{0}$ ). Apesar de não apresentar uma discussão detalhada sobre a precisão dos resultados obtidos, este método se mostrou capaz de estimar corretamente a direção do olhar em um monitor dividido em $10 \times 8$ regiões.

A técnica mais utilizada pelos rastreadores remotos hoje em dia é a técnica baseada na detecção da pupila e da reflexão sobre a córnea. Essa técnica utiliza-se de uma fonte de luz infravermelha para gerar um reflexo sobre a córnea, que deve ser detectado e rastreado. Como o olho possui uma forma aproximadamente esférica, que rotaciona em torno de seu centro, e a câmera e a fonte de luz infravermelha estão fixas, a posição do reflexo de luz gerado sobre a córnea não se move com a rotação do olho e assim o reflexo pode ser tomado como um ponto de referência. Conforme o usuário dirige seu olhar a diferentes pontos, a sua pupila se movimenta e seu centro e o reflexo definem um vetor na imagem que é mapeado para as coordenadas da tela através de um processo de calibração. Nesse processo, que define o mapeamento do vetor na imagem para o ponto de interesse na tela, é pedido ao usuário que fixe o olhar em alguns pontos da tela. Em particular, no trabalho de Morimoto et al. [MKAF99], 9 pontos de calibração são utilizados e um polinômio de segunda ordem é utilizado como função de calibração. A função de calibração é dada pelas equações abaixo:

$$
\begin{aligned}
& s x=a_{0}+a_{1} x+a_{2} y+a_{3} x y+a_{4} x^{2}+a_{5} y^{2} \\
& s y=b_{0}+b_{1} x+b_{2} y+b_{3} x y+b_{4} x^{2}+b_{5} y^{2}
\end{aligned}
$$

onde $(s x, s y)$ são as coordenadas do monitor e $(x, y)$ é o vetor definido pelo centro da pupila e o reflexo sobre a córnea. Os parâmetros $a_{i}$ e $b_{i}$ são desconhecidos, mas como temos 9 pontos de calibração, então temos 2 conjuntos de 9 equações e 6 incógnitas, e estas podem ser obtidas usando o método dos mínimos quadrados. O uso de polinômios de maior ordem mostrou 
melhora na precisão do sistema, mas o ganho não é tão grande, além de exigir um número maior de pontos de calibração [MM05].

A fim de testar a tolerância desta técnica para pequenos movimentos de cabeça, Morimoto e Mimica [MM05] realizaram uma série de experimentos utilizando imagens sintéticas do olho geradas por traçamento de raios. Para este experimento, o centro óptico da câmera foi tomado como origem do sistema de coordenadas 3D, com seu eixo óptico apontando para a direção do eixo $z \cdot P_{0}=(0,27,60)$ (unidades em $\mathrm{cm}$ ) foi tomado como a posição inicial do olho e para os cantos superior esquerdo e inferior direito do monitor foram tomados, respectivamente, os pontos $(-18.3,27.4,0)$ e $(18.3,0,0)$ (medidas que correspondem aproximadamente à área útil de um monitor de 19 polegadas). Podemos ver na figura 2.7 essa configuração utilizada no experimento. Para calibrar o sistema a região do monitor foi divida em uma grade de $3 \times 3$ posições e imagens do olho apontando para o centro de cada célula foram renderizadas. Para testar a calibração, cada célula da grade foi por sua vez subdividida em outra grade $3 \times 3$ e imagens do olho apontando para cada centro dessas sub-células foram geradas e utilizadas como entrada para o sistema. Para o olho posicionado em $P_{0}$, o erro médio (medido como a distância entre o ponto real apontado pelo olho e o ponto estimado) foi de $0.8 \mathrm{~cm}$, ou $0.8^{\circ}$.

Para testar como a precisão do sistema é afetada por movimentos de cabeça, a posição do olho foi transladada ao longo dos três eixos. Para cada nova posição, imagens do olho foram renderizadas apontando para cada uma das 81 células da grade. Para o olho transladado 10 cm no eixo $x$, na posição $(-10,27,60)$, obteve-se um erro médio de $0.99 \mathrm{~cm}\left(1.0^{\circ}\right)$ na estimação do olhar. Já para translação no eixo $y$, para o ponto $(0,17,60)$, obteve-se um erro médio de $2.18 \mathrm{~cm}\left(2.1^{\circ}\right)$. Finalmente para translação no eixo $z$, para o ponto $(0,27,70)$, o erro médio foi de $4.06 \mathrm{~cm}\left(3.3^{\circ}\right)$. Esses resultados mostram que a calibração do sistema não é muito afetada por pequenas translações no eixo $x$ e pequenas rotações da cabeça para cima e para baixo, que são os movimentos mais comuns realizados pelas pessoas. A translação no eixo $y$ não é algo 


\section{Ambiente Simulado para Testes}

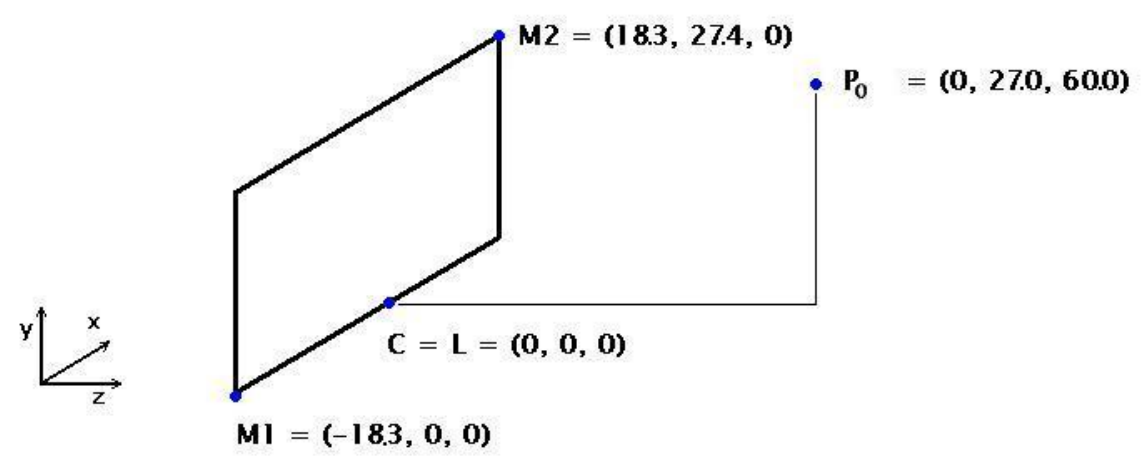

Figura 2.7: Configuração utilizada no experimento para avaliar a técnica baseada no rastreamento da pupila e da reflexão sobre a córnea.

tão comum, contudo um movimento de aproximação ou afastamento do monitor (translação no eixo $z$ ) realmente compromete a calibração e a precisão do sistema.

\subsection{Técnicas robustas a movimentos de cabeça}

Apresentamos até agora alguns dos métodos tradicionais desenvolvidos para a deteç̧ão e rastreamento do olhar. Começamos com alguns métodos intrusivos e terminamos com métodos não intrusivos baseados em visão computacional. Estes últimos seriam bastante adequados para o uso no dia a dia das pessoas já que não oferecem o desconforto ao usuário de ter que utilizar equipamentos em contato com seu corpo. Contudo há ainda dois pontos que impedem a popularização do uso dos rastreadores. São eles: a necessidade de calibração (uma calibração realizada de forma incorreta pode comprometer a eficiência do rastreador e pessoas não acostumadas com este tipo de dispositivos podem ter dificuldade para realizá-la) e a intolerância a movimentos do usuário. Mostraremos a seguir algumas técnicas mais recentes 
cujo objetivo é eliminar, ou pelo menos minimizar, essas duas desvantagens.

\subsubsection{Uma câmera}

Morimoto et al. [MAF02a][MAF02b] desenvolveram um método para estimar o eixo óptico do olho através do cálculo do centro da córnea e do eixo óptico no espaço 3D. Utilizando algumas medidas do olho, obtidas do modelo de Gullstrand, o método proposto utiliza apenas uma câmera e duas fontes de luz para calcular o centro da córnea e o centro da pupila. As medidas utilizadas do modelo de Gullstrand são: o raio da pupila $(7.7 \mathrm{~mm})$, o índice de refração da córnea (1.376) e a distância da pupila ao centro da córnea (3.6 mm).

Para calcular o centro da córnea, esta foi modelada como um espelho convexo, com centro de curvatura em $C$ e de raio $r$. Sendo $O$ o centro óptico da câmera e a linha $\overline{O C}$ o eixo principal da córnea, então o vértice da córnea $V$ e o centro focal $F$ estão sobre esta linha $\overline{O C}$ e $F$ está localizado no ponto médio do segmento $\overline{V C}$. Considerando a câmera calibrada e que uma fonte de luz está numa posição conhecida $L$, então $I$ é a imagem virtual de $L$ localizada atrás da córnea. A figura 2.8 ilustra como $I$ é formada sobre a córnea.

A posição de $I$ pode ser computada pela fórmula dos espelhos convexos:

$$
\frac{1}{f}=\frac{2}{r}=\frac{1}{d}+\frac{1}{d^{\prime}}
$$

onde $f=r / 2, d=\left|V L^{\prime}\right|, d^{\prime}=\left|V I^{\prime}\right|$, sendo $L^{\prime}$ e $I^{\prime}$ a projeção ortogonal de $L$ e $I$, respectivamente, sobre a linha $\overline{O C}$. Nessa modelagem da córnea como um espelho convexo, em uma aplicação de rastreamento de olhar, é razoável assumir que o valor de $d$ é muito maior que o valor de $r$. Assim $I^{\prime}$ localiza-se no centro focal $F$. Considere agora que outra fonte de luz é posicionada no eixo óptico da câmera próximo a $O$. Está fonte de luz gera um reflexo sobre a córnea localizado em $V$. Como a câmera é calibrada, podemos obter a direção dos vetores 


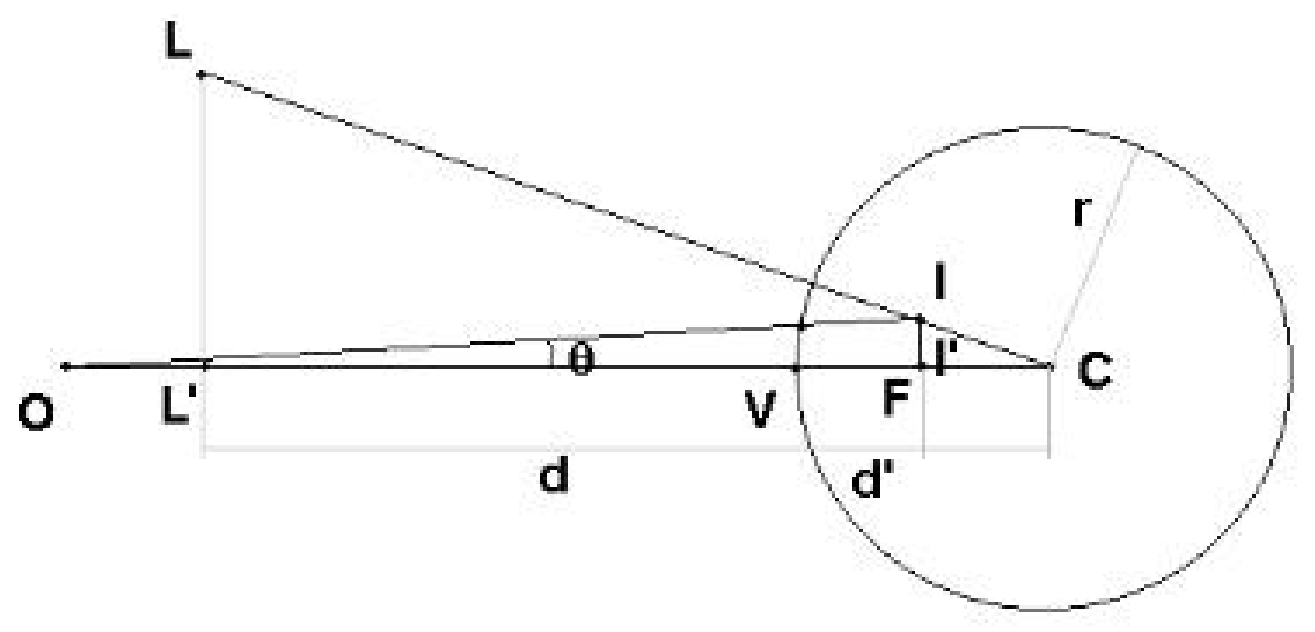

Figura 2.8: formação do reflexo sobre a córnea pelo LED infravermelho.

$\overrightarrow{O V}$ e $\overrightarrow{O I}$ (mas não suas magnitudes) e calcular o ângulo $\theta$ formado por eles.

Seja $O=(0,0), C=\left(c_{x}, 0\right)$ e $L=\left(l_{x}, l_{y}\right)$. Construindo a equação da reta $L C$ (que passa por $I$ ) temos:

$$
y-l_{y}=\left(x-l_{x}\right) \frac{-l_{y}}{c_{x}-l_{x}}
$$

Como $I$ está no ponto médio entre $V$ e $C$ as coordenadas de $I$ podem ser escritas como $\left(c_{x}-\frac{r}{2}, \tan \theta\left(c_{x}-\frac{r}{2}\right)\right)$. Substituindo $I$ escrito em função de $c_{x}$ e $\theta$ na equação da reta $L C$ temos:

$$
\left[\tan \theta\left(c_{x}-\frac{r}{2}\right)-l_{y}\right]\left(c_{x}-l_{x}\right)=-l_{y}\left(c_{x}-\frac{r}{2}-l_{x}\right)
$$

Rearranjando a equação acima temos a seguinte equação de segundo grau: 


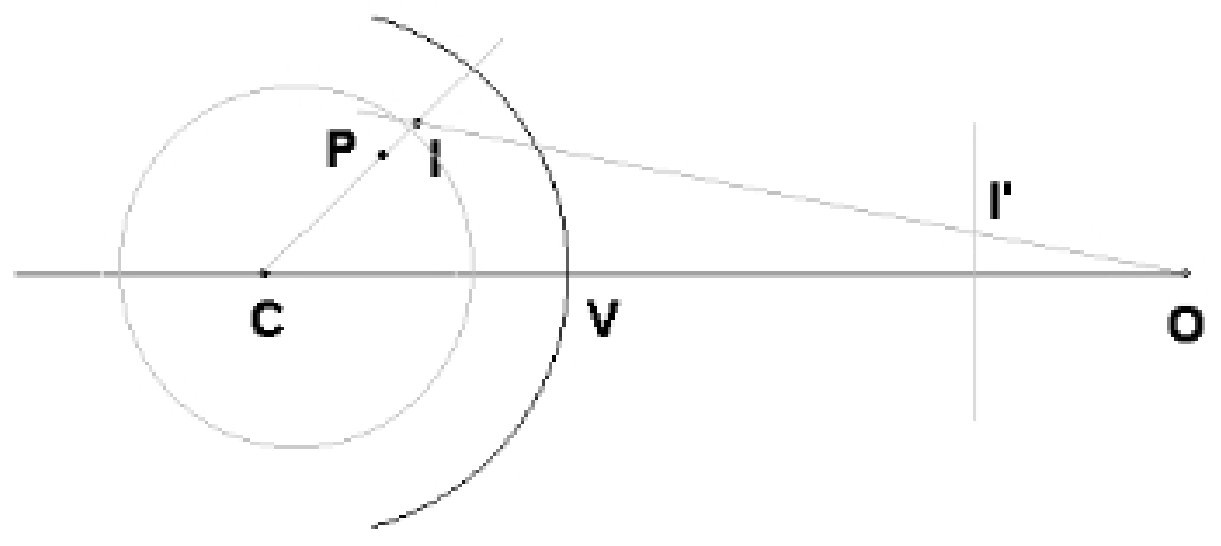

Figura 2.9: processo de refração da imagem da pupila.

$$
c_{x}^{2}-c_{x}\left(\frac{r}{2}+l_{x}\right)+\frac{r}{2}\left(l_{x}-\frac{l_{y}}{\tan \theta}\right)=0
$$

Resolvendo 2.9 e tomando o menor resultado positivo obtemos $c_{x}$ e, conseqüentemente, a posição do centro da córnea.

Para calcular o eixo óptico, a córnea é considerada como uma superfície esférica côncava separando o ar (índice de refração aproximadamente $=1$ ) do interior do olho (índice de refração aproximadamente $=1.376$ ). A equação de refração para superfícies esféricas é dada por:

$$
\frac{n}{d}+\frac{n^{\prime}}{d^{\prime}}=\frac{n^{\prime}-n}{r}
$$

onde $n$ e $n^{\prime}$ são, respectivamente, os índices de refração do interior do olho e do ar, $d$ e $d^{\prime}$ são as distâncias do objeto e sua imagem para o vértice da superfície $V$, e $r$ é o raio de curvatura da superfície.

A figura 2.9 ilustra o processo de refração. Nela podemos ver $I$, que é o centro da imagem 
da pupila formada devido a refração, e $P$, que é o centro da pupila real. Sabe-se, usando dados do modelo de Gullstrand, que a pupila fica localizada 4.1 milímetros atrás da córnea $(d=4.1$ milímetros) mas, utilizando a equação 2.10, temos que a imagem da pupila (isto é, aquela observada pela câmera) forma-se aproximadamente a 3.5 milímetros da córnea. Assume-se então que $I$ (imagem da pupila) está sobre em uma esfera localizada 3.5 milímetros adentro da córnea (ou uma esfera localizada no centro da córnea de raio 4.2 milímetros). Pela imagem capturada pela câmera pode-se determinar o vetor que aponta na direção $\overrightarrow{O I}$, e pela intersecção desse vetor com essa esfera interna, é possível calcular a posição de $I$ no espaço. Como $P$ pertence à reta $\overline{C I}$, isto é, aquela que passa pelo centro da córnea e pelo centro da imagem da pupila, então o vetor procurado para estimar a direção do olhar (vetor que liga $C$ a $P$ ) é o mesmo vetor que liga $C$ a $I$. Como já se conhece $C$ e $I$ acabou de ser calculado, tem-se os dois pontos necessários para calcular a direção do olhar, definida pelo vetor que parte de $\overrightarrow{C I}$.

Imagens sintéticas geradas por traçamento de raios foram utilizadas para testar a técnica desenvolvida, sob diferentes posições do olho e da fonte de luz localizada fora do eixo óptico da câmera. O erro médio na estimação da direção do olhar ficou em torno de $3^{\circ}$. Contudo este método possui as vantagens de permitir a livre movimentação do usuário, não exigir calibração, além de ser computacionalmente eficiente e apropriado para uso em tempo real. Em comparação a outros métodos, apesar de menos preciso, este método tem a vantagem de utilizar apenas uma câmera, o que torna o processo de configuração e calibração do sistema mais simples.

\subsubsection{Múltiplas Câmeras}

A técnica desenvolvida por Wang e Sung [WS02] estima o eixo visual no espaço 3D através de uma câmera, porém utiliza uma segunda câmera auxiliar para estimar a orientação da face do usuário. Esse sistema auxiliar detecta os cantos do olho e da boca e a orientação da face no 
espaço 3D. A partir da localização inicial dos olhos, a câmera responsável pelo rastreamento do olhar é direcionada a um dos olhos obtendo imagens detalhadas do mesmo. O olho é modelado como uma esfera de raio $R$, a íris como um círculo de raio $r$ e a distância do plano da íris ao centro do olho é dado por $d$. A relação entre $R, r$ e $d$ é dada por:

$$
R^{2}=r^{2}+d^{2}
$$

Foi observado pelos autores que a razão $R / r$ é um valor bastante estável e por isso é tomado como uma constante. Como $r$ é medido via calibração é possível calcular tanto $R$ quanto $d$ usando a relação acima. A característica detectada utilizada na estimação do olhar é a íris. A projeção do contorno da íris no plano da imagem é uma elipse. Assim, através da excentricidade da elipse, é possível estimar o plano no espaço sobre o qual a íris se localiza, bem como seu centro. Como essa estimação produz duas soluções possíveis, para escolher o valor correto é utilizado um critério de desempate que consiste em escolher o centro do olho cujas distâncias aos seus cantos sejam iguais. Experimentos realizados pelos autores da técnica apontaram uma precisão de menos de $1^{\circ}$.

Shih et al. [SWL00] e Shih e Liu [SL04] usam múltiplas câmeras e múltiplas fontes de luz para estimar o eixo óptico do olho. Usando o modelo simplificado do olho de LeGrand (similar ao modelo de Gullstrand, mas considera a córnea e o humor aquoso como um único meio), este trabalho mostra que, utilizando duas câmeras calibradas e pelo menos dois pontos de luz com posições conhecidas, é possível calcular o eixo óptico do olho. A idéia do método é calcular primeiramente a posição do centro da córnea no espaço 3D e em seguida usar essa informação, juntamente com os centros observados das pupilas, para computar o eixo óptico do olho. O ângulo entre o eixo visual e o eixo óptico é obtido através de um processo de calibração por usuário, que só necessita ser feito uma vez.

A figura 2.10, ilustra o processo de formação do reflexo gerado pelo LED infravermelho. 


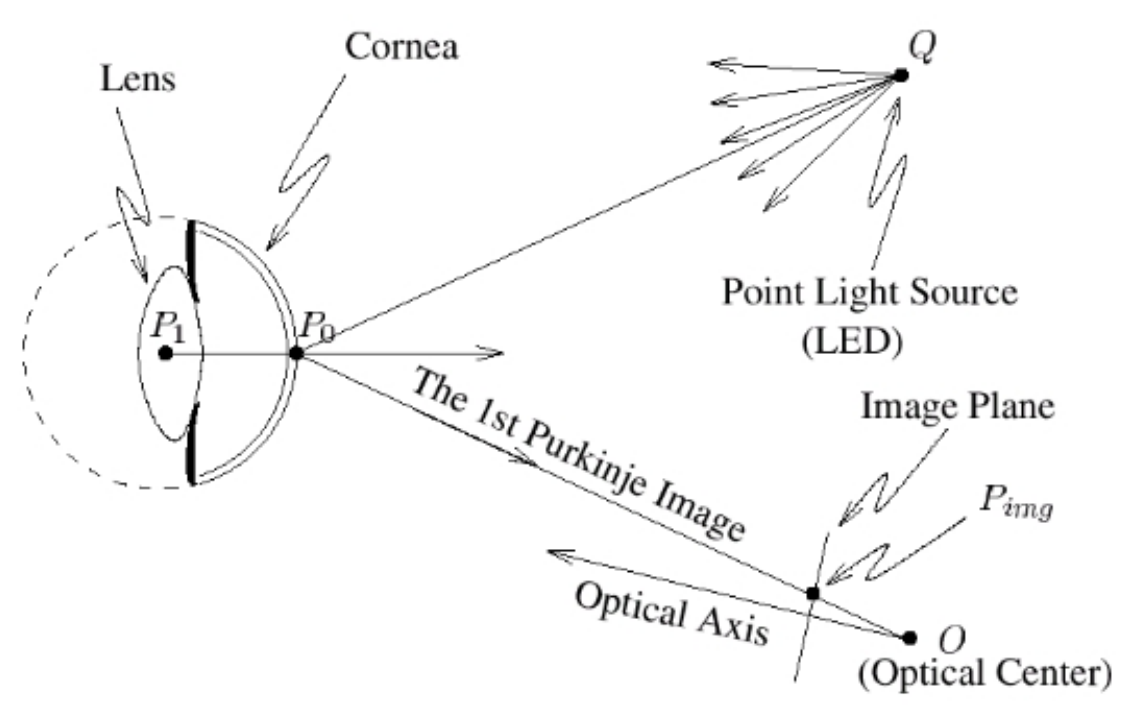

Figura 2.10: formação do reflexo sobre a córnea pelo LED infravermelho [SL04].

Seja $O$ o observador (isto é, uma das câmeras), $Q$ uma fonte de luz e $P_{0}$ o ponto correspondente ao reflexo especular da fonte de luz sobre a córnea. Embora $P_{0}$ não seja conhecido, pela calibração da câmera consegue-se calcular o vetor que parte de $O$ e segue em direção a $P_{0}$. Esse vetor, juntamente com o vetor que parte de $O$ e segue em direção a $Q$ define um plano que contem $P_{1}$, isto é, o centro da córnea. Se tivermos mais uma fonte de luz tal que as fontes de luz e o ponto $O$ não sejam colineares, definimos outro plano que contem $P_{1}$. A intersecção dos dois planos definidos define uma reta que contém $P_{1}$. Como são utilizadas duas câmeras, tem-se então duas retas às quais $P_{1}$ pertence, e a intersecção dessa retas nos dá o centro da córnea no espaço 3D.

Em seguida, dado o centro da pupila $P_{c}$, o centro virtual da pupila $P_{c}^{\prime}$ que é observado devido a refração da córnea e do humor aquoso, temos que $O, P_{1}$, e $P_{c}^{\prime}$ definem um plano (embora não saibamos a posição de $P_{c}^{\prime}$, o vetor que parte de $O$ e passa por $P_{c}^{\prime}$ pode ser computado 
a partir da imagem capturada), e que $P_{c}$ também está contido nesse plano. Assim, o eixo óptico que queremos estimar (segmento de reta que parte de $P_{1}$ e passa por $P_{c}$ ) também está contido neste plano. Como temos outra câmera, é possível definir outro plano e a intersecção deles nos dá o eixo óptico que queremos computar. A implementação realizada, que utiliza 3 fontes de luz infravermelha, é capaz de processar 30 quadros por segundo com uma precisão de menos de $1^{\circ}$. Contudo, apesar das vantagens, o uso de duas câmeras e a necessidade de calibração das mesmas torna a configuração inicial do sistema um pouco complexa.

Beymer e Flickner [BF03] também desenvolveram um método para estimar a linha de visão no espaço 3D usando câmeras estéreo. Em particular foram utilizados dois pares de câmeras. Um par que proporciona um grande campo de visão e outro par, com campo de visão reduzido, capaz de obter imagens detalhadas do olho. O primeiro par detecta a cabeça do usuário e estima a posição 3D do seu olho direito, usando essa informação para direcionar o segundo par de câmeras. Um modelo 3D da anatomia do olho é utilizado neste trabalho. O modelo inclui a córnea, a pupila e a diferença angular entre o eixo óptico e o eixo visual. O rastreamento basicamente consiste em casar iterativamente a projeção das características do modelo 3D com as características detectadas nas imagens capturadas pelo par de câmeras com pequeno campo de visão. As características rastreadas são a borda da pupila e reflexos sobre a córnea de LEDs infravermelhos posicionados nas câmeras. Para se obter os dados do modelo 3D do olho é feito um processo de calibração, contudo, este processo é realizado uma única vez para cada usuário. Uma precisão de $0.6^{\circ}$ foi obtida com esta técnica, mas a configuração inicial do sistema também sofre do problema de ser um pouco complexa uma vez que trabalha-se com dois pares de câmeras estéreo. 


\subsubsection{Projeção de padrão de luz}

Uma técnica bastante recente foi introduzida por Yoo et al. em [YLC02] e posteriormente refinada por Yoo e Chung em [YC05]. O sistema desenvolvido emprega duas câmeras, uma com um campo visual estreito, proporcionando a captura de imagens detalhadas do olho, e outra com um amplo campo visual, que obtém imagens da face do usuário. As duas câmeras são montadas sobre um suporte motorizado de modo que tanto a face quanto um olho possam ser rastreados simultaneamente. A câmera responsável pelo rastreamento do olhar propriamente dito é a que captura imagens detalhadas do olho e, de fato, quanto maior o tamanho do olho nas imagens obtidas por essa câmera melhor a precisão atingida pelo sistema. Contudo, é difícil rastrear o olho apenas utilizando essa câmera pois pequenos movimentos de cabeça são suficientes para tirar o olho do campo de visão. Por isso, a segunda câmera é utilizada para rastrear o olho de forma robusta, através de um sistema auxiliar de rastreamento de faces que mantém a primeira câmera sempre apontando na direção do olho pelo acionamento do suporte motorizado.

Para o rastreamento do olhar, 5 LEDs infravermelhos são utilizados. Desses LEDs, 4 são fixados aos cantos do monitor, produzindo 4 reflexos sobre a córnea. O 5ํㅡ LED é posicionado no eixo óptico da câmera com campo visual estreito para explorar o efeito da pupila brilhante. Os LEDs do monitor e da câmera são acionados de forma alternada, controlados pela porta paralela do computador. Assim, quando os LEDs do monitor estão acesos, o LED da câmera está apagado e vice-versa. Como os reflexos sobre a córnea são produzidos pelos LEDs posicionados no monitor, o polígono formado por esses reflexos pode ser considerado como a reflexão do monitor sobre a córnea. Esses reflexos, juntamente com a posição observada do centro da pupila, são usados para estimar a direção do olhar mapeando-os do espaço da imagem capturada para a tela do monitor. O LED posicionado no eixo óptico da câmera, além de gerar imagens com a pupila brilhante, também produz uma reflexão sobre a córnea quando ativo 
(veremos a utilidade deste reflexo adiante).

A grande vantagem desta técnica sobre as discutidas até agora é que ela requer apenas uma câmera (apesar do sistema estudado empregar duas) que não necessita estar calibrada, não requer conhecimento sobre o posicionamento da câmera e do monitor no espaço, e dispensa calibração por parte do usuário para cada sessão de uso. Os únicos parâmetros que precisam ser conhecidos são as dimensões da tela do monitor. Além disso, ela permite que o usuário movimente sua cabeça, sem perda significativa de precisão. Testes feitos pelos autores da técnica obtiveram como resultado médio uma precisão de $1.12 \mathrm{~cm}$, o que corresponde a uma precisão de $1.3^{\circ}$ para o usuário posicionado a uma distância de $50 \mathrm{~cm}$ do monitor. Devido a esses fatores, essa técnica se mostra bastante promissora para o uso cotidiano de rastreadores de olhar, tendo sido escolhida como base para a implementação do nosso rastreador. No restante deste capítulo estudamos esta técnica de forma mais detalhada e, no capítulo a seguir, realizamos uma análise exploratória através de simulações para analisar o desempenho da mesma.

\section{Geometria do sistema}

Sejam $L_{1}, L_{2}, L_{3}$ e $L_{4}$ os pontos correspondentes aos 4 cantos da tela do monitor, $O$ a posição da córnea e $P$ o centro da pupila no espaço, ilustrados na figura 2.11 . Considerando o eixo óptico e o eixo visual do olho como sendo os mesmos, a intersecção do segmento de reta que parte de $O$ e segue em direção a $P$ com o plano do monitor define o ponto sendo observado que chamaremos de $G$. Fixando $O$ e apontando o eixo óptico do olho para todos os pontos da tela do monitor obtemos um conjunto de posições de $P$ que cobre visualmente toda a área da tela.

Esse conjunto de posições para $P$ define uma região delimitada sobre a córnea que, devido ao posicionamento típico da câmera, monitor e usuário, não possui uma curvatura muito 
acentuada. Assim, considera-se que essa região está localizada em um plano virtual tangente à superfície da córnea e que, de fato, a região delimitada sobre esse plano nada mais é do que uma projeção do quadrilátero da tela do monitor sobre esse plano, sendo $O$ o centro de projeção. Dessa forma, as projeções de $L_{1}, L_{2}, L_{3}$ e $L_{4}$ sobre este plano virtual definem um quadrilátero de vértices $V_{1}, V_{2}, V_{3}$ e $V_{4}$ e, além disso, o ponto $G$ também é projetado para esse plano como o ponto $V_{G}$ interno ao quadrilátero $V_{1} V_{2} V_{3} V_{4}$. Uma vez que o plano virtual de projeção não existe, os pontos projetados sobre ele são chamados de projeções virtuais. Como $P$ pertence à reta ligando $O$ a $V_{G}$ e a $G$, a posição de $P$ está relacionada ao ponto $G$ observado. De fato, se $P$ estivesse localizado na superfície da córnea, $P$ e $V_{G}$ seriam aproximadamente o mesmo ponto e, para fins de explicação da técnica, vamos considerar esses pontos como sendo os mesmos.

Quando esses pontos $V_{1}, V_{2}, V_{3}, V_{4}$ e $P$ são capturados pela câmera, eles são novamente projetados mas, desta vez, para o plano da imagem. Dessa forma temos novos pontos (chamaremos de $U_{V 1}, U_{V 2}, U_{V 3}, U_{V 4}$ e $\left.U_{P}\right)$ que foram obtidos pela aplicação de duas transformações projetivas sobre os pontos $L_{1}, L_{2}, L_{3}, L_{4}$, e $G$. Uma vez que se considera as projeções virtuais como pertencentes a um mesmo plano e obtidas por uma transformação projetiva, é possível utilizar uma propriedade invariante do espaço projetivo. A técnica proposta por Yoo et al. [YLC02] [YC05] visa justamente explorar tal invariante para, dados $L_{1}, L_{2}, L_{3}$ e $L_{4}$ e $U_{V 1}$, $U_{V 2}, U_{V 3}, U_{V 4}$ e $U_{P}$, obter-se o ponto observado sobre a superfície do monitor.

\section{Calculando as projeções virtuais}

Considerando a existência de um plano tangente à superfície da córnea e o seu centro como o centro de projeção, sabemos que é possível estimar o ponto observado pelo usuário a partir dos pontos no plano da imagem correspondentes ao centro da pupila $\left(U_{P}\right)$ e às projeções virtuais dos LEDs $\left(U_{V 1}, U_{V 2}, U_{V 3}, U_{V 4}\right)$. Entretanto, as projeções virtuais dos LEDs consistem em 


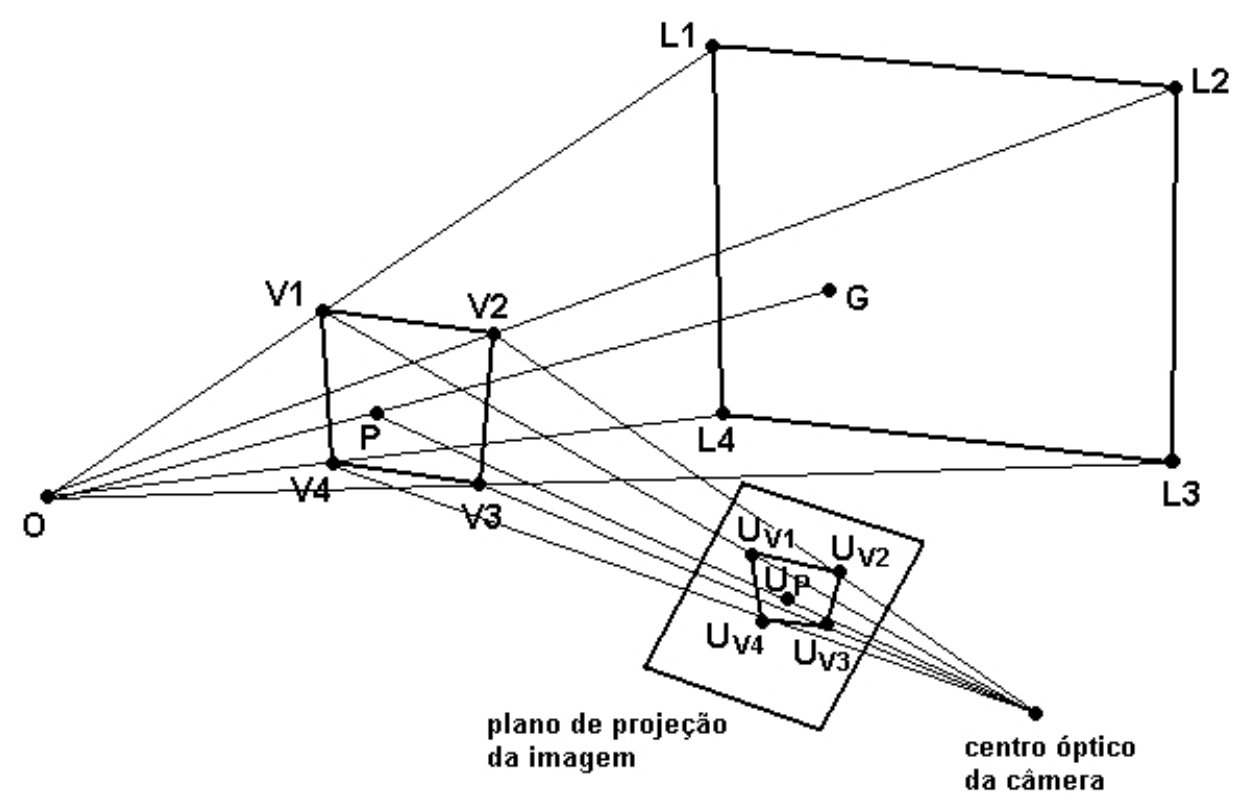

Figura 2.11: projeção dos pontos correspondentes aos 4 cantos do monitor sobre o plano virtual tangente à superfície da córnea e no plano da imagem.

uma informação que não se tem disponível dada uma imagem do olho. Para resolver esse problema, as projeções virtuais dos LEDs devem ser computadas. Sejam $R_{1}, R_{2}, R_{3}, R_{4}$ e $R_{C}$ os reflexos gerados sobre a córnea pelos 4 LEDs do monitor e pelo LED posicionado no eixo da câmera respectivamente. Como conhecemos as posições dos reflexos na imagem, que chamaremos de $U_{R 1}, U_{R 2}, U_{R 3}, U_{R 4}$ e $U_{R C}$, o que se faz então é estimar as projeções virtuais a partir desses pontos.

O cálculo das projeções virtuais a partir dos reflexos não é simples porque a relação existente entre esses pontos é um tanto complexa. Felizmente, limitando o espaço de movimento 
do usuário a uma região específica é possível chegar a uma boa aproximação da relação existente entre os reflexos e as projeções virtuais. Tipicamente, segundo os autores da técnica, o usuário está sentado à frente do monitor e olhando diretamente para ele a uma distância de $30-50 \mathrm{~cm}$, e com uma variação de posição menor do que $30 \mathrm{~cm}$. Para facilitar a compreensão, o problema será simplificado para o caso bidimensional (veja figura 2.12). Seja $x_{c a m}$ a distância entre a câmera e o centro da córnea, $R_{1}$ o reflexo gerado sobre a córnea pelo LED $L_{1}, V_{1}$ a projeção virtual de $L_{1}$ sobre o plano tangente à córnea e $C$ o reflexo do LED posicionado no eixo da câmera (que também é a projeção virtual desse LED sobre o plano tangente). Sejam $U_{R 1}, U_{V 1}$ e $U_{C}$ as projeções de $R_{1}, V_{1}$ e $C$ sobre o plano da imagem respectivamente. No plano da imagem, cuja origem do sistema de coordenada é $\Sigma_{i}$ temos:

$$
\begin{gathered}
U_{C}=\frac{f}{\tan \phi} \\
U_{R 1}=\frac{r f \cos \left(\theta_{1}+\phi\right)-f x_{c a m} \cos \phi}{r \sin \left(\theta_{1}+\phi\right)-x_{\operatorname{cam}} \sin \phi} \\
U_{V 1}=\frac{r f\left(\cos \phi-\tan \left(\theta_{1}+\theta_{2}\right) \sin \phi\right)-f x_{c a m} \cos \phi}{r\left(\sin \phi+\tan \left(\theta_{1}+\theta_{2}\right) \cos \phi\right)-x_{c a m} \sin \phi}
\end{gathered}
$$

onde $r$ é o raio da córnea, $f$ é a distância focal da câmera e $\phi$ é a orientação da câmera relativa à córnea. $\theta_{1}$ é o ângulo entre os pontos $C$ e $R_{1}$, e $\theta_{2}$ é o ângulo entre os pontos $R_{1}$ e $V_{1}$. Quando um usuário opera o computador, esses dois ângulos são bastante similares porque a distância entre o monitor e o olho é maior que a distância entre a câmera e o LED. Dessa forma, podemos assumir que $\theta_{1} \approx \theta_{2}$. Além disso, como a câmera responsável por capturar as imagens do olho possui um campo de visão estreito, $\phi$ tem um valor próximo a $\pi / 2$. Por essas aproximações, as equações 2.12 - 2.14 podem ser simplificadas da seguinte forma: 


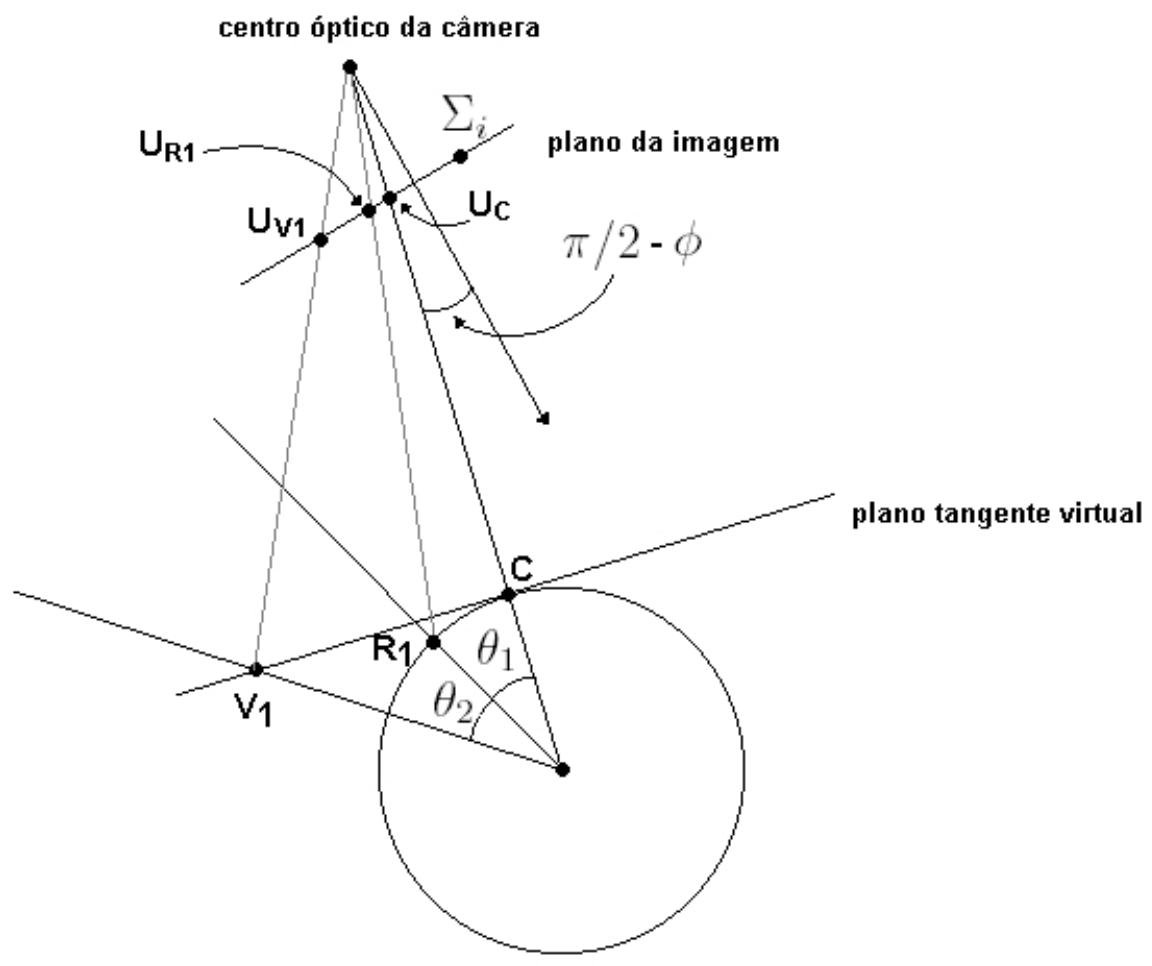

Figura 2.12: relação entre as projeções virtuais e os reflexos dos LEDs sobre a córnea.

$$
\begin{gathered}
U_{C} \approx 0 \\
U_{R 1} \approx \frac{-r f \sin \theta_{1}}{r \cos \theta_{1}-x_{\text {cam }}} \\
U_{V 1} \approx \frac{-r f \tan 2 \theta_{1}}{r-x_{\text {cam }}}
\end{gathered}
$$

Essas equações simplificadas estão em função de $x_{c a m}$ e $\theta_{1}$. Como, para o posicionamento considerado do usuário, $\theta_{1}$ é menor que $10^{\circ}$, então a razão entre $U_{V 1}$ e $U_{R 1}$ é aproximadamente 
2. Assim é possível obter a seguinte equação relacionando $U_{V 1}$ e $U_{R 1}: U_{V 1}=2 U_{R 1}$. Contudo, $U_{C}$ pode estar transladado em relação ao centro da imagem. Para compensar isso, eliminase esse deslocamento pela subtração de $U_{C}$ de $U_{R 1}$ e $U_{V 1}$, como ilustrado na figura 2.13. Conseqüentemente as projeções virtuais podem ser computadas pela seguinte equação:

$$
U_{V i}=U_{C}+\alpha\left(U_{R i}-U_{C}\right)
$$

Onde $\alpha$ é uma constante próxima a 2. Este valor pode ser determinado também por uma simples calibração descrita a seguir.

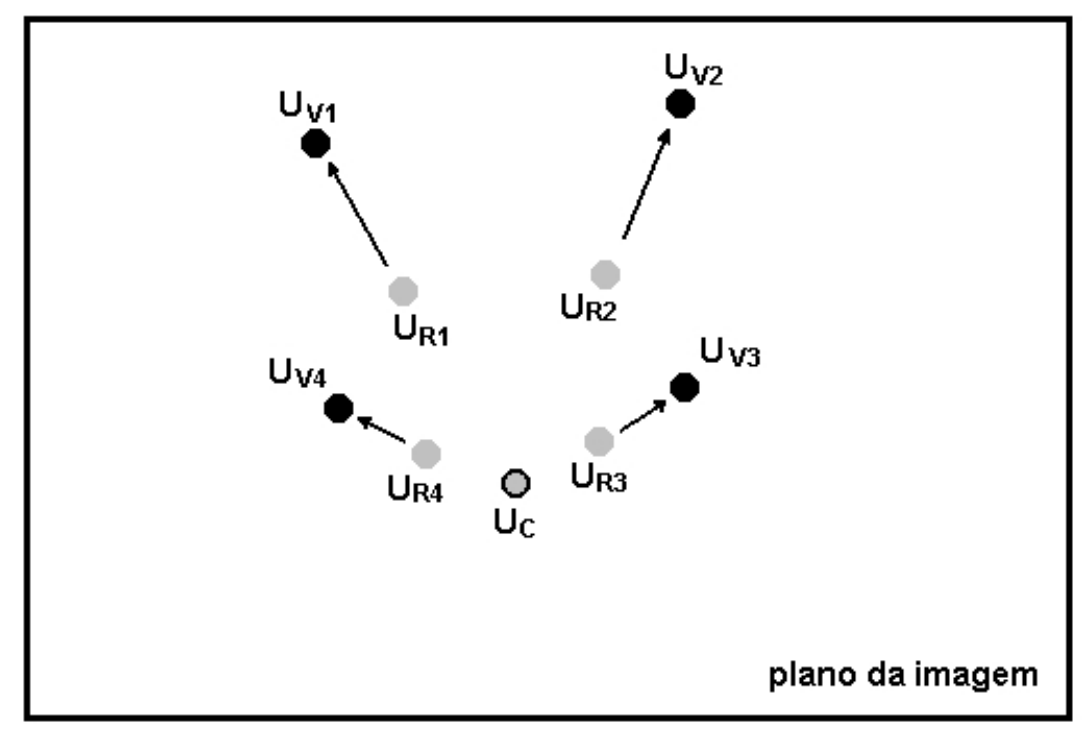

Figura 2.13: cálculo das projeções virtuais dos LEDs a partir dos reflexos sobre a córnea. 


\section{Estimando a direção do olhar pela razão cruzada}

O ponto observado pelo usuário é estimado utilizando a razão cruzada, que é uma propriedade invariante do espaço projetivo. Sejam $P_{1}, P_{2}, P_{3}$ e $P_{4}$ pontos colineares no espaço. A razão cruzada entre esses pontos é definida pela seguinte equação:

$$
r c(P 1, P 2, P 3, P 4)=\frac{\left|P_{1} P_{2}\right|\left|P_{3} P_{4}\right|}{\left|P_{1} P_{3}\right|\left|P_{2} P_{4}\right|}
$$

sendo $\left|P_{i} P_{j}\right|$ dado pelo determinante da matriz $M$, sendo a primeira coluna de $M$ formada pelas coordenadas de $P_{i}$ e a segunda coluna de $M$ formada pelas coordenadas de $P_{j}$. A característica importante dessa razão é que, se a reta que contém os quatro pontos sofrer qualquer transformação projetiva, a razão se mantém invariante [HZ00].

A figura 2.14 ilustra o processo do cálculo de $G$ utilizando essa razão. $L_{1}, L_{2}, L_{3} \mathrm{e}$ $L_{4}$ correspondem aos LEDs do monitor, $G$ ao ponto observado e $E$ é o ponto definido pelo cruzamento das diagonais do monitor. $G_{x}$ é o ponto obtido pelo cruzamento de uma linha vertical passando por $G$ e a reta $\overline{L_{1} L_{2}}$. Já $G_{y}$ é o ponto obtido pelo cruzamento de uma linha horizontal passando por $G$ e a reta $\overline{L_{1} L_{4}}$. Os pontos $U_{V 1}, U_{V 2}, U_{V 3}$ e $U_{V 4}$ são as projeções virtuais de $L_{1}, L_{2}, L_{3}$ e $L_{4}$ calculadas pelo método descrito na seção anterior. $U_{P}$ é o centro da pupila e $U_{E}$ é o ponto definido pelo encontro das diagonais do quadrilátero $U_{V 1} U_{V 2} U_{V 3} U_{V 4}$. O processo para calcular $G$ é dividido em duas partes. Primeiro calcula-se $G_{x}$ e em seguida $G_{y}$. Tendo esses pontos calculados, basta tomar $G$ como a intersecção da reta vertical que passa por $G_{x}$ com a reta horizontal que passa por $G_{y}$.

O método a seguir descreve como calcular $G_{x}$. Primeiro precisamos calcular o ponto de fuga referente as linhas verticais do quadrilátero $U_{V 1} U_{V 2} U_{V 3} U_{V 4}$. Como esse quadrilátero é uma projeção da tela do monitor, e as linhas verticais do monitor são paralelas, então podemos calcular o ponto de fuga considerado pela intersecção das linhas $\overline{U_{V 1} U_{V 4}}$ e $\overline{U_{V 2} U_{V 3}}$. A partir 


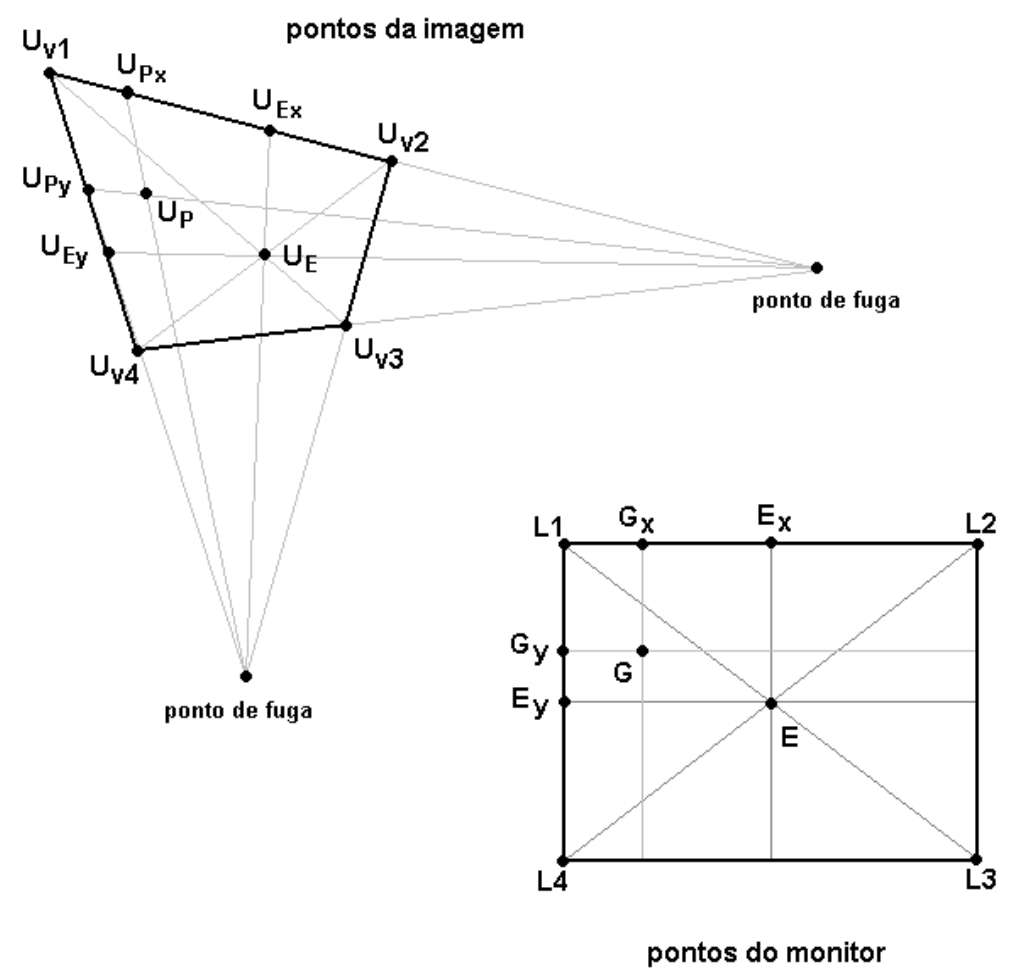

Figura 2.14: cálculo do ponto observado através da razão cruzada.

desse ponto podemos calcular os pontos $U_{P x}$ e $U_{E x}$. $U_{P x}$ é o ponto de interseç̧ão da linha $\overline{U_{V 1} U_{V 2}}$ com a linha que conecta $U_{P}$ ao ponto de fuga e corresponde à projeção do ponto $G_{x}$ do monitor para o plano da imagem. Já $U_{E x}$ é o ponto de intersecção da linha $\overline{U_{V 1} U_{V 2}}$ com a linha que conecta $U_{E}$ ao ponto de fuga e corresponde à projeção do ponto médio do segmento $\overline{L_{1} L_{2}}$ sobre o plano da imagem. Tendo esses quatro pontos $\left(U_{V 1}, U_{P x}, U_{E x}\right.$ e $\left.U_{V 2}\right)$, podemos calcular a razão cruzada $r c_{x}=r c\left(U_{V 1}, U_{P x}, U_{E x}, U_{V 2}\right)$ segundo a fórmula 2.19 .

Como os pontos $U_{V 1}, U_{P x}, U_{E x}$ e $U_{V 2}$ são obtidos por uma transformação projetiva a partir pontos $L_{1}, G_{x}, E_{x}$ e $L_{2}$ e a razão cruzada é invariante a transformações projetivas, então $r c\left(L_{1}, G_{x}, E_{x}, L_{2}\right)$ deve ser igual a $r c_{x}$. Aplicando novamente a fórmula 2.19, dessa vez 
para os pontos do monitor, e utilizando o valor $r c_{x}$, calculamos o ponto $G_{x}$.

Para calcular o ponto $G_{y}$ o processo é análogo, mas utilizando o ponto de fuga referente às linhas horizontais do quadrilátero $U_{V 1} U_{V 2} U_{V 3} U_{V 4}$. Obtendo esse outro ponto de fuga pela intersecção das linhas $\overline{U_{V 1} U_{V 2}}$ e $\overline{U_{V 3} U_{V 4}}$ é possível calcular $U_{P y}$ e $U_{E y}$. Em seguida, dados os quatro pontos $U_{V 1}, U_{P y}, U_{E y}$ e $U_{V 4}$ calcula-se uma nova razão cruzada $r c_{y}=r c\left(U_{V 1}, U_{P y}, U_{E y}, U_{V 4}\right)$. Utilizando esse valor na fórmula 2.19, para os pontos correspondentes do monitor, obtém-se $G_{y}$ e, conseqüentemente, o ponto de interesse $G$ que se queria estimar.

\section{Calibração}

Como já foi dito, o valor de $\alpha$ a ser utilizado na equação 2.18 é próximo a 2. Contudo existe o fato de, na prática, a pupila não se localizar sobre a superfície da córnea. Como conseqüência, a região delimitada por todas as posições do centro da pupila, quando o olho observa todos os pontos da tela, não será semelhante ao quadrilátero definido pelas projeções virtuais dos LEDs. Por isso, o centro da pupila na imagem também deve ser corrigido de forma a estimarmos o ponto de interseç̧ão do eixo óptico com a córnea. Embora os autores da técnica estudada não entrem de forma explicita nos detalhes dessa questão, a calibração proposta por eles, que veremos adiante, já compensa esse fato. Mesmo assim, vamos fazer um parêntesis aqui para analisar um pouco esse problema.

Para verificar possíveis maneiras de se corrigir o centro observado da pupila alguns testes foram feitos utilizando imagens geradas por traçamento de raios a partir do modelo de Gullstrand. Medidas relevantes desse modelo para este teste em particular são o raio da córnea $(r=7.7)$, a distância do centro da pupila ao centro da córnea $\left(d_{p}=3.6 \mathrm{~mm}\right)$ e a distância do centro da pupila observada (devido a refração) ao centro da córnea $\left(d_{p}^{\prime}=4.2 \mathrm{~mm}\right)$. Além disso, para este teste, foi adicionado ao modelo do olho um ponto de referência correspondendo à intersecção do eixo óptico com a superfície da córnea. O olho foi posicionado sobre o eixo 
óptico da câmera a uma distância de $50 \mathrm{~cm}$ e foi utilizada apenas uma fonte de luz posicionada no centro óptico da câmera. Foram geradas imagens aplicando rotações de 5, 10, 15, 20,25 e 30 graus sobre o eixo vertical do olho (simulando movimentos horizontais da linha da visão) e para cada imagem foram marcados o reflexo da fonte de luz sobre a córnea, o centro da pupila e o ponto de referência. Em seguida foram medidas a distância do reflexo ao centro da pupila (que chamaremos de $d$ ), a distância do reflexo ao ponto de referência (chamaremos de $D$ ), bem como a razão $D / d$ (veja a tabela 2.2). Como podemos ver, os valores obtidos para a razão $D / d$ são aproximadamente constantes e correspondem à razão $r / d_{p}^{\prime}=1.83$. Dessa forma, verificamos que é possível corrigir o centro observado da pupila de maneira similar ao que é feito para computar as projeções virtuais dos LEDs, mas utilizando um outro fator de escala, $\alpha_{p}=r / d_{p}^{\prime}$.

\begin{tabular}{|l|c|c|c|}
\hline Rotação & $\mathbf{d}$ & $\mathbf{D}$ & $\mathbf{D} / \mathbf{d}$ \\
\hline 5 graus & 9 pixels & 17 pixels & 1.89 \\
\hline 10 graus & 19 pixels & 34 pixels & 1.79 \\
\hline 15 graus & 28 pixels & 51 pixels & 1.82 \\
\hline 20 graus & 36 pixels & 67 pixels & 1.86 \\
\hline 25 graus & 45 pixels & 82 pixels & 1.82 \\
\hline 30 graus & 53 pixels & 97 pixels & 1.83 \\
\hline
\end{tabular}

Tabela 2.2: medidas obtidas no teste para avaliar a relação entre o centro da pupila e o ponto de intersecção do eixo óptico do olho com a córnea.

Assim, dada uma imagem do olho com os 4 reflexos (correspondentes aos LEDs do monitor) e o centro da pupila, todos esses pontos devem ser transformados antes de se aplicar o algoritmo baseado na razão cruzada utilizando dois fatores de correção: $\alpha$ (para os reflexos) e $\alpha_{p}$ (para o centro da pupila). Entretanto é possível combinar esses dois fatores em um só (dado por $\alpha / \alpha_{p}$ e que continuaremos chamando apenas de $\alpha$ ) e utilizá-lo para transformar os pontos $U_{R 1}, U_{R 2}$, $U_{R 3}$ e $U_{R 4}$, mantendo o valor de $U_{P}$. Como conseqüência, considerando casos reais de aplicação 
do algoritmo para estimação do olhar, o valor aproximado de 2.0 para o cálculo das projeções virtuais deixa de ser apropriado. Uma nova aproximação para esse valor, obtida utilizando os dados do modelo de Gullstrand seria 2.0/1.83 1 1.1. Contudo, como esse valor é dependente de pessoa para pessoa o ideal é utilizar um processo de calibração para computá-lo.

Quando uma pessoa olha para um LED no monitor, o centro da pupila e os reflexos gerados pelos LEDs são detectados. Como essa pessoa está olhando diretamente para o LED, considerando inexistente a diferença de eixos do olho, a posição da projeção virtual deste LED deve ser a mesma do centro da pupila. Dada essa restrição, é possível calcular o fator de correção $\alpha$ pela seguinte equação:

$$
\alpha=\frac{d\left(U_{P}, U_{C}\right)}{d\left(U_{R 1}, U_{C}\right)}
$$

onde $d(x, y)$ é a distância euclidiana entre os pontos $x$ e $y . U_{P}, U_{C}$ e $U_{R 1}$ são as coordenadas da pupila, do reflexo do LED da câmera, e do reflexo do LED do monitor, respectivamente, sobre o plano da imagem. Como existem 4 projeções virtuais (uma para cada LED do monitor), e o valor exato do fator de correção para cada uma delas pode apresentar variações, 4 valores de $\alpha$ são necessários. Este processo é então repetido 4 vezes conforme a pessoa olha para cada LED do monitor. Embora essa forma de calibração seja adequada quando não se considera a diferença de eixos do olho, suspeitamos que, na prática, ela não produza resultados muito precisos. 


\section{Capítulo 3}

\section{Análise exploratória}

Neste capítulo descrevemos uma série de experimentos feitos para avaliar o desempenho da técnica baseada na projeção de um padrão de luz sobre a córnea (vista em detalhes na seção 2.4.3). Em particular, queremos observar os resultados obtidos para algumas variações na maneira de estimar as projeções virtuais dos LEDs e do valor $\alpha$ utilizado. Além disso, queremos verificar também como esses resultados são afetados por movimentos de cabeça e pela consideração ou não da diferença entre o eixo óptico e visual do olho.

Para eliminar a necessidade de processar imagens, bem como eliminar erros decorrentes deste processamento, optamos por realizar os experimentos através de simulações, ao invés de utilizar imagens sintéticas geradas por traçamento de raios. Nessas simulações são calculados todos os pontos necessários para a aplicação da técnica avaliada que são, em seguida, projetados para o plano de formação da imagem da câmera.

Para que seja possível comparar os resultados obtidos nestes testes com a técnica tradicional de rastreamento de olhar baseada na detecção da pupila e reflexão sobre a córnea [MKAF99], vamos utilizar a mesma configuração espacial do teste utilizando imagens sintéticas realizado por Morimoto e Mimica em [MM05]. Nessa configuração, a câmera é posicionada na origem do 
sistema de coordenadas, isto é, no ponto $(0,0,0)$, e os LEDs do monitor são posicionados no plano $x y$ nos pontos $(-18.3,27.4,0),(18.3,27.4,0),(18.3,0,0)$ e $(-18.3,0,0)$, correspondendo às medidas aproximadas em centímetros da área útil de um monitor de 19 polegadas. A esfera correspondente à córnea é posicionada em $(0,27,60)$ e possui o raio definido segundo o modelo de Gullstrand, de $0.77 \mathrm{~cm}$. Assumimos que o centro da pupila está localizado sobre a superfície da córnea, não havendo assim refração deste ponto, e o vetor que parte do centro da córnea e segue em direção ao centro da pupila é tomado como o eixo óptico do olho, que possui como valor inicial as coordenadas $(0,0,-1)$.

Para ilustrar melhor a maneira como as rotações do olho foram modeladas vamos considerar o seguinte sistema de coordenadas do olho: centro da córnea localizado na origem, eixo $y$ apontando para cima, eixo $z$ apontando em direção ao eixo óptico do olho e eixo $x$ tomado como o produto vetorial do eixo y pelo eixo $z$ (veja a figura 3.1). Quando o olho é rotacionado para apontar em uma determinada direção, temos na verdade uma composição de duas rotações aplicadas sobre a orientação inicial do olho. A primeira rotação é feita sobre o eixo y, e é responsável pelo movimento da direção do olhar no plano $x z$. Já a segunda rotação é feita sobre o eixo $R_{y}(x)$ (isto é, o eixo $x$ transformado pela primeira rotação sobre o eixo $y$ ) e define o movimento da direção do olhar no plano yz.

Para modelar a diferença de eixos do olho, o eixo óptico é rotacionado, como descrito acima, para a obtenção do eixo visual. Foram utilizados os valores $4.5^{\circ}$ e $3.0^{\circ}$ que, combinados, resultam em uma diferença angular de aproximadamente $5.5^{\circ}$ entre os eixos (estando de acordo com a diferença observada para o olho humano que varia de 4-8 [WS82]). Além disso, a escolha dos dois valores baseou-se em resultados empíricos com uma versão preliminar do rastreador implementado, onde constatou-se que o eixo visual apresentava um desvio horizontal e vertical significativos em relação ao eixo óptico, sendo a diferença horizontal um pouco maior. Como é o eixo visual aquele que realmente aponta para o ponto observado, quando queremos que o 


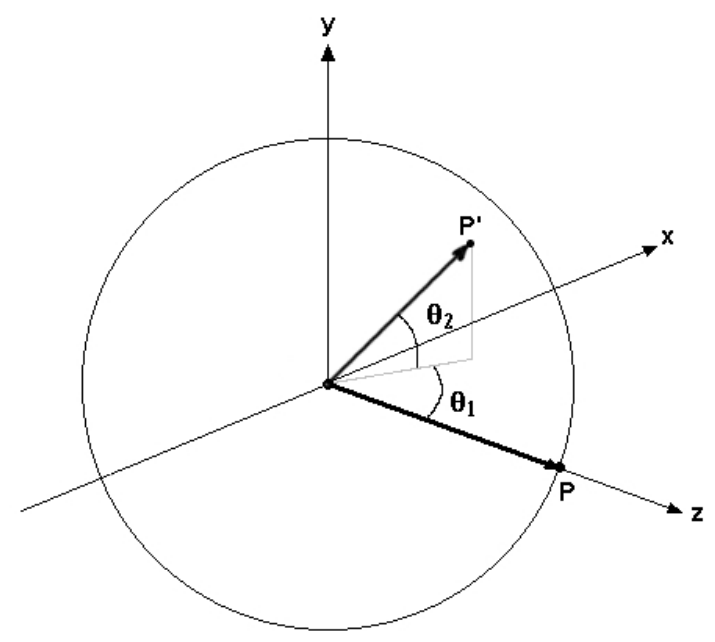

Figura 3.1: sistema de coordenadas utilizado para rotacionar o olho. $P$ indica a posição do centro da pupila para a orientação inicial do olho. $P^{\prime}$ é o ponto obtido ao aplicar as rotações $\theta_{1}$ e $\theta_{2}$ sobre $P$.

olho se direcione para um certo ponto, aplicamos uma rotação sobre o olho de forma que este eixo, e não o óptico, aponte para este ponto.

Usando experimentos similares aos de [MM05], a córnea, em sua posição inicial, é transladada de $10 \mathrm{~cm}$ em cada eixo do espaço nos sentidos positivo e negativo, gerando uma combinação de 7 posições possíveis. Para cada posição, a região correspondente ao monitor é dividida em uma grade de $8 \times 6$, e o olho é rotacionado de forma que seu eixo visual aponte para o centro de cada elemento da grade. Para cada configuração do olho determinada pela sua posição e o ponto de observação real, estimamos o ponto observado e o comparamos com o valor real. A estimação do olhar é feita utilizando os pontos correspondentes aos 5 reflexos sobre a córnea e o centro da pupila que, como mencionado anteriormente, são calculados, a partir do modelo do olho e da configuração espacial do experimento, e posteriormente projetados para o plano de projeção da câmera. A figura 3.2 mostra uma imagem gerada pela 
aplicação de teste utilizada nos experimentos onde é possível observar os pontos utilizados na determinação da direção do olhar.

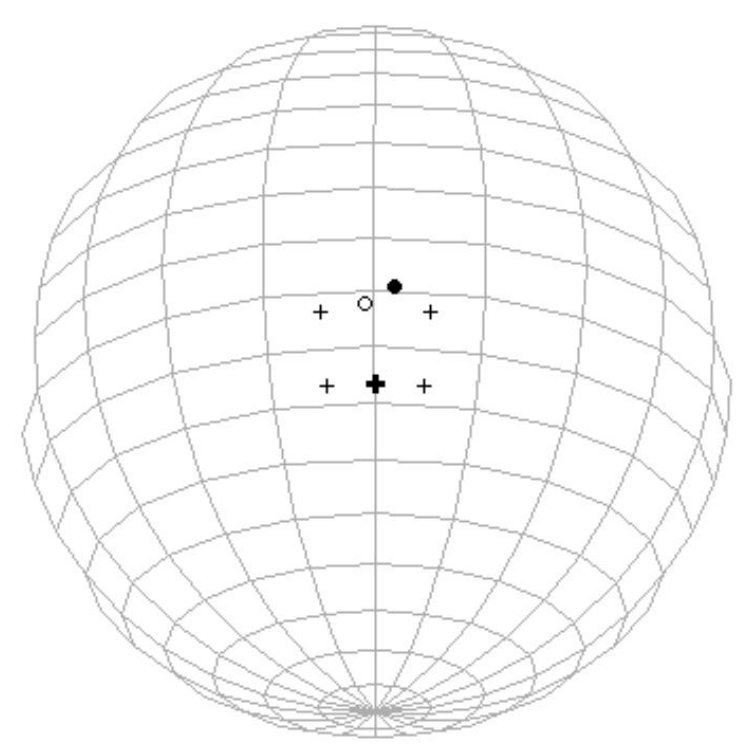

Figura 3.2: imagem gerada pela aplicação de teste utilizada nos experimentos. Nela podemos ver a superfície esférica da córnea com os reflexos gerados sobre ela (cruzes, sendo a cruz mais grossa o reflexo do LED da câmera), o centro da pupila (círculo preto) e o ponto de intersecção do eixo visual com a córnea (círculo branco). Note que este ponto não é utilizado nos cálculos, mas ele foi desenhado para dar uma idéia sobre a orientação do eixo visual em relação ao eixo óptico.

Cada experimento avalia um método diferente para estimar as projeções virtuais dos LEDs, considerando variações na posição da córnea e a existência ou não da diferença de eixos do olho. Quando tal diferença não é considerada, o eixo visual é definido como sendo igual ao eixo óptico. Além disso, conforme o método avaliado, pode ser necessária a execução de um processo de calibração. Os experimentos realizadas foram os seguintes:

- Reflexos: utiliza diretamente os reflexos dos LEDs sobre a córnea, sem fazer qualquer 
tipo de cálculo das projeções virtuais.

- Sem calibração: utiliza um valor de $\alpha$ constante (que não é obtido via calibração) para estimar as projeções virtuais de todos os LEDs sobre o plano tangente à córnea.

- Com calibração: utiliza o método de Yoo e Chung [YC05] para estimar as projeções virtuais dos LEDs, empregando um valor diferente de $\alpha$, obtido via calibração, para cada LED.

Em cada seção a seguir, discutimos de forma detalhada cada experimento realizado e os resultados obtidos.

\subsection{Reflexos}

Neste primeiro experimento o objetivo era verificar como o algoritmo para estimar o olhar baseado na razão cruzada se comportava utilizando diretamente os reflexos dos LEDs, sem fazer o cálculo das projeções virtuais e sem empregar qualquer tipo de calibração. Desconsiderando inicialmente a diferença de eixos do olho, os seguintes resultados foram obtidos para a córnea localizada na posição inicial: erro médio de $16.12 \mathrm{~cm}$ (aproximadamente $15^{\circ}$ ), erro máximo foi de $23.94 \mathrm{~cm}\left(22^{\circ}\right)$ e o desvio padrão foi de $5.35 \mathrm{~cm}$. A figura 3.3 mostra a relação entre os pontos reais e estimados para a posição inicial da córnea. Podemos ver na tabela 3.1 os resultados obtidos quando a córnea é transladada de $10 \mathrm{~cm}$ ao longo dos eixos $x, y$ e $z$, além da posição inicial.

Como pode ser observado, o resultado obtido nesse primeiro teste é muito impreciso mostrando a necessidade de se utilizar as projeções virtuais dos LEDs ao invés de seus reflexos na estimação do ponto observado. Mesmo assim outro teste foi feito utilizando os reflexos dos LEDs, mas desta vez considerando a diferença de eixos do olho para observar como os pontos 


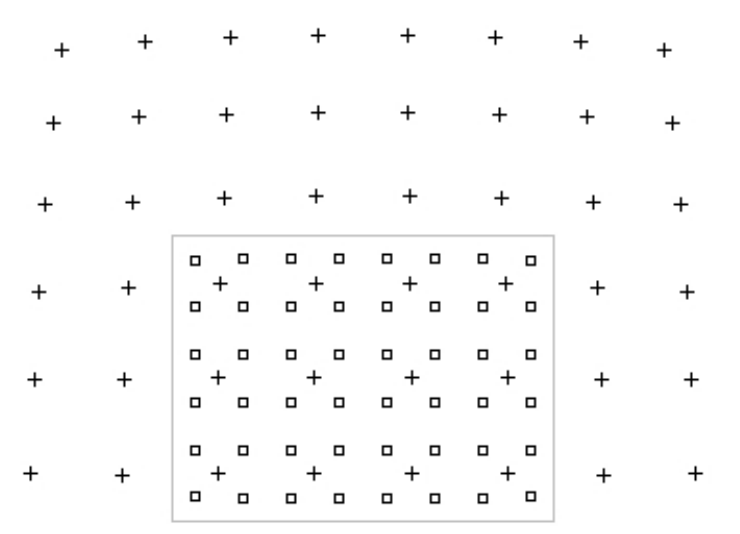

Figura 3.3: pontos estimados (cruzes) e pontos reais (quadrados) para a córnea na posição inicial. Neste teste foram utilizados diretamente os reflexos dos LEDs sobre a córnea e não foi considerada a diferença de eixos do olho.

estimados são afetados. Quando o olho é rotacionado para fixar o olhar sobre um dos pontos de teste, como o eixo que aponta diretamente para o ponto em questão é agora o eixo visual, são esperadas alterações nos resultados.

Para o olho localizado na sua posição inicial, o erro médio obtido foi de $22.45 \mathrm{~cm}\left(20.5^{\circ}\right)$, sendo o erro máximo de $31.65 \mathrm{~cm}\left(28^{\circ}\right)$ e o desvio padrão de $5.69 \mathrm{~cm}$. A tabela 3.2 mostra os resultados obtidos para as outras posições da córnea, transladada de $10 \mathrm{~cm}$ nos eixos $x$, $y$ e $z$, além da posição inicial. Apesar do resultado ainda pior do que o obtido no primeiro teste, pode-se observar na figura 3.4 que a nuvem de pontos estimados neste teste é similar 


\begin{tabular}{|l|c|c|c|}
\hline Posição & Erro médio & Erro máximo & Desvio padrão \\
\hline posição inicial & $16.12 \mathrm{~cm}\left(15.03^{\circ}\right)$ & $23.94 \mathrm{~cm}\left(21.76^{\circ}\right)$ & $5.35 \mathrm{~cm}$ \\
\hline translação no eixo x (-) & $16.13 \mathrm{~cm}\left(15.04^{\circ}\right)$ & $25.8 \mathrm{~cm}\left(23.27^{\circ}\right)$ & $5.44 \mathrm{~cm}$ \\
\hline translação no eixo x (+) & $16.13 \mathrm{~cm}\left(15.04^{\circ}\right)$ & $25.8 \mathrm{~cm}\left(23.27^{\circ}\right)$ & $5.44 \mathrm{~cm}$ \\
\hline translação no eixo y (-) & $17.28 \mathrm{~cm}\left(16.06^{\circ}\right)$ & $26.55 \mathrm{~cm}\left(23.87^{\circ}\right)$ & $6.09 \mathrm{~cm}$ \\
\hline translação no eixo y (+) & $15.23 \mathrm{~cm}\left(14.24^{\circ}\right)$ & $22.1 \mathrm{~cm}\left(20.22^{\circ}\right)$ & $4.84 \mathrm{~cm}$ \\
\hline translação no eixo z (-) & $15.68 \mathrm{~cm}\left(17.41^{\circ}\right)$ & $22.31 \mathrm{~cm}\left(24.05^{\circ}\right)$ & $4.93 \mathrm{~cm}$ \\
\hline translação no eixo z (+) & $16.45 \mathrm{~cm}\left(13.22^{\circ}\right)$ & $25.19 \mathrm{~cm}\left(19.79^{\circ}\right)$ & $5.68 \mathrm{~cm}$ \\
\hline
\end{tabular}

Tabela 3.1: resultados obtidos para o experimento da seção 3.1, utilizando os reflexos dos LEDs sobre a córnea e desconsiderando a diferença de eixos do olho. $(+)$ e $(-)$ indicam, respectivamente, translações positivas e negativas ao longo dos eixos.

na forma à nuvem de pontos estimados observados na figura 3.3 embora esteja transladada para cima e para a direita. Essa observação sugere que a diferença angular entre o eixo óptico e visual do olho pode ser compensada pela translação dos pontos estimados. Contudo, como os resultados obtidos nesse primeiro experimento foram bastante imprecisos, vamos explorar melhor essa observação no próximo experimento.

\begin{tabular}{|l|c|c|c|}
\hline Posição & Erro médio & Erro máximo & Desvio padrão \\
\hline posição inicial & $22.45 \mathrm{~cm}\left(20.52^{\circ}\right)$ & $31.65 \mathrm{~cm}\left(27.81^{\circ}\right)$ & $5.69 \mathrm{~cm}$ \\
\hline translação no eixo x $(-)$ & $23.19 \mathrm{~cm}\left(21.13^{\circ}\right)$ & $35.32 \mathrm{~cm}\left(30.49^{\circ}\right)$ & $6.83 \mathrm{~cm}$ \\
\hline translação no eixo x $(+)$ & $22.1 \mathrm{~cm}\left(20.22^{\circ}\right)$ & $28.89 \mathrm{~cm}\left(25.71^{\circ}\right)$ & $4.87 \mathrm{~cm}$ \\
\hline translação no eixo y $(-)$ & $23.75 \mathrm{~cm}\left(21.6^{\circ}\right)$ & $35.2 \mathrm{~cm}\left(30.4^{\circ}\right)$ & $6.73 \mathrm{~cm}$ \\
\hline translação no eixo y $(+)$ & $21.83 \mathrm{~cm}\left(19.99^{\circ}\right)$ & $29.48 \mathrm{~cm}\left(26.16^{\circ}\right)$ & $4.94 \mathrm{~cm}$ \\
\hline translação no eixo z $(-)$ & $20.7 \mathrm{~cm}\left(22.49^{\circ}\right)$ & $28.14 \mathrm{~cm}\left(29.37^{\circ}\right)$ & $5.04 \mathrm{~cm}$ \\
\hline translação no eixo z $(+)$ & $24.2 \mathrm{~cm}\left(19.07^{\circ}\right)$ & $34.84 \mathrm{~cm}\left(26.46^{\circ}\right)$ & $6.22 \mathrm{~cm}$ \\
\hline
\end{tabular}

Tabela 3.2: resultados obtidos para o experimento da seção 3.1, utilizando os reflexos dos LEDs sobre a córnea e considerando a diferença de eixos do olho. (+) e (-) indicam, respectivamente, translações positivas e negativas ao longo dos eixos. 


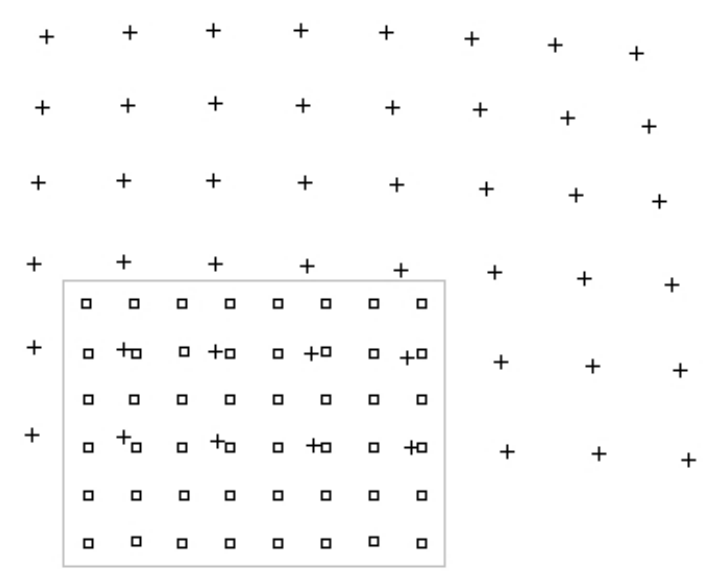

Figura 3.4: pontos estimados (cruzes) e pontos reais (quadrados) para a córnea na posição inicial. Neste teste foram utilizados diretamente os reflexos dos LEDs sobre a córnea e foi considerada a diferença de eixos do olho.

\subsection{Sem calibração do $\alpha$}

Através dos resultados obtidos no experimento anterior, foi possível notar a necessidade de se estimar as projeções virtuais dos LEDs ao aplicar o algoritmo para estimar o olhar baseado na aplicação do razão cruzada. Além disso verificamos que é necessário levar em conta a diferença entre o eixo óptico e visual do olho humano em uma implementação da técnica.

Vimos na seção 2.4.3 que, dado $L$ (um dos LEDs do monitor), $L_{C}$ (o LED posicionado no eixo da câmera) e seus reflexos no plano da imagem $U_{R}$ e $U_{C}$ respectivamente, podemos 
estimar a projeção virtual $U_{V}$ de $L$ da seguinte forma:

$$
U_{V}=\alpha\left(U_{R}-U_{C}\right)+U_{C}
$$

Vimos também que uma aproximação adequada para $\alpha$, no caso da câmera e monitor distantes do olho e da pupila localizada na superfície da córnea, é o valor 2.0. Embora esse fator de escala varie para cada reflexo e também varie conforme a posição do olho, as variações do valor de $\alpha$ também são pequenas quando a condição acima a respeito do posicionamento da câmera, monitor e olho é válida. Com isso, para este experimento, o processo utilizado para estimar os projeções virtuais dos LEDs simplesmente consiste em aplicar a fórmula acima utilizando $\alpha=2.0$. Embora seja um valor escolhido de forma aproximada e sem calibração, o objetivo é ver como os resultados do experimento são afetados por este valor. Como queremos analisar apenas o efeito deste método para estimar as projeções virtuais, estamos novamente desconsiderando a diferença de eixos do olho no primeiro teste deste experimento. Novamente nenhum processo de calibração adicional foi feito.

Para o olho localizado na posição inicial, obteve-se um erro médio de $0.32 \mathrm{~cm}$ ( 0.29 graus) com erro máximo de $0.62 \mathrm{~cm}$ (0.59 graus) e desvio padrão de $0.18 \mathrm{~cm}$ (veja figura 3.5), um resultado muito superior em relação aos obtidos no primeiro experimento, confirmando a necessidade do uso das projeções virtuais e que $\alpha=2.0$ é um valor adequado a ser utilizado no cálculo dessas projeções para as condições do experimento.

A tabela 3.3 mostra os resultados obtidos para as outras posições da córnea, transladada de $10 \mathrm{~cm}$ nos eixos $x, y$ e $z$, além da posição inicial. Através dela podemos ver que translações em qualquer um dos eixos pouco afetam os resultados em relação a posição inicial, embora seja possível notar ligeira melhora da precisão com afastamento do olho em relação ao monitor (translação positiva no eixo $z$ ) e ligeira piora com aproximação (translação negativa no eixo $z$ ). Isso pode ser explicado pelo fato de que conforme o olho se afasta do monitor, a região 
delimitada sobre a córnea pelas projeções dos LEDs se torna menor e conseqüentemente "mais coplanar". Assim o efeito da curvatura da córnea sobre algoritmo para estimação do olhar é menor. Por outro lado, quando o olho se aproxima do monitor, a região delimitada sobre a córnea pelas projeções dos LEDs se torna maior e mais curva, produzindo um resultado menos preciso.

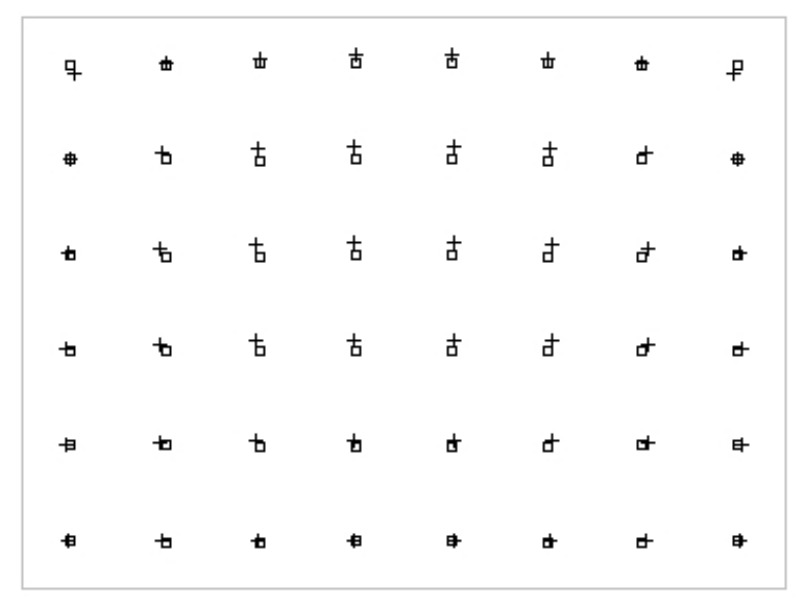

Figura 3.5: pontos estimados (cruzes) e pontos reais (quadrados) para a córnea na posição inicial. Neste teste as projeções virtuais do LEDs foram estimadas utilizando $\alpha=2.0$. Não foi considerada a diferença de eixos do olho.

Para verificar como a diferença de eixos do olho afeta os resultados obtidos neste experimento utilizando as projeções virtuais, esta diferença foi novamente considerada para o próximo teste. Para o olho localizado na sua posição inicial, o erro médio obtido foi de $6.03 \mathrm{~cm}$ $\left(5.74^{\circ}\right)$, sendo o erro máximo de $6.55 \mathrm{~cm}\left(6.23^{\circ}\right)$ e o desvio padrão de $0.38 \mathrm{~cm}$. Os resultados observados na figura 3.6, aliados à pouca diferença observada entre o erro máximo e o erro médio, e o baixo desvio padrão, indicam que o vetor deslocamento entre cada ponto real e o 


\begin{tabular}{|l|c|c|c|}
\hline Posição & Erro médio & Erro máximo & Desvio padrão \\
\hline posição inicial & $0.32 \mathrm{~cm}\left(0.3^{\circ}\right)$ & $0.62 \mathrm{~cm}\left(0.6^{\circ}\right)$ & $0.18 \mathrm{~cm}$ \\
\hline translação no eixo x $(-)$ & $0.31 \mathrm{~cm}\left(0.3^{\circ}\right)$ & $0.6 \mathrm{~cm}\left(0.57^{\circ}\right)$ & $0.17 \mathrm{~cm}$ \\
\hline translação no eixo x $(+)$ & $0.31 \mathrm{~cm}\left(0.3^{\circ}\right)$ & $0.6 \mathrm{~cm}\left(0.57^{\circ}\right)$ & $0.17 \mathrm{~cm}$ \\
\hline translação no eixo y $(-)$ & $0.34 \mathrm{~cm}\left(0.33^{\circ}\right)$ & $0.66 \mathrm{~cm}\left(0.63^{\circ}\right)$ & $0.19 \mathrm{~cm}$ \\
\hline translação no eixo y $(+)$ & $0.28 \mathrm{~cm}\left(0.27^{\circ}\right)$ & $0.56 \mathrm{~cm}\left(0.54^{\circ}\right)$ & $0.16 \mathrm{~cm}$ \\
\hline translação no eixo z $(-)$ & $0.44 \mathrm{~cm}\left(0.5^{\circ}\right)$ & $0.88 \mathrm{~cm}\left(1^{\circ}\right)$ & $0.25 \mathrm{~cm}$ \\
\hline translação no eixo z $(+)$ & $0.25 \mathrm{~cm}\left(0.2^{\circ}\right)$ & $0.47 \mathrm{~cm}\left(0.39^{\circ}\right)$ & $0.14 \mathrm{~cm}$ \\
\hline
\end{tabular}

Tabela 3.3: resultados obtidos para o experimento da seção 3.2, utilizando $\alpha=2.0$ e desconsiderando a diferença de eixos do olho. $(+)$ e $(-)$ indicam, respectivamente, translações positivas e negativas ao longo dos eixos.

correspondente estimado, isto é, o vetor que liga o ponto estimado ao real, é aproximadamente constante. Esse deslocamento constante sugere que a diferença angular entre o eixo óptico e o eixo visual do olho pode ser compensada pela soma de um vetor aos pontos estimados. Para a posição inicial da córnea, o valor médio encontrado para esse vetor deslocamento foi de (-4.94, -3.43). Podemos ver na tabela 3.4 os resultados obtidos para as outras posições da córnea, transladada de $10 \mathrm{~cm}$ nos eixos $x, y$ e $z$, além da posição inicial.

\begin{tabular}{|l|c|c|c|c|}
\hline Posição & Erro médio & Erro máx. & Desvio padrão & Desloc. médio \\
\hline posição inicial & $6.03 \mathrm{~cm}\left(5.74^{\circ}\right)$ & $6.55 \mathrm{~cm}\left(6.23^{\circ}\right)$ & $0.38 \mathrm{~cm}$ & $(-4.94,-3.43)$ \\
\hline translação no eixo x (-) & $6.12 \mathrm{~cm}\left(5.82^{\circ}\right)$ & $6.65 \mathrm{~cm}\left(6.32^{\circ}\right)$ & $0.32 \mathrm{~cm}$ & $(-5.13,-3.31)$ \\
\hline translação no eixo x $(+)$ & $6.2 \mathrm{~cm}\left(5.9^{\circ}\right)$ & $7.21 \mathrm{~cm}\left(6.85^{\circ}\right)$ & $0.58 \mathrm{~cm}$ & $(-5.03,-3.61)$ \\
\hline translação no eixo y $(-)$ & $5.9 \mathrm{~cm}\left(5.62^{\circ}\right)$ & $6.22 \mathrm{~cm}\left(5.92^{\circ}\right)$ & $0.3 \mathrm{~cm}$ & $(-4.83,-3.38)$ \\
\hline translação no eixo y $(+)$ & $6.33 \mathrm{~cm}\left(6.03^{\circ}\right)$ & $7.23 \mathrm{~cm}\left(6.87^{\circ}\right)$ & $0.5 \mathrm{~cm}$ & $(-5.17,-3.62)$ \\
\hline translação no eixo z $(-)$ & $5.23 \mathrm{~cm}\left(5.97^{\circ}\right)$ & $5.81 \mathrm{~cm}\left(6.62^{\circ}\right)$ & $0.44 \mathrm{~cm}$ & $(-4.21,-3.05)$ \\
\hline translação no eixo z $(+)$ & $6.89 \mathrm{~cm}\left(5.62^{\circ}\right)$ & $7.35 \mathrm{~cm}\left(5.99^{\circ}\right)$ & $0.34 \mathrm{~cm}$ & $(-5.69,-3.87)$ \\
\hline
\end{tabular}

Tabela 3.4: resultados obtidos para o experimento da seção 3.2, utilizando $\alpha=2.0$ e considerando a diferença de eixos do olho. (+) e (-) indicam, respectivamente, translações positivas e negativas ao longo dos eixos. 


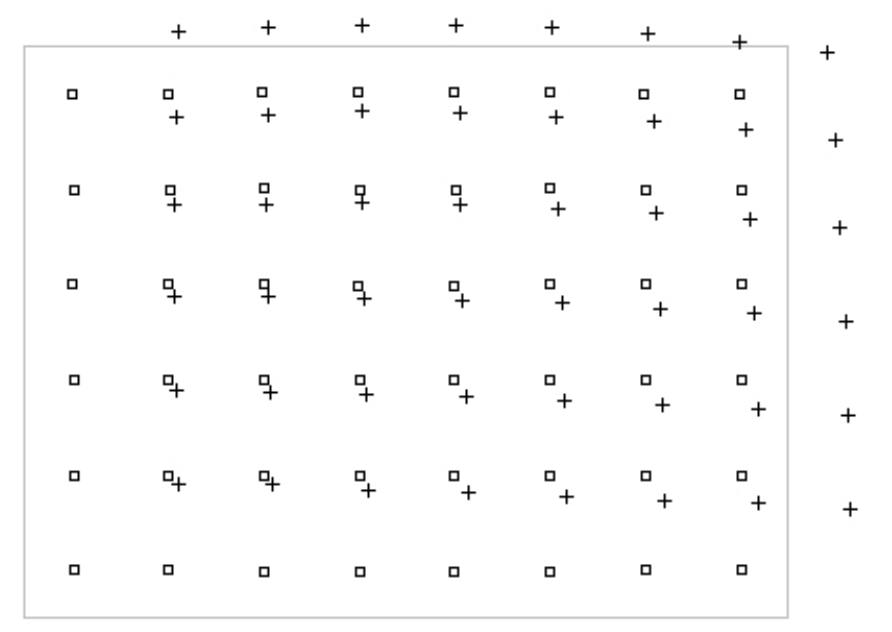

Figura 3.6: pontos estimados (cruzes) e pontos reais (quadrados) para a córnea na posição inicial. Neste teste as projeções virtuais do LEDs foram estimadas utilizando $\alpha=2.0$. Foi considerada a diferença de eixos do olho.

Pela tabela, podemos ver que, enquanto translações sobre o plano $x y$ não afetam muito os resultados, translações no eixo $z$ possuem uma maior influência no erro médio obtido. Além disso, apesar da direção do vetor deslocamento médio para todas as posições da córnea ser aproximadamente a mesma, sua magnitude varia para deslocamentos em $z$. Essa observação implica que, se for utilizada uma compensação de eixos do olho baseada na soma de um vetor de correção aos pontos estimados, essa compensação possuirá maior sensibilidade a movimentos no eixo z uma vez que a diferença de eixos é uma diferença angular e, conforme o olho se aproxima ou se afasta do monitor, a diferença entre o ponto estimado e o real será proporcional a essa distância. 


\subsection{Com calibração}

Nos testes realizados para esta seção, utilizamos o método proposto no trabalho desenvolvido em [YC05] para estimar as projeções virtuais dos LEDs. O método é similar ao utilizado na seção 3.2, mas, ao invés de utilizar um único fator de correção com um valor pré-determinado para calcular todas as 4 projeções virtuais dos LEDs, são utilizados 4 fatores de correção, um para cada LED. O valor de cada um desses fatores é obtido através do processo de calibração descrito na seção 2.4.3 que consiste em direcionar o olho para cada um dos 4 LEDs do monitor e para cada um deles calcular o fator correspondente $\left(\alpha_{i}\right)$ da seguinte forma:

$$
\alpha_{i}=\frac{d\left(U_{P}, U_{C}\right)}{d\left(U_{R i}, U_{C}\right)}
$$

onde $U_{P}, U_{C}$ e $U_{R i}$ são, respectivamente, as projeções sobre o plano da imagem da pupila, do reflexo do LED no eixo da câmera e do reflexo do LED observado.

Primeiramente desconsideramos a diferença de eixos do olho para analisar exclusivamente o procedimento de estimação das projeções virtuais. Queríamos verificar como esse procedimento se comporta com movimentações do olho uma vez que os valores obtidos pelo processo de calibração são restritos à posição inicial.

Os resultados obtidos são mostrados na tabela 3.5 e na figura 3.7. Como podemos notar, os resultados são similares aos do primeiro teste da seção 3.2. Além disso, o procedimento se mostrou robusto para a movimentação do olho em todos os eixos no espaço, notando mais uma vez ligeira melhora para translação positiva em $z$ (afastamento do monitor) e ligeira piora para translação negativa em $z$ (aproximação do monitor). Os valores de $\alpha_{i}$ calculados pelo processo de calibração para os LEDs superior-esquerdo, superior-direito, inferior-direito e inferior-esquerdo foram, respectivamente, 1.93, 1.93, 1.98 e 1.98.

Em seguida, no segundo teste do experimento, verificamos os resultados obtidos pelo 


\begin{tabular}{|c|c|c|c|c|c|c|c|}
\hline 古 & + & + & $\begin{array}{l}+ \\
\square\end{array}$ & ${ }_{0}^{+}$ & ${ }_{0}^{+}$ & ${ }_{{ }^{+}}^{+}$ & t \\
\hline$t_{\square}$ & ${ }^{+}$ & ++ & $\begin{array}{l}+ \\
\text { a }\end{array}$ & व & ${ }_{\square}^{+}$ & $a^{+}$ & $\mathrm{a}^{+}$ \\
\hline$t_{\square}$ & $+{ }_{0}$ & + & ${ }^{+}$ & ${ }_{0}^{+}$ & ${ }^{+}$ & $\mathrm{a}^{+}$ & $\mathrm{a}^{+}$ \\
\hline$t_{t}$ & $t_{\square}$ & ${ }^{+}$ & 古 & 吉 & $\mathrm{a}^{+}$ & $\mathrm{a}^{+}$ & वt \\
\hline 加 & to & 古 & 古 & 古 & वे & 마 & 마 \\
\hline † & to & $t$ & $\mathbf{t}$ & d & \& & 마 & 마 \\
\hline
\end{tabular}

Figura 3.7: pontos estimados(cruzes) e pontos reais (quadrados) para a córnea na posição inicial. As projeções virtuais dos LEDs foram estimadas segundo o método proposto em [YC05]. Não foi considerada a diferença de eixos do olho.

método avaliado nesta seção quando se considera a diferença de eixos do olho. No trabalho desenvolvido em [YC05], a diferença de eixos óptico e visual do olho não é considerada, mas repetimos o teste anterior considerando agora essa diferença a fim de observar se o método de calibração utilizado para determinar os parâmetros $\alpha_{i}$ implicitamente considera e compensa a diferença de eixos.

Note que no primeiro teste, onde desconsideramos a diferença de eixos, quando o olho era direcionado a algum dos LEDs do monitor, como o eixo óptico e visual eram os mesmos, a pupila projetada no plano da imagem $U_{P}$ pertencia ao segmento de reta partindo de $U_{C}$ e seguindo em direção a $U_{R i}$. Entretanto, quando consideramos a diferença de eixos, $U_{P}$ não necessariamente pertence mais a esse segmento de reta. Quem na realidade pertence a ele é a projeção, no plano da imagem, do ponto dado pela intersecção do eixo visual com a superfície 


\begin{tabular}{|l|c|c|c|}
\hline Posição & Erro médio & Erro máximo & Desvio padrão \\
\hline posição inicial & $0.73 \mathrm{~cm}\left(0.7^{\circ}\right)$ & $1.27 \mathrm{~cm}\left(1.21^{\circ}\right)$ & $0.33 \mathrm{~cm}$ \\
\hline translação no eixo x $(-)$ & $0.72 \mathrm{~cm}\left(0.69^{\circ}\right)$ & $1.23 \mathrm{~cm}\left(1.18^{\circ}\right)$ & $0.31 \mathrm{~cm}$ \\
\hline translação no eixo x $(+)$ & $0.72 \mathrm{~cm}\left(0.69^{\circ}\right)$ & $1.23 \mathrm{~cm}\left(1.18^{\circ}\right)$ & $0.31 \mathrm{~cm}$ \\
\hline translação no eixo y $(-)$ & $0.77 \mathrm{~cm}\left(0.73^{\circ}\right)$ & $1.31 \mathrm{~cm}\left(1.25^{\circ}\right)$ & $0.34 \mathrm{~cm}$ \\
\hline translação no eixo y $(+)$ & $0.68 \mathrm{~cm}\left(0.65^{\circ}\right)$ & $1.22 \mathrm{~cm}\left(1.16^{\circ}\right)$ & $0.31 \mathrm{~cm}$ \\
\hline translação no eixo z (-) & $0.83 \mathrm{~cm}\left(0.95^{\circ}\right)$ & $1.48 \mathrm{~cm}\left(1.7^{\circ}\right)$ & $0.39 \mathrm{~cm}$ \\
\hline translação no eixo z $(+)$ & $0.67 \mathrm{~cm}\left(0.55^{\circ}\right)$ & $1.19 \mathrm{~cm}\left(0.97^{\circ}\right)$ & $0.3 \mathrm{~cm}$ \\
\hline
\end{tabular}

Tabela 3.5: resultados obtidos para o experimento da seção 3.3, utilizando método proposto em [YC05] para estimação das projeções virtuais dos LEDs e desconsiderando a diferença de eixos do olho. $(+)$ e $(-)$ indicam, respectivamente, translações positivas e negativas ao longo dos eixos.

da córnea.

Neste teste, para a posição inicial do olho, foram obtidos os seguintes resultados: erro médio de $4.2 \mathrm{~cm}\left(3.78^{\circ}\right)$, erro máximo de $5.91 \mathrm{~cm}\left(5.4^{\circ}\right)$ e desvio padrão de $1.02 \mathrm{~cm}$. Os valores de $\alpha_{i}$ calculados pelo processo de calibração para os LEDs superior-esquerdo, superior-direito, inferior-direito e inferior-esquerdo foram, respectivamente, 1.96, 2.22, 2.59 e 1.51. Observando a figura 3.8, que ilustra os pontos reais e os pontos estimados para a posição inicial da córnea, podemos ver que além da baixa precisão nos pontos estimados, os deslocamentos entre estes e os pontos reais não são tão uniformes como visto no experimento da seção 3.2 quando também era considerada a diferença de eixos. A diferença maior entre o erro médio e máximo, e o desvio padrão maior também comprovam isso. Na tabela 3.6 podemos observar os resultados obtidos para as demais posições da córnea (transladada em $10 \mathrm{~cm}$ ao longo dos eixos $x, y$ e $z$ ), além da posição inicial. Através deste teste foi possível verificar que o método utilizado para estimar as projeções virtuais dos LEDs não é muito apropriado pois a calibração não considera a diferença de eixos do olho de forma implícita e também não conserva a uniformidade dos vetores deslocamento, impedindo assim a compensação da diferença de eixos pela soma de um 
vetor de correção aos pontos estimados.

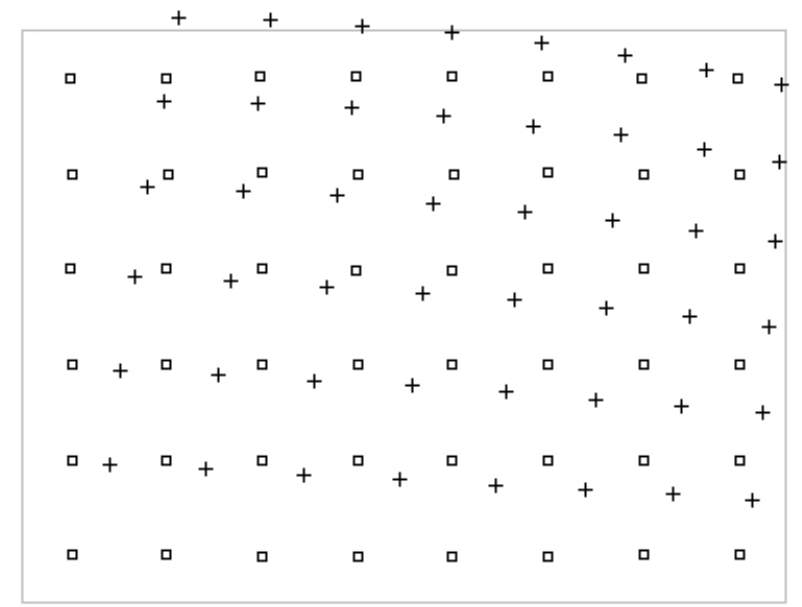

Figura 3.8: pontos estimados (cruzes) e pontos reais (quadrados) para a córnea na posição inicial. As projeções virtuais dos LEDs foram estimadas segundo o método proposto em [YC05]. Foi considerada a diferença de eixos do olho.

A figura 3.9 ilustra melhor o porquê do resultado obtido. Nela podemos ver os reflexos sobre a córnea, as projeções virtuais dos LEDs (calculados segundo o método de Yoo e Chung, e também segundo o método testado na seção anterior, utilizando $\alpha=2.0$ ), e as posições do centro da pupila quando o olho aponta para cada um dos LEDs. Note que, utilizando o método testado na seção anterior, embora os centros da pupila não se encaixem perfeitamente nas projeções virtuais dos LEDs, o deslocamento observado é aproximadamente o mesmo. Já para o método de Yoo e Chung, as relações entre os centros da pupila e as projeções virtuais não são uniformes. Além disso, para que o método funcionasse sem ser afetado pela diferença de eixos do olho, seria esperado que os centros da pupila se encaixassem sobre as projeções virtuais, mas isso também não ocorre. 


\begin{tabular}{|l|c|c|c|}
\hline Posição & Erro médio & Erro máximo & Desvio padrão \\
\hline posição inicial & $4.2 \mathrm{~cm}\left(4^{\circ}\right)$ & $5.91 \mathrm{~cm}\left(5.63^{\circ}\right)$ & $1.02 \mathrm{~cm}$ \\
\hline translação no eixo x $(-)$ & $4.12 \mathrm{~cm}\left(3.93^{\circ}\right)$ & $5.67 \mathrm{~cm}\left(5.4^{\circ}\right)$ & $0.89 \mathrm{~cm}$ \\
\hline translação no eixo x $(+)$ & $4.49 \mathrm{~cm}\left(4.28^{\circ}\right)$ & $6.4 \mathrm{~cm}\left(6.09^{\circ}\right)$ & $1.17 \mathrm{~cm}$ \\
\hline translação no eixo y $(-)$ & $4.06 \mathrm{~cm}\left(3.87^{\circ}\right)$ & $5.88 \mathrm{~cm}\left(5.6^{\circ}\right)$ & $1.01 \mathrm{~cm}$ \\
\hline translação no eixo y $(+)$ & $4.51 \mathrm{~cm}\left(4.3^{\circ}\right)$ & $6.14 \mathrm{~cm}\left(5.84^{\circ}\right)$ & $1.08 \mathrm{~cm}$ \\
\hline translação no eixo z $(-)$ & $3.5 \mathrm{~cm}\left(4.01^{\circ}\right)$ & $4.99 \mathrm{~cm}\left(5.69^{\circ}\right)$ & $0.99 \mathrm{~cm}$ \\
\hline translação no eixo z $(+)$ & $4.98 \mathrm{~cm}\left(4.07^{\circ}\right)$ & $6.85 \mathrm{~cm}\left(5.59^{\circ}\right)$ & $1.06 \mathrm{~cm}$ \\
\hline
\end{tabular}

Tabela 3.6: resultados obtidos para o experimento da seção 3.3, utilizando método proposto em [YC05] para estimação das projeções virtuais dos LEDs e considerando a diferença de eixos do olho. (+) e (-) indicam, respectivamente, translações positivas e negativas ao longo dos eixos.

\subsection{Conclusão}

Com base nos experimentos realizados, nos quais foram testadas variações no método utilizado para cálculo das projeções virtuais, bem como analisados os efeitos da movimentação do usuário e da diferença de eixos do olho, podemos fazer algumas observações importantes.

Primeiramente, podemos notar a necessidade do cálculo das projeções virtuais na estimação do olhar. Em seguida verificamos que o uso de apenas um fator de correção $\alpha$, obtido a partir de uma estimativa teórica, produz bons resultados quando se considera o eixo visual igual ao óptico, contudo perde-se bastante precisão quando se considera a diferença de eixos. Mesmo assim, pôde-se notar nesse último caso que os pontos estimados podem ser descritos como os pontos observados transladados por um vetor deslocamento, o que sugeriu uma maneira de se compensar a diferença de eixos.

Uma vez que esse valor de $\alpha$ pode variar de pessoa para pessoa, pois depende da distância do centro da pupila à superfície da córnea (veja seção 2.4.3), mesmo que nas condições do experimento essa variação não esteja presente, é importante considerar essa possibilidade visando uma implementação do rastreador. Assim outra necessidade que se faz presente é a 


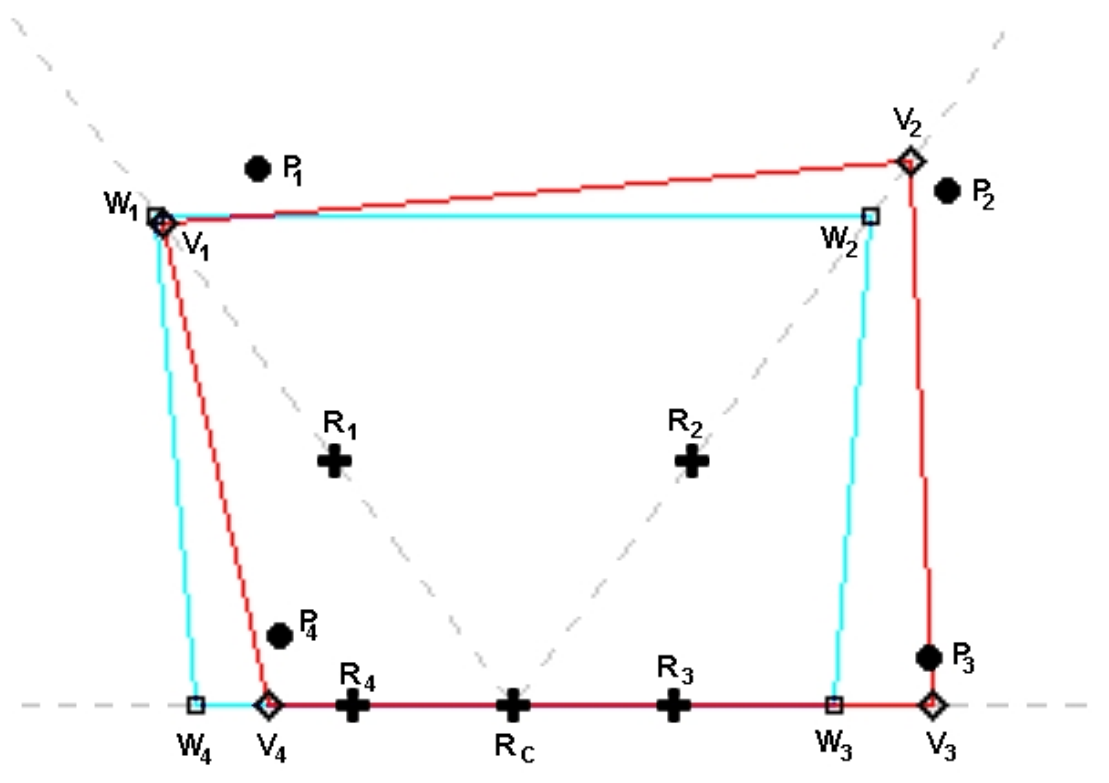

Figura 3.9: imagem ilustrando as projeções virtuais dos LEDs obtidas pelo método de Yoo e Chung (pontos $V_{1}, V_{2}, V_{3}$ e $V_{4}$ ) e pelo método testado na seção anterior (pontos $W_{1}, W_{2}$, $\left.W_{3}, W_{4}\right)$. $R_{1}, R_{2}, R_{3}$ e $R_{4}$ são os reflexos dos LEDs do monitor, $R_{C}$ o reflexo do LED da câmera, e $P_{1}, P_{2}, P_{3}$ e $P_{4}$ as posições do centro da pupila quando o olho observa os LEDs 1-4 respectivamente.

utilização de algum método de calibração para a obtenção do valor mais apropriado para o fator de correção. Testamos o método proposto por Yoo e Chung [YC05], que usa um processo de calibração para obter 4 valores de $\alpha$, um para a projeção virtual de cada LED do monitor. Embora os resultados para a estimação do olhar utilizando esse método e desconsiderando a diferença de eixos do olho tenham sido satisfatórios, quando se considera a diferença de eixos também se perde precisão. Além disso, a relação entre os pontos estimados e observados descrita por uma translação uniforme para todos os pontos deixa de existir, inviabilizando a compensação da diferença de eixos pela soma de um vetor aos pontos estimados. 
Dessa forma, uma nova maneira para obtenção dos melhores valores de $\alpha$ e que leve em consideração a diferença de eixos do olho se faz necessária, levando ao desenvolvimento de um novo método que é discutido em detalhes no capítulo a seguir. 


\section{Capítulo 4}

\section{Novo Método}

Através dos experimentos realizados no capítulo anterior constatamos a necessidade de uma nova forma de se estimar as projeções virtuais dos LEDs que leve em consideração a diferença de eixos do olho. O novo método desenvolvido utiliza os mesmos cálculos das projeções virtuais segundo a equação 2.18, mas fazendo uso de apenas um fator de correção $(\alpha)$ para todos os LEDs, uma vez que foi observado que a utilização de apenas um valor produz resultados satisfatórios. Além disso, após estimar o ponto observado pelo usuário, fazemos a adição de um vetor deslocamento ao ponto estimado para compensar a diferença de eixos.

A obtenção tanto de $\alpha$ quanto do vetor deslocamento é feita via um novo processo de calibração um pouco diferente do processo utilizado por Yoo e Chung [YC05] uma vez que não se pode assumir que a posição da pupila, quando o olho é direcionado a um dos LEDs, corresponda exatamente à projeção virtual do LED observado. Nesse novo processo, o olho é direcionado para alguns pontos pré-determinados do monitor e informações relativas a cada ponto são armazenadas. Essas informações consistem nas posições dos 5 reflexos dos LEDs e do centro da pupila na imagem, bem como o ponto real observado.

A idéia por trás do novo método de calibração é calcular o valor de $\alpha$ que gera um conjunto 
de pontos estimados que também podem ser descritos em função de uma translação do conjunto dos pontos reais observados. Dado $n$ pontos de calibração, seja $C=\left\{c_{i} \mid i \in[1 . . n]\right\}$ o conjunto desses pontos e $E^{\alpha}=\left\{e_{i}{ }^{\alpha} \mid e_{i}{ }^{\alpha}=T\left(c_{i}, \alpha\right), i \in[1 . . n]\right\}$ o conjunto dos pontos estimados, onde $T\left(c_{i}, \alpha\right)$ corresponde à aplicação do algoritmo de estimação do olhar para as informações relativas ao ponto de calibração $c_{i}$ e para o dado $\alpha$. Sejam ainda $D^{\alpha}=\left\{\overrightarrow{d_{i}^{\alpha}} \mid \overrightarrow{d_{i}^{\alpha}}=\left(c_{i}-e_{i}{ }^{\alpha}\right), i \in\right.$ $[1 . . n]\}$ o conjunto dos vetores deslocamento para os $n$ pontos de calibração e $\overrightarrow{m_{\alpha}}$ o vetor deslocamento médio definido pela equação a seguir:

$$
\overrightarrow{m_{\alpha}}=\frac{1}{n} \sum_{i=1}^{n} \overrightarrow{d_{i}^{\alpha}}
$$

Idealmente, para o melhor valor de $\alpha$, seria esperado que qualquer elemento de $D^{\alpha}$ fosse igual a $\overrightarrow{m_{\alpha}}$. Entretanto, apesar da uniformidade observada para os vetores deslocamento entre os pontos reais e estimados, eles apresentam variações entre si. Dessa forma, o valor ótimo de $\alpha$ será aquele que gera um conjunto $D^{\alpha}$ cujos elementos sejam o mais uniformes entre si. Isto é, queremos um $\alpha$ que minimize a seguinte soma:

$$
\operatorname{soma}(\alpha)=\sum_{i=1}^{n}\left|\overrightarrow{d_{i}{ }^{\alpha}}-\overrightarrow{m_{\alpha}}\right|
$$

Como a plotagem de $\operatorname{soma}(\alpha)$ em função de $\alpha$ gera uma curva que decresce até o valor mínimo e depois volta a crescer (veja a figura 4.1), utilizamos um método iterativo de bissecção para determinar o valor ótimo de $\alpha$. Seja $\min =0.75$ e $\max =2.5$ os extremos do intervalo inicial de procura (obtidos experimentalmente e que oferecem uma margem de segurança para garantir que o valor ótimo de $\alpha$ vai estar contido nesse intervalo). A cada iteração tomamos $\alpha=(\min +\max ) / 2, \alpha_{-}=\alpha-\delta$ e $\alpha_{+}=\alpha+\delta$, sendo $\delta$ um valor pequeno escolhido conforme a precisão desejada. Se $\alpha$ estiver em uma região crescente da curva, isto é, $\operatorname{soma}\left(\alpha_{-}\right)<$ $\operatorname{soma}(\alpha)<\operatorname{soma}\left(\alpha_{+}\right)$, redefinimos $\max =\alpha$ e continuamos o processo iterativo. Caso $\alpha$ esteja 
em uma região decrescente da curva, isto é, $\operatorname{soma}\left(\alpha_{-}\right)>\operatorname{soma}(\alpha)>\operatorname{soma}\left(\alpha_{+}\right)$, redefinimos $\min =\alpha$ e também continuamos o processo. Por fim, caso soma $(\alpha)<\operatorname{soma}\left(\alpha_{-}\right)$e $\operatorname{soma}(\alpha)<$ soma $\left(\alpha_{+}\right)$, então achamos o valor ótimo de $\alpha$ com uma precisão de $\delta$. O critério de parada do método iterativo também pode ser definido como o número máximo de iterações (maxIt) a serem realizadas, obtendo o valor ótimo de $\alpha$ com uma precisão de $(2.5-0.75) / 2^{\text {maxIt }}$ caso o método não pare antes devido à primeira condição explicada. Uma vez que temos o valor ótimo de $\alpha$ calculado, o vetor $\overrightarrow{m_{\alpha}}$ é tomado como o vetor deslocamento médio para ser utilizado na compensação da diferença de eixos do olho.

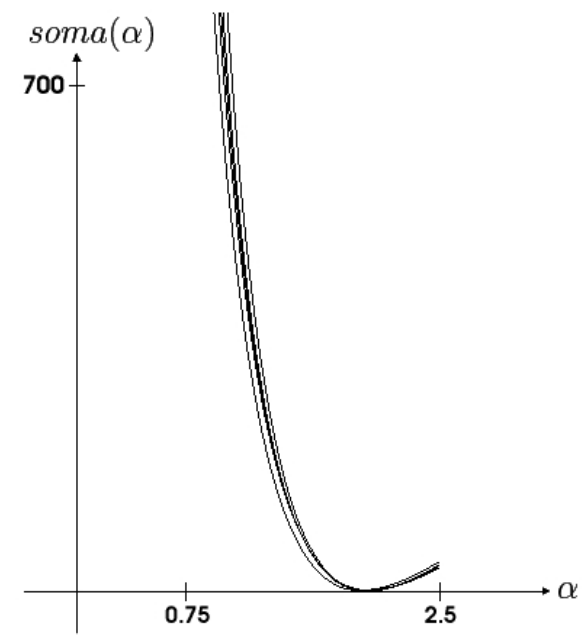

Figura 4.1: gráfico de $\operatorname{soma}(\alpha)$ em função de $\alpha$, para algumas posições diferentes da córnea no espaço. Note que, mesmo variando a posição da córnea, as curvas mantêm o seu aspecto.

Para analisar este novo método proposto foram feitos experimentos da mesma forma como os executados no capítulo anterior. Como o método considera a diferença de eixos do olho para o cálculo do fator de correção $\alpha$, não foram feitos testes que desconsideravam essa diferença. Dois testes foram feitos para avaliar o método. No primeiro, utilizamos apenas 4 pontos de calibração que correspondem aos 4 LEDs do monitor. No segundo, utilizamos 9 pontos de 
calibração. Esses 9 pontos correspondem aos centros dos elementos de uma grade $3 \times 3$ que ocupa toda a área do monitor. O valor de $\delta$ utilizado foi de 0.001 e o número máximo de iterações para o processo de procura do valor ótimo de $\alpha$ foi definido em 20.

A figura 4.2 ilustra os resultados obtidos para a córnea na posição inicial para o teste utilizando 4 pontos de calibração. Na tabela 4.1 podemos ver os resultados obtidos para a córnea transladada em $10 \mathrm{~cm}$ ao longo dos eixos $x, y$ e $z$, além da posição inicial para este teste. Os resultados para o teste utilizando 9 pontos de calibração podem ser vistos na figura 4.3 (para a posição inicial da córnea) e na tabela 4.2 (para a córnea transladada ao longo dos eixos $x, y$ e $z$, além da posição inicial). Os valores de $\alpha$ obtidos para o primeiro e segundo teste foram, respectivamente, 1.91 e 1.99 .

\begin{tabular}{|c|c|c|c|c|c|c|c|}
\hline$t_{0}$ & ${ }^{+}$ & + & + & 吉 & 古 & d & 丹 \\
\hline${ }^{+}$ & + & + & $\begin{array}{l}+ \\
\text { - }\end{array}$ & $\stackrel{+}{a}$ & ${ }_{{ }^{+}}^{+}$ & $\mathrm{a}^{+}$ & 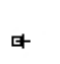 \\
\hline${ }^{+}$ & ${ }^{+}$ & + & $\begin{array}{l}+ \\
\square\end{array}$ & ${ }_{a}^{+}$ & $a^{+}$ & $\mathrm{a}^{+}$ & 마 \\
\hline${ }^{+}$ & + & + & $\stackrel{+}{a}$ & ${ }_{a}^{+}$ & $a^{+}$ & $\mathrm{a}^{+}$ & a+ \\
\hline${ }^{+}$ & ${ }^{+}$ & $\stackrel{+}{\square}$ & ${ }^{+}$ & $a^{+}$ & $\mathrm{a}^{+}$ & at & $a+$ \\
\hline+ & ${ }_{a}^{+}$ & $\stackrel{+}{a}$ & む & $\mathrm{a}^{+}$ & a & a & $a_{+}$ \\
\hline
\end{tabular}

Figura 4.2: pontos estimados (cruzes) e pontos reais (quadrados) para a córnea na posição inicial. As projeções virtuais dos LEDs foram estimadas pelo novo método proposto. Foi considerada a diferença de eixos do olho. Neste teste foram utilizados 4 pontos de calibração.

Comparando os resultados dos dois testes, podemos ver que a utilização de 9 pontos de 


\begin{tabular}{|l|c|c|c|}
\hline Posição & Erro médio & Erro máximo & Desvio padrão \\
\hline posição inicial & $1 \mathrm{~cm}\left(0.96^{\circ}\right)$ & $1.45 \mathrm{~cm}\left(1.38^{\circ}\right)$ & $0.28 \mathrm{~cm}$ \\
\hline translação no eixo x $(-)$ & $1.13 \mathrm{~cm}\left(1.08^{\circ}\right)$ & $1.92 \mathrm{~cm}\left(1.83^{\circ}\right)$ & $0.32 \mathrm{~cm}$ \\
\hline translação no eixo x $(+)$ & $1.05 \mathrm{~cm}\left(1^{\circ}\right)$ & $1.57 \mathrm{~cm}\left(1.5^{\circ}\right)$ & $0.37 \mathrm{~cm}$ \\
\hline translação no eixo y $(-)$ & $0.95 \mathrm{~cm}\left(0.91^{\circ}\right)$ & $1.41 \mathrm{~cm}\left(1.35^{\circ}\right)$ & $0.3 \mathrm{~cm}$ \\
\hline translação no eixo y $(+)$ & $1.22 \mathrm{~cm}\left(1.17^{\circ}\right)$ & $1.68 \mathrm{~cm}\left(1.6^{\circ}\right)$ & $0.32 \mathrm{~cm}$ \\
\hline translação no eixo z (-) & $0.99 \mathrm{~cm}\left(1.13^{\circ}\right)$ & $1.79 \mathrm{~cm}\left(2.06^{\circ}\right)$ & $0.51 \mathrm{~cm}$ \\
\hline translação no eixo z (+) & $1.63 \mathrm{~cm}\left(1.33^{\circ}\right)$ & $1.92 \mathrm{~cm}\left(1.57^{\circ}\right)$ & $0.2 \mathrm{~cm}$ \\
\hline
\end{tabular}

Tabela 4.1: resultados obtidos para o experimento utilizando 4 pontos de calibração. (+) e (-) indicam, respectivamente, translações positivas e negativas ao longo dos eixos.

\begin{tabular}{|l|c|c|c|}
\hline Posição & Erro médio & Erro máximo & Desvio padrão \\
\hline posição inicial & $0.48 \mathrm{~cm}\left(0.46^{\circ}\right)$ & $1.64 \mathrm{~cm}\left(1.56^{\circ}\right)$ & $0.26 \mathrm{~cm}$ \\
\hline translação no eixo x $(-)$ & $0.55 \mathrm{~cm}\left(0.53^{\circ}\right)$ & $1.34 \mathrm{~cm}\left(1.28^{\circ}\right)$ & $0.32 \mathrm{~cm}$ \\
\hline translação no eixo x $(+)$ & $0.58 \mathrm{~cm}\left(0.55^{\circ}\right)$ & $1.82 \mathrm{~cm}\left(1.74^{\circ}\right)$ & $0.34 \mathrm{~cm}$ \\
\hline translação no eixo y $(-)$ & $0.39 \mathrm{~cm}\left(0.37^{\circ}\right)$ & $1.51 \mathrm{~cm}\left(1.44^{\circ}\right)$ & $0.24 \mathrm{~cm}$ \\
\hline translação no eixo y $(+)$ & $0.67 \mathrm{~cm}\left(0.64^{\circ}\right)$ & $1.6 \mathrm{~cm}\left(1.53^{\circ}\right)$ & $0.32 \mathrm{~cm}$ \\
\hline translação no eixo z $(-)$ & $1 \mathrm{~cm}\left(1.15^{\circ}\right)$ & $2.7 \mathrm{~cm}\left(3.09^{\circ}\right)$ & $0.41 \mathrm{~cm}$ \\
\hline translação no eixo z $(+)$ & $0.94 \mathrm{~cm}\left(0.77^{\circ}\right)$ & $1.27 \mathrm{~cm}\left(1.04^{\circ}\right)$ & $0.21 \mathrm{~cm}$ \\
\hline
\end{tabular}

Tabela 4.2: resultados obtidos para o experimento utilizando 9 pontos de calibração. (+) e $(-)$ indicam, respectivamente, translações positivas e negativas ao longo dos eixos.

calibração produziu um resultado mais preciso, como podemos ver pelo erro médio obtido para todas as posições de teste da córnea, bem como pelas figuras 4.2 e 4.3. Isso é explicado pelo fato de que os 9 pontos de calibração fornecerem uma amostra de pontos que cobrem todas as regiões do monitor ao invés de priorizar apenas as suas extremidades. É importante notar também que o novo método proposto é robusto para translações do olho no plano $x y$, embora translações no eixo z comprometam a precisão do algoritmo. Mesmo assim a tolerância à movimentações em qualquer um dos três eixos é consideravelmente maior do que a tolerância observada pela técnica tradicional para rastreamento de olhar baseada na detecção da pupila 


\begin{tabular}{|c|c|c|c|c|c|c|c|}
\hline 古 & $P$ & + & $P$ & $P$ & f & $\stackrel{+}{+}$ & + \\
\hline$\theta$ & b & t & 七 & $t$ & 甲 & 中 & $\stackrel{0}{+}$ \\
\hline b & 古 & 专 & 古 & d & 7 & q & $\stackrel{\text { p }}{+}$ \\
\hline 古 & 古 & 古 & t & d & 마 & 7 & q \\
\hline 古 & 古 & 古 & d & at & 마 & ${ }_{4}$ & q \\
\hline 古 & 古 & 古 & of & 마 & 마 & $\square_{4}$ & q \\
\hline
\end{tabular}

Figura 4.3: pontos estimados (cruzes) e pontos reais (quadrados) para a córnea na posição inicial. As projeções virtuais dos LEDs foram estimadas pelo novo método proposto. Foi considerada a diferença de eixos do olho. Neste teste foram utilizados 9 pontos de calibração.

e de um reflexo sobre a córnea [MKAF99]. A tabela 4.3 compara os resultados obtidos neste último experimento com os resultados obtidos por Morimoto e Mimica em [MM05].

Para explorar um pouco mais os efeitos da translação do olho nos resultados obtidos, alguns testes adicionais foram feitos, dessa vez utilizando translações de 10, 20 e $30 \mathrm{~cm}$ para ambos os sentidos dos eixos $x, y$ e $z$. Note que a translação máxima de $30 \mathrm{~cm}$ é um valor bastante acima do esperado em casos normais de utilização do rastreador. Continuamos utilizando 9 pontos de calibração pelos melhores resultados obtidos. Os novos resultados podem ser observados no gráfico da figura 4.4. Como podemos ver, a maior sensibilidade reside para translações ao longo do eixo $z$ no qual o crescimento do erro médio é mais acelerado do que para os outros eixos. A estranha melhora do erro médio obtido para translações de -10 e $-20 \mathrm{~cm}$ no eixo $y$ pode ser explicada pelo fato da posição inicial da córnea estar alinhada verticalmente com a 


\begin{tabular}{|l|c|c|c|}
\hline Posição & \multicolumn{3}{|c|}{ Erro médio } \\
\hline & técnica tradicional & razão cruzada $(4$ pontos $)$ & razão cruzada (9 pontos) \\
\hline inicial & $0.80 \mathrm{~cm}$ & $1.0 \mathrm{~cm}$ & $0.48 \mathrm{~cm}$ \\
\hline $\mathrm{x}(-)$ & $0.99 \mathrm{~cm}$ & $1.13 \mathrm{~cm}$ & $0.55 \mathrm{~cm}$ \\
\hline $\mathrm{y}(-)$ & $2.17 \mathrm{~cm}$ & $0.95 \mathrm{~cm}$ & $0.39 \mathrm{~cm}$ \\
\hline $\mathrm{z}(+)$ & $4.05 \mathrm{~cm}$ & $1.63 \mathrm{~cm}$ & $0.94 \mathrm{~cm}$ \\
\hline
\end{tabular}

Tabela 4.3: comparação dos erros médios obtidos pela técnica tradicional e pela técnica escolhida para implementação, utilizando o novo método proposto para estimar as projeções virtuais dos LEDs (com 4 e 9 pontos de calibração). (+) e (-) indicam, respectivamente, translações positivas e negativas ao longo dos eixos.

borda superior do monitor. Dessa forma, quando o olho é transladado de -10 e -20 cm no eixo $y$, as distâncias da córnea às bordas superiores e inferiores do monitor ficam mais uniformes, e essa simetria maior entre a posição da córnea e dos LEDs favorece resultados melhores (em um caso totalmente simétrico, se utilizássemos um fator de correção $\alpha_{i}$ para cada LED, seus valores seriam exatamente os mesmos e, nesse caso, utilizar apenas um valor para $\alpha$ não acarretaria quaisquer perda de precisão, embora como já constatado, é razoável utilizar um valor único de $\alpha$ no caso geral). Podemos ver também que para translações no plano $x y$ dentro do intervalo de -20 a $20 \mathrm{~cm}$, que proporciona uma grande liberdade de movimento ao usuário, os resultados ainda são satisfatórios com um erro médio de menos de $1 \mathrm{~cm}$ na estimação do olhar. 


\section{Erro médio obtido para translações da córnea}

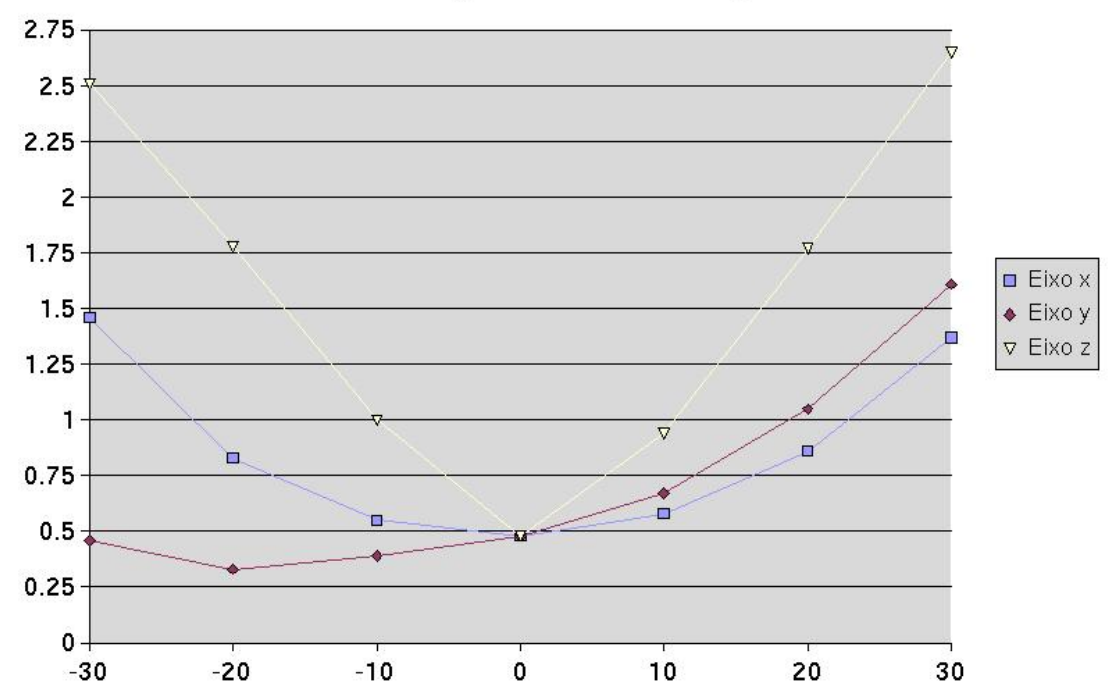

Figura 4.4: erro médio obtido (em $\mathrm{cm}$ ) para testes utilizando o novo método proposto para estimação das projeções virtuais, para translações da córnea de até $30 \mathrm{~cm}$ para ambos os sentidos dos eixos $x, y$ e $z$. Foram utilizados 9 pontos de calibração. 


\section{Capítulo 5}

\section{Implementação}

Neste capítulo discutimos de forma detalhada a implementação do nosso rastreador de olhar, construído com base na técnica desenvolvida por Yoo et al., descrita na seção 2.4.3, e utilizando o novo método desenvolvido para estimação das projeções virtuais, descrito no capítulo 4 . Nossa escolha por essa técnica é justificada por ela se mostrar mais apropriada para utilização em aplicações interativas, com uma configuração de hardware simplificada, boa precisão e tolerância à movimentação do usuário, sendo essas duas últimas características confirmadas através dos resultados experimentais introduzidos nos dois capítulos anteriores. Para facilitar a descrição do rastreador detalhamos primeiramente os componentes de hardware utilizados e, em seguida, o software desenvolvido.

\section{$5.1 \quad$ Hardware}

O hardware que compõe o sistema de rastreamento de olhar implementado consiste de um microcomputador (Athlon $1.4 \mathrm{Ghz}, 512 \mathrm{Mb}$ de memória RAM), uma placa de captura de vídeo (modelo Osprey 100), uma câmera, LEDs infravermelhos e um monitor. A câmera 
utilizada (figura 5.1) possui um conjunto de luzes infravermelhas posicionado próximo ao eixo óptico da câmera e outro conjunto afastado do eixo. O conjunto próximo ao eixo óptico gera imagens com a pupila brilhante enquanto o outro gera imagens com a pupila escura. Em nossa implementação, substituímos o conjunto afastado do eixo da câmera pelos LEDs fixados nos quatro cantos do monitor com dois LEDs em cada canto (figura 5.2). Esse novo conjunto, além de continuar gerando imagens com a pupila escura e manter a iluminação do ambiente, gera também os quatro reflexos sobre a córnea que são utilizados na técnica de rastreamento de olhar implementada. Através de um circuito externo, os conjuntos de LEDs são ativados alternadamente e de forma sincronizada com a varredura das linhas pares/ímpares de uma imagem entrelaçada. A lente utilizada na câmera proporciona um pequeno ângulo visual, possibilitando a captura de imagens detalhadas do olho. O monitor utilizado na implementação do sistema é um monitor LCD de 17 polegadas com $33.8 \mathrm{~cm}$ de largura por $27.0 \mathrm{~cm}$ de altura e resolução de $1280 \times 1024$ pixels.

Apesar de não existir um posicionamento fixo para a câmera em relação ao monitor, ela é tipicamente posicionada abaixo do monitor e entre o monitor e o usuário (figura 5.2). Podemos ver na figura $5.3 \mathrm{um}$ exemplo de imagem obtida através desse sistema. 


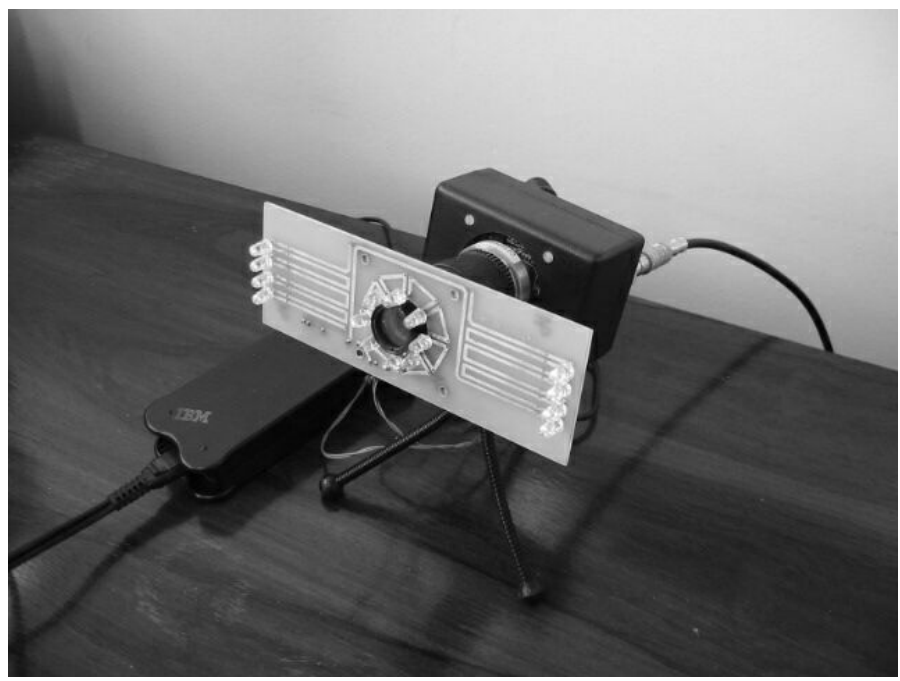

Figura 5.1: câmera utilizada na implementação do rastreador. Próximo ao eixo óptico temos o conjunto de LEDs infravermelhos que, quando acesos, geram imagens da pupila brilhante. O conjunto externo de LEDs foi desativado, sendo substituído pelos LEDs localizados no monitor.

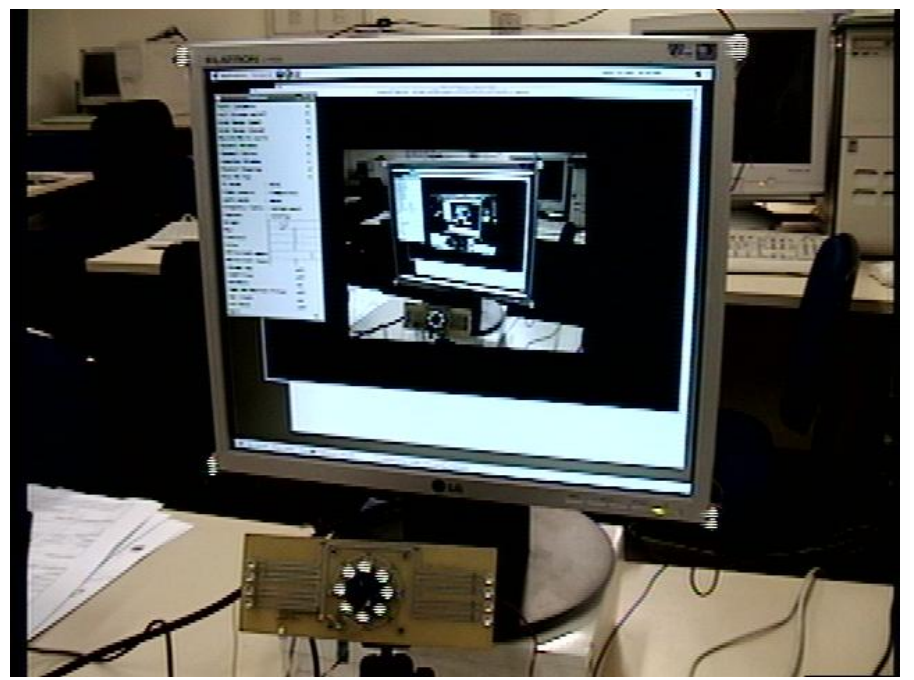

Figura 5.2: visão geral do hardware do rastreador. Na foto podemos ver o monitor com os LEDs fixados em seus cantos, e a câmera utilizada. 


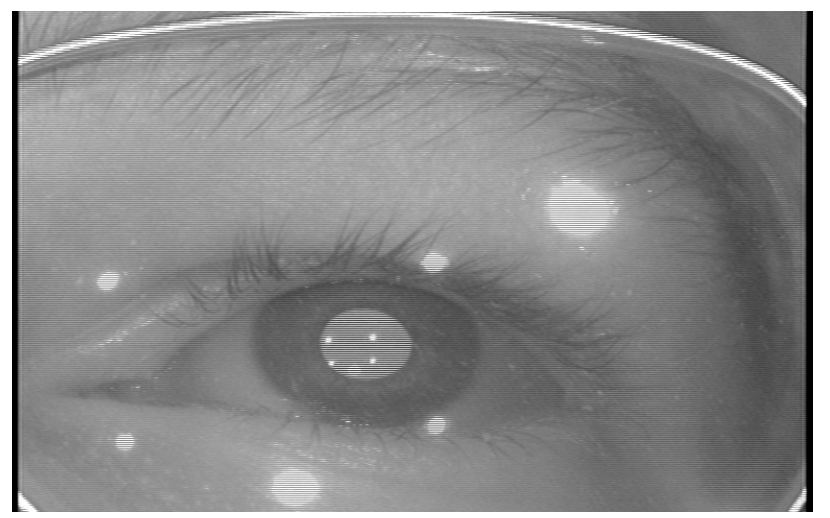

Figura 5.3: exemplo de imagem entrelaçada capturada com o rastreador. 


\subsection{Software}

A parte de software do sistema consiste de um aplicativo (para ambiente Linux) que é responsável pela aquisição e processamento das imagens capturadas e posterior cálculo do ponto visualizado pelo usuário. A aquisição de imagens é feita utilizando a API video4linux (V4L) que fornece uma interface padronizada para manipular diversos dispositivos de captura de vídeo, áudio e TV. Para as operações de processamento de imagens foi utilizada a biblioteca OpenCV que oferece uma grande quantidade de funções para este fim como escala, limiares, soma, subtração, aplicação de filtros, operadores morfológicos, entre outras. A aplicação fornece ainda uma interface básica que permite ajustar alguns valores de limiar utilizados no processamento das imagens.

Um detalhe importante sobre a aquisição de imagens utilizando a V4L é que, para se obter uma taxa ótima de quadros processados por segundo (isto é, 30 quadros por segundo), foram utilizados recursos da API que permitem:

- mapear diretamente a memória utilizada pelo dispositivo de captura;

- fazer captura assíncrona, isto é, enquanto estamos processando um quadro, o driver do dispositivo já foi notificado e está capturando o próximo;

- utilizar uma fila de captura com capacidade para vários quadros. No caso configuramos a fila para 8 quadros.

Cada imagem capturada pela câmera possui uma dimensão de 768 x 480 pixels e a seguinte seqüência de processamento é feita sobre ela:

- desentrelaçamento

- detecção inicial da pupila 
- detecção dos reflexos sobre a córnea

- detecção detalhada da pupila

- determinação da direção do olhar

Veremos a seguir uma descrição mais detalhada de cada uma dessas etapas.

\subsubsection{Desentrelaçamento}

No desentrelaçamento da imagem de entrada as linhas pares são separadas das ímpares, obtendo-se assim duas imagens com a metade da resolução vertical da imagem original. Como a captura das linhas pares e ímpares é sincronizada com o acionamento dos LEDs da câmera ou do monitor, em uma das imagens desentrelaçadas aparecem a pupila brilhante e o reflexo dos LEDs da câmera sobre a córnea. Já na outra imagem temos a pupila escura e os 4 reflexos gerados pelos LEDs posicionadas nos cantos do monitor. A figura 5.4 mostra as imagens obtidas pelo desentrelaçamento da imagem da figura 5.3.

\subsubsection{Detecção inicial da pupila}

Nesta etapa, queremos apenas obter uma localização aproximada da pupila a fim de definir uma região de interesse (RDI) para realizar os processamentos posteriores. Para isso tomamos as duas imagens obtidas do desentrelaçamento e reduzimos os seus tamanhos de 768 x 240 pixels para 128 x 40 pixels. Em seguida subtraímos a imagem com a pupila escura da imagem com a pupila brilhante. Devido à diferença de iluminação da pupila nas duas imagens, a região correspondente a ela na imagem obtida pela subtração possui intensidade maior do que no restante da imagem. Aplicando um limiar (configurável pela interface, uma vez que a intensidade da pupila brilhante varia de pessoa para pessoa [NWKF02]), segmentamos a região 

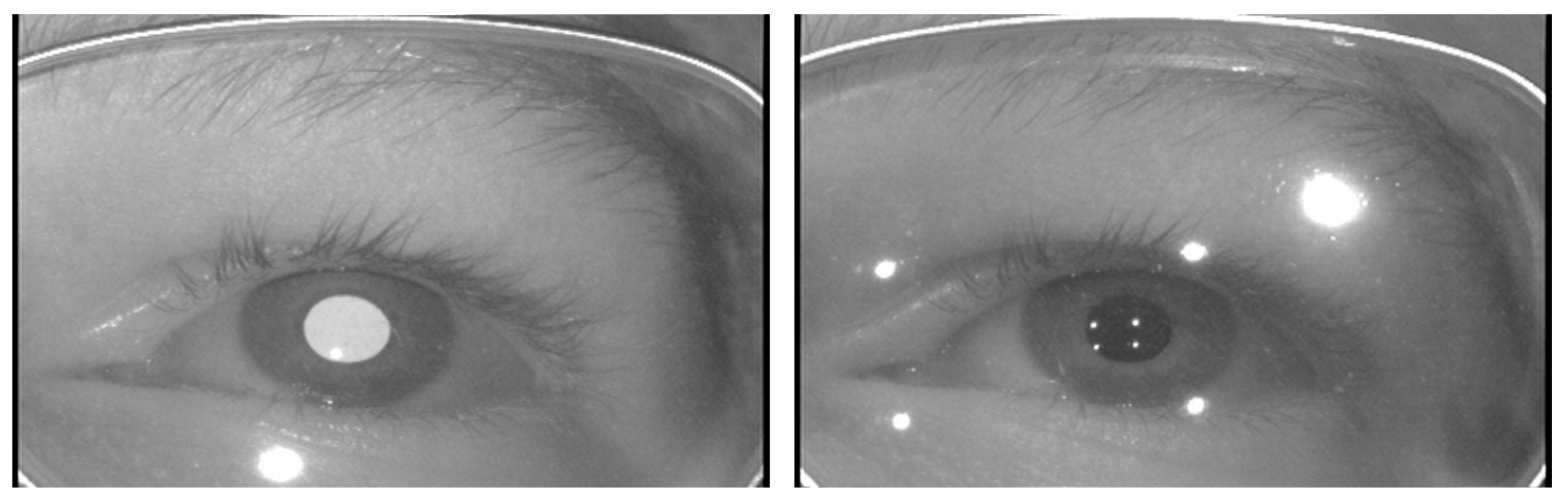

Figura 5.4: imagens obtidas pelo desentrelaçamento da figura 5.3. Na imagem à esquerda temos a pupila brilhante e o reflexo sobre a córnea correspondente à fonte de luz posicionada no eixo óptico da câmera. Na imagem à direita temos a imagem com a pupila escura com os reflexos sobre a córnea das 4 fontes de luz posicionadas no monitor. As imagens foram escaladas para manter o aspecto original da imagem capturada.

correspondente à pupila (veja figura 5.5) e tomamos o centro de massa da região segmentada como sua localização inicial. Como não é garantido que a segmentação pelo limiar resulta em apenas uma região conexa, o candidato à pupila é selecionado pelos seguintes critérios: deve ser a maior região obtida e não pode ser exageradamente alongada. Isto é, dado o retângulo circunscrito à região candidata, a maior dimensão do retângulo não deve ser maior do que duas vezes sua menor dimensão. A configuração manual do limiar aplicado sobre a imagem resultante da operação de subtração também pode ajudar a eliminar regiões que são falsas candidatas à pupila. Outra possibilidade que deve ser levada em conta é a ausência de regiões adequadas após a operação de limiar. Neste caso considera-se que não há um olho na imagem.

Note que poderíamos pular essa procura inicial da região da pupila e partir diretamente para os próximos passos descritos a seguir. Contudo realizar os próximos passos sobre toda a região das imagens em suas dimensões originais seria computacionalmente custoso e demorado. É por isso que fazemos a procura inicial da pupila utilizando cópias reduzidas das imagens. 

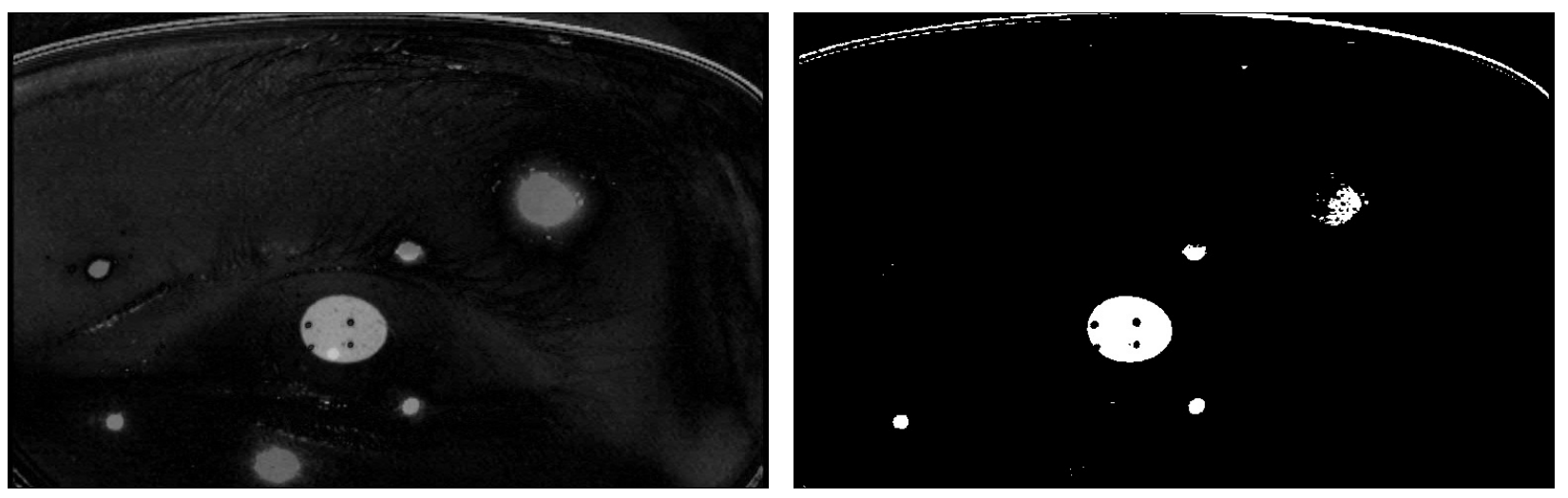

Figura 5.5: à esquerda: resultado da subtração da imagem da pupila escura da imagem da pupila clara mostradas na figura 5.4. À direita: resultado da aplicação de um limiar sobre a imagem resultante da subtração. As imagens foram escaladas para manter o aspecto original da imagem capturada.

Dessa forma, a procura inicial é feita rapidamente e podemos definir uma região de interesse nas imagens originais reduzindo a área de processamento significativamente. A RDI obtida após a localização inicial da pupila possui uma dimensão de $160 \times 80$ pixels com a pupila localizada no centro dessa região (veja figura 5.6).

\subsubsection{Procura dos reflexos sobre a córnea}

Uma vez definido o ROI em torno da localização inicial da pupila, o próximo passo da implementação é a procura dos reflexos sobre a córnea. Essa procura é feita tanto sobre a imagem com a pupila clara, para se obter o reflexo correspondente ao LED sobre o eixo óptico da câmera, quanto sobre a imagem com a pupila escura, a fim de se obter os 4 reflexos gerados pelos LEDs localizados nos quatro cantos do monitor.

Os reflexos são formados pela reflexão especular das fontes de luz sobre a córnea gerando pontos muito brilhantes na imagem. Por isso sua segmentação é relativamente simples, através 

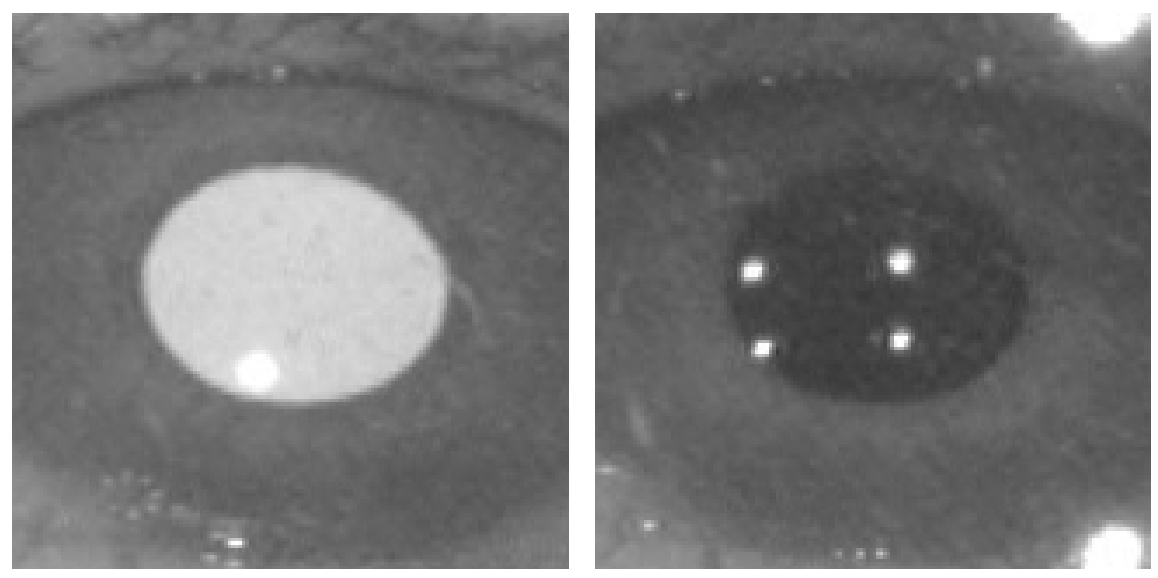

Figura 5.6: RDIs selecionadas nas imagens da pupila clara (à esquerda) e escura (à direita), após detecção inicial da pupila. As imagens foram escaladas para manter o aspecto original da imagem capturada.

da aplicação de um limiar sobre as imagens e posterior rotulação de cada região conexa. Entretanto alguns problemas podem acontecer nesta etapa. Como queremos encontrar um número determinado de reflexos em cada imagem, a falta ou o excesso (veja um exemplo na figura 5.7) deles são condições que podem ocorrer e precisamos encontrar maneiras de contornar essa situação quando possível.

A primeira solução para evitar esse problema de excesso ou falta de reflexos detectados na imagem é a aplicação de uma operação morfológica de fechamento. Essa operação, feita após a aplicação do limiar sobre a imagem e antes de marcar as componentes conexas, consiste de uma dilatação seguida de uma erosão e tende a tampar pequenos buracos de uma imagem binária ou agrupar regiões desconexas muito próximas [GW01]. Com isso, reflexos que possivelmente estivessem fragmentados em mais de uma componente logo após a limiarização, devido a utilização de um valor não apropriado para o limiar, são novamente agrupados. Contudo, mesmo com a aplicação da operação de fechamento, ainda é possível que a quantidade de componentes conexas encontrada na imagem não seja a esperada, podendo haver tanto excesso 


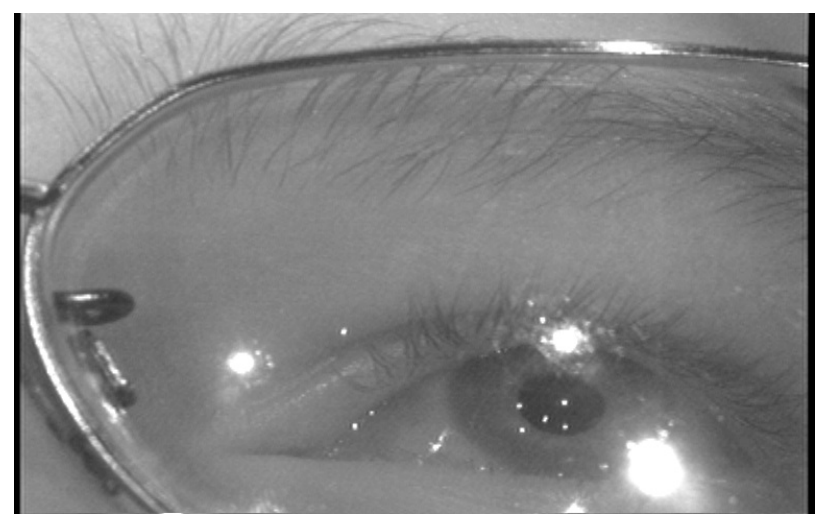

Figura 5.7: exemplo de imagem capturada onde há excesso de reflexos sobre a córnea.

quanto falta de reflexos.

Para contornar o problema do excesso de reflexos, depois da localização inicial, rejeitamos aqueles que são excessivamente grandes (uma ocorrência freqüente para usuários que usam óculos) uma vez que, quando a imagem capturada está em foco, os reflexos são pequenos. Também rejeitamos os reflexos que estão afastados demais da localização inicial da pupila. O motivo para isso é que, em um cenário normal de uso, o usuário esta olhando para o monitor e assim os quatro reflexos gerados pelos LEDs do monitor devem estar sempre a uma distância máxima do centro da pupila. Para o LED posicionado no eixo óptico da câmera vale a mesma idéia. A medida máxima da distância reflexo-pupila utilizada (máximo de 70 pixels na horizontal ou vertical) foi obtida experimentalmente e tem por objetivo apenas excluir rapidamente candidatos certamente inapropriados.

O passo final que visa descartar os reflexos inválidos que ainda temos neste ponto é diferente para a imagem da pupila clara e escura. Para a imagem da pupila clara, como queremos detectar a localização de apenas um reflexo, escolhemos o maior dentre os candidatos restantes.

Já para a imagem da pupila escura, a seleção dos reflexos válidos é feita da seguinte forma: tomamos todas as combinações possíveis de 4 reflexos e fazemos o cálculo da sua 
retangularidade. Essa medida, que indica o quão próximo um quadrilátero é de um retângulo (que teria retangularidade zero), é definida por:

$$
r e t=\sum_{i=1}^{4}\left|a_{i}-90\right|
$$

onde $a_{i}$ é o i-ésimo ângulo interno do quadrilátero em graus. O conjunto de quatro reflexos que tiver a menor retangularidade é tomado como os quatro reflexos válidos gerados pelos LEDs posicionados no monitor. Isso porque, embora o quadrilátero desejado não seja um retângulo perfeito, ele não é deformado em demasia considerando o posicionamento normal do usuário em relação ao sistema rastreador. Além disso, na grande maioria dos casos, os reflexos em excesso (que sobram após as etapas descritas acima), são apenas um ou dois que destoam dos

quatro reflexos válidos. É importante notar que se chegarmos a essa etapa da procura dos reflexos e o número de reflexos em excesso for maior que dois, então simplesmente desistimos de selecionar os reflexos esperados e consideramos que não foi possível fazer o processamento completo para a dada imagem de entrada. Isso porque, sem haver essa limitação, o número de combinações cresce muito rapidamente inviabilizando o processamento em tempo real da imagem.

Para a falta de reflexos, tanto para a imagem da pupila clara, quanto para a imagem da pupila escura, nenhuma solução foi implementada. Assim, havendo falta de reflexos detectados em qualquer uma das imagens, consideramos que não foi possível fazer o processamento completo da imagem capturada.

\subsubsection{Procura detalhada da pupila}

Apesar de termos uma estimativa aproximada sobre a localização da pupila na imagem, para que os resultados obtidos pelo algoritmo de estimação do olhar sejam os melhores possíveis é 
necessário ter uma estimativa precisa do seu centro já que o algoritmo implementado baseia-se na posição relativa entre o centro da pupila e os reflexos gerados pelos LEDs do monitor.

Para tanto, essa segmentação é similar à segmentação inicial da posição da pupila, mas usando as imagens na sua dimensão original e considerando apenas a RDI em torno da localização inicial a fim de ganhar desempenho. Dessa forma, primeiro a imagem da pupila escura é subtraída da imagem da pupila brilhante. Em seguida, é aplicado um limiar (o mesmo utilizado na segmentação inicial) e da imagem binária resultante são extraídos os contornos externos de cada região conexa. Sabemos que a pupila é uma das regiões conexas obtidas na imagem binária, mas podem haver outras regiões conexas resultantes de outras áreas que possuem grande variação na intensidade de seus pixels nas imagens da pupila clara/escura. Contudo essas regiões são em sua maioria resultantes dos próprios reflexos sobre a imagem sendo assim fácil descartá-los. Basta tomar o maior contorno obtido uma vez que os reflexos são menores do que a pupila.

A etapa seguinte consiste em aproximar esse contorno para uma elipse, mas antes disso é necessário verificar se o contorno achado possui interferências externas que possam comprometer a aproximação. Na grande maioria dos casos, são os próprios reflexos que interferem no contorno quando ficam localizados exatamente sobre a borda da pupila na imagem do olho. Para resolver isso, tomamos todos os reflexos encontrado nas imagens tanto da pupila clara quanto escura e excluímos as regiões destes reflexos do contorno da pupila. O contorno resultante, embora "incompleto", está livre de interferências e pode ser utilizado para se fazer a aproximação de uma elipse. Feita a aproximação, tomamos o centro da pupila como sendo o centro da elipse. Note que não utilizamos o centro de massa da região correspondente à pupila, como fizemos na sua localização inicial, uma vez que os reflexos podem afetar tanto a borda quanto o interior dessa região e, nesses casos, o cálculo do centro da pupila baseado no seu centro de massa não seria preciso. 


\subsubsection{Estimando a direção do olhar}

Após a execução das etapas anteriores, temos todas as características necessárias para estimar o olhar do usuário. Para realizar esse cálculo, devemos descobrir as correspondências entre os quatro reflexos detectados e os quatro cantos do monitor, isto é, devemos saber qual o reflexo superior-esquerdo, superior-direito, inferior-direito e inferior-esquerdo. Assumindo que a câmera tem o seu eixo y apontando aproximadamente para cima, isto é, na direção vertical, pode-se determinar as correspondências através do seguinte procedimento. Primeiro ordenase os quatro reflexos pela sua coordenada $x$, obtendo-se assim dois grupos de reflexos: os da esquerda e os da direita. Depois para cada grupo, tomamos os reflexos com menor coordenada $y$ como os reflexos superiores e os com maior coordenada $y$ como os inferiores (considerando a origem do sistema de coordenadas da imagem como sendo o canto superior esquerdo, o eixo $x$ crescendo para a direita e o eixo $y$ crescendo para baixo).

Em seguida, com os reflexos classificados, estimamos as projeções virtuais dos LEDs correspondentes. Para fins de comparação, além do novo método desenvolvido, utilizando 9 pontos de calibração (capítulo 4), foi implementado também o método de Yoo e Chung (seção 2.4.3) para estimação das projeções virtuais. Note que, para ambos os métodos, é necessário realizar um processo de calibração, antes de iniciar o rastreamento do olhar propriamente dito, que consiste em fazer o usuário olhar para pontos determinados da tela e armazenar as informações sobre as características detectadas na imagem para cada um desses pontos. Ao final desse processo, computa-se os parâmetros utilizados no cálculo das projeções virtuais e inicia-se a fase do rastreamento em si. Após o cálculo das projeções virtuais, são calculadas as razões cruzadas horizontais e verticais, como estudado na seção 2.4.3, obtendo-se a coordenada do ponto do monitor correspondente ao ponto visualizado pelo usuário. Por fim, no caso em que o novo método sugerido para calibração e estimação das projeções virtuais estiver sendo utilizado, soma-se ao ponto estimado o vetor deslocamento médio para corrigir a diferença entre o eixo 
óptico e o eixo visual do olho. 


\section{Capítulo 6}

\section{Resultados}

Nos primeiros testes do rastreador foi observado que, nas imagens onde o usuário olha fixamente para os LEDs, a posição do centro da pupila é relativamente próxima da posição do reflexo do LED sendo observado. Isso sugeriu que o fator de correção $\alpha$ a ser utilizado para a estimação das projeções virtuais dos LEDs fosse mais próximo a 1.0 do que 2.0, estando de acordo com a discussão feita na seção 2.4.3 sobre o valor de $\alpha$ esperado na prática. Com isso, inicialmente realizamos alguns testes nos quais desconsideramos a necessidade de se estimar as projeções virtuais dos LEDs, utilizando diretamente os reflexos dos mesmos.

Para medir de forma detalhada a precisão do sistema, foi implementada uma função de teste na aplicação do rastreador. Nessa função de teste, a tela é dividida em uma grade de $8 \times 6$ blocos de 4.2 por $4.5 \mathrm{~cm}$ de lado. O cursor é então posicionado no centro do primeiro bloco e o usuário deve olhar para o cursor, confirmando com um clique no mouse. A cada clique, a posição estimada do olhar é registrada e passa-se para o próximo ponto de teste até que o usuário tenha percorrido todos os 48 pontos da grade. Ao final do teste é gerada uma listagem contendo os pares de pontos reais e pontos estimados.

Baseado nessas observações iniciais, implementamos uma versão preliminar do rastreador 
sem estimar as projeções virtuais dos LEDs e sem considerar a diferença de eixos do olho. O erro médio obtido nesse teste inicial foi de aproximadamente $5.0 \mathrm{~cm}$ (aproximadamente $5.0^{\circ}$ ), confirmando as conclusões obtidas nos experimentos teóricos sobre como a diferença de eixos do olho afeta o resultado do algoritmo e como proceder para compensá-la. A maneira de se fazer tal correção seria através de uma rotação do eixo óptico no espaço 3D (como feito em [SWL00], [SL04] e [BF03]). Contudo, na técnica implementada, apenas temos informação sobre o ponto estimado sobre uma superfície plana e não temos informação sobre a posição do olho em 3D. De qualquer forma, os resultados dos experimentos simulados mostraram que a diferença de eixos resulta em um deslocamento do ponto de interesse que é relativamente constante. Assim, para a versão final do rastreador, foi implementado o novo método proposto para calibração e cálculo das projeções virtuais (descrito no capítulo 4) e para comparar, na prática, os resultados deste método com o método de Yoo e Chung, o método deles também foi implementado.

Para testar a implementação do sistema contamos com a participação de 5 usuários. Cada usuário executou a função de teste do rastreador 3 vezes, sendo que após cada execução eles eram orientados a mudar de posição. Para cada teste realizado foram estimados os pontos de interesse usando ambos os métodos de calibração. O erro médio obtido para todos os testes realizados utilizando o método de Yoo e Chung foi de $2.48 \mathrm{~cm}$ (aproximadamente $2.37^{\circ}$ ) com desvio padrão de $1.12 \mathrm{~cm}$. Já para o nosso método proposto neste trabalho, o erro médio obtido foi de $0.95 \mathrm{~cm}$ (aproximadamente $0.91^{\circ}$ ) com desvio padrão de $0.7 \mathrm{~cm}$. Na figuras $6.1 \mathrm{e}$ 6.2 podemos ver os resultados obtidos para cada técnica. Apesar dos resultados para o método de Yoo e Chung terem sido melhores do que os obtidos nas simulações (mostrando que, na prática, a influência da diferença angular entre os eixos do olho é menor do que observado nos experimentos), eles ainda são piores do que os obtidos pelo método proposto neste trabalho que leva em conta a diferença de eixos do olho em seu processo de calibração. Na tabela 6.1, 
podemos ver os resultados individuais obtidos para cada usuário na primeira execução do teste (isto é, logo após a calibração). Já na tabela 6.2, temos os resultados obtidos para as demais execuções. Separamos os resultados obtidos na primeira execução do teste das demais para que fosse possível avaliar o impacto da movimentação do usuário no resultado, sendo constatada ligeira piora, após a movimentação dos usuários, para ambos os métodos testados. Podemos ver também que os resultados obtidos para o método de Yoo e Chung não são tão uniformes entre os usuários, mostrando assim que a diferença de eixos do olho é uma característica que apresenta certa variabilidade entre as pessoas. A tabela 6.3 mostra os valores dos parâmetros obtidos via calibração, para cada usuário, para os métodos de Yoo e Chung e para o novo método. Para este último, também é exibida a diferença angular estimada entre os eixos do olho.

\begin{tabular}{|l|c|c|c|c|}
\hline & \multicolumn{2}{|c|}{ Método Yoo - $\mathbf{1}^{\mathbf{0}}$ teste } & \multicolumn{2}{c|}{ Método proposto - $\mathbf{1}^{\mathbf{0}}$ teste } \\
\hline Usuário & Erro médio & Desvio padrão & Erro médio & Desvio padrão \\
\hline usuário $1^{*}$ & $1.51 \mathrm{~cm}\left(1.44^{\circ}\right)$ & $0.69 \mathrm{~cm}$ & $1.23 \mathrm{~cm}\left(1.17^{\circ}\right)$ & $1.39 \mathrm{~cm}$ \\
\hline usuário 2 & $2.51 \mathrm{~cm}\left(2.4^{\circ}\right)$ & $0.82 \mathrm{~cm}$ & $0.73 \mathrm{~cm}\left(0.7^{\circ}\right)$ & $0.29 \mathrm{~cm}$ \\
\hline usuário $3^{* *}$ & $1.75 \mathrm{~cm}\left(1.67^{\circ}\right)$ & $0.48 \mathrm{~cm}$ & $0.73 \mathrm{~cm}\left(0.7^{\circ}\right)$ & $0.39 \mathrm{~cm}$ \\
\hline usuário 4 & $3.15 \mathrm{~cm}\left(3.0^{\circ}\right)$ & $1.13 \mathrm{~cm}$ & $0.88 \mathrm{~cm}\left(0.84^{\circ}\right)$ & $0.48 \mathrm{~cm}$ \\
\hline usuário 5 & $2.98 \mathrm{~cm}\left(2.84^{\circ}\right)$ & $0.86 \mathrm{~cm}$ & $0.78 \mathrm{~cm}\left(0.75^{\circ}\right)$ & $0.43 \mathrm{~cm}$ \\
\hline
\end{tabular}

Tabela 6.1: resultados obtidos para cada usuário na primeira execução do teste, comparando o método de Yoo e Chung com o novo método proposto para estimação das projeções virtuais. Os usuários marcados com $\left(^{*}\right)$ e $(* *)$ utilizavam, respectivamente, lentes de contato e óculos.

Como o método proposto obteve melhores resultados, outro conjunto de testes foi realizado, desta vez testando apenas nosso método para estimação das projeções virtuais. Para esse teste contamos com a participação de mais 4 usuários (diferentes dos 5 primeiros), sendo que cada um também executou a função de teste do rastreador 3 vezes. Os resultados obtidos para este novo teste foram os seguintes: erro médio de $0.96 \mathrm{~cm}$ (aproximadamente $0.91^{\circ}$ ) e desvio 

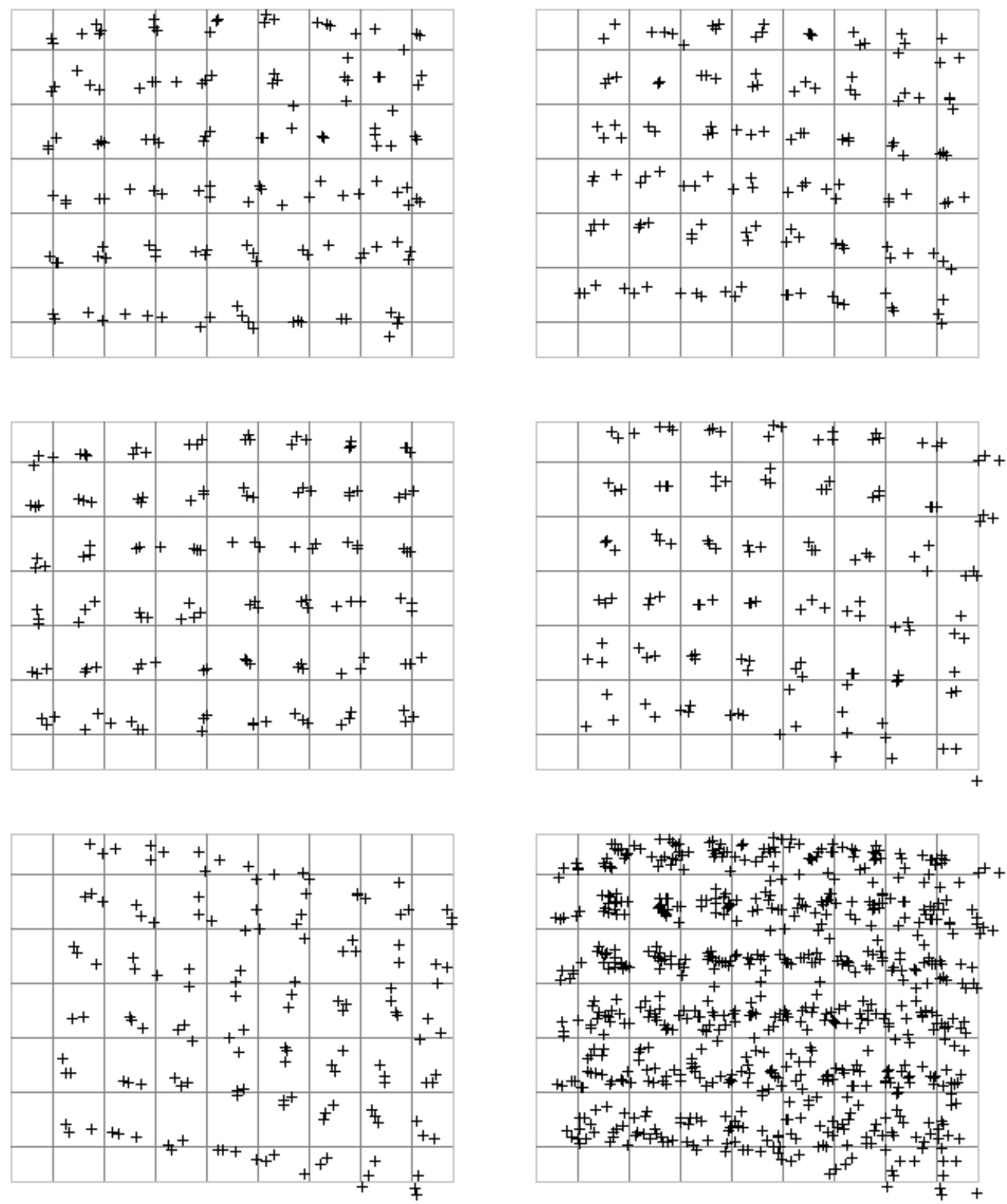

Figura 6.1: resultados obtidos com a implementação do rastreador utilizando o método de Yoo e Chung para estimar as projeções virtuais. As cruzes representam os pontos estimados e os cruzamentos das linhas os pontos reais observados. Seguindo da esquerda para a direita e de cima para baixo, as primeiras 5 imagens mostram os resultados individuais para os usuários 1-5 respectivamente. A última imagem reúne os resultados de todos os usuários. 

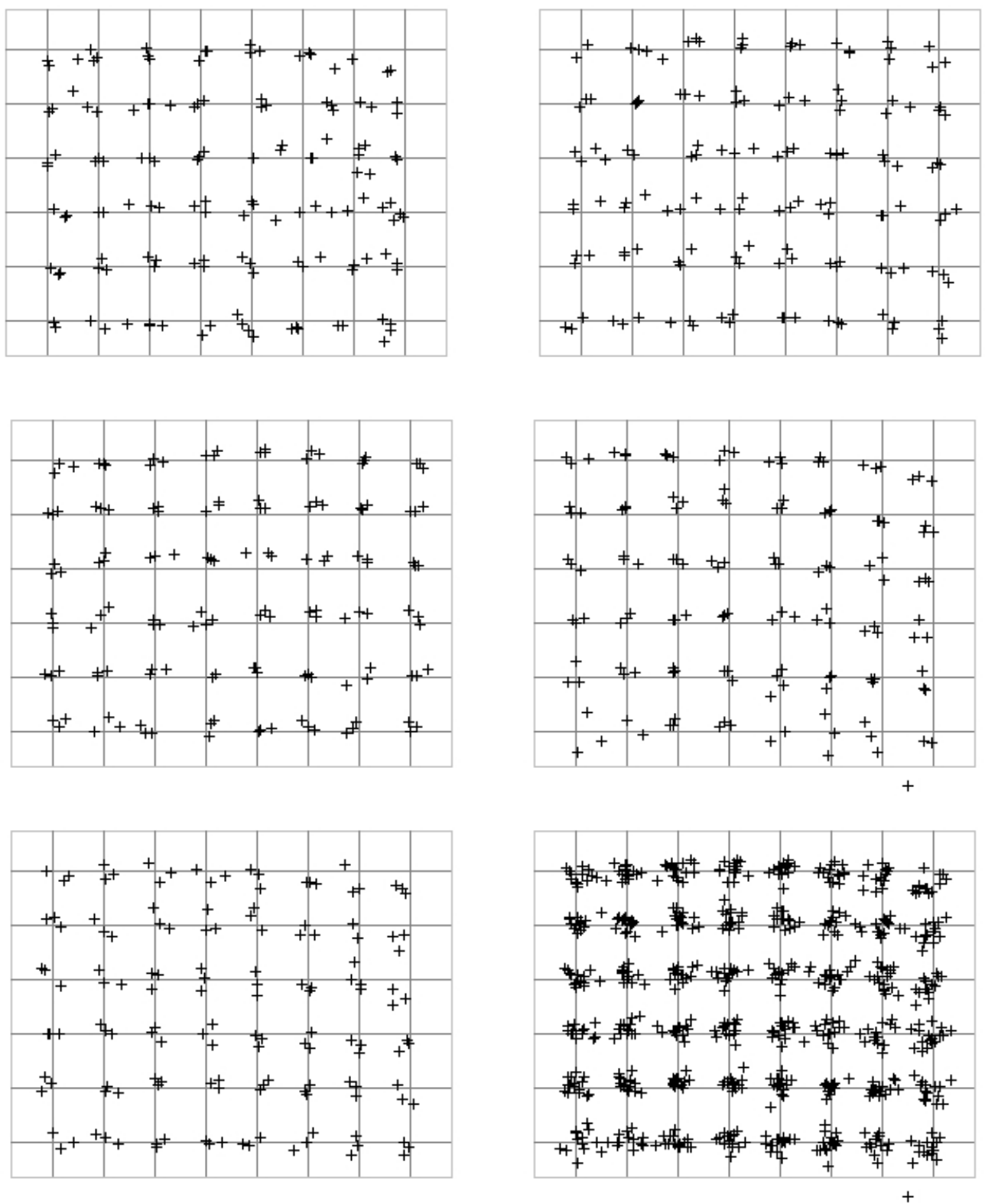

Figura 6.2: resultados obtidos com a implementação do rastreador utilizando o método proposto neste trabalho para estimar as projeções virtuais. As cruzes representam os pontos estimados e os cruzamentos das linhas os pontos reais observados. Seguindo da esquerda para a direita e de cima para baixo, as primeiras 5 imagens mostram os resultados individuais para os usuários 1-5 respectivamente. A última imagem reúne os resultados de todos os usuários. 


\begin{tabular}{|l|c|c|c|c|}
\hline & \multicolumn{2}{|c|}{ Método Yoo - demais testes } & \multicolumn{2}{c|}{ Método proposto - demais testes } \\
\hline Usuário & Erro médio & Desvio padrão & Erro médio & Desvio padrão \\
\hline usuário 1 & $1.98 \mathrm{~cm}\left(1.89^{\circ}\right)$ & $0.96 \mathrm{~cm}$ & $1.15 \mathrm{~cm}\left(1.1^{\circ}\right)$ & $0.96 \mathrm{~cm}$ \\
\hline usuário 2 & $2.53 \mathrm{~cm}\left(2.42^{\circ}\right)$ & $1.03 \mathrm{~cm}$ & $0.98 \mathrm{~cm}\left(0.94^{\circ}\right)$ & $0.62 \mathrm{~cm}$ \\
\hline usuário $3^{* *}$ & $1.8 \mathrm{~cm}\left(1.72^{\circ}\right)$ & $0.59 \mathrm{~cm}$ & $0.9 \mathrm{~cm}\left(0.86^{\circ}\right)$ & $0.55 \mathrm{~cm}$ \\
\hline usuário 4 & $2.95 \mathrm{~cm}\left(2.81^{\circ}\right)$ & $1.15 \mathrm{~cm}$ & $0.98 \mathrm{~cm}\left(0.94^{\circ}\right)$ & $0.62 \mathrm{~cm}$ \\
\hline usuário 5 & $3.36 \mathrm{~cm}\left(3.21^{\circ}\right)$ & $1.11 \mathrm{~cm}$ & $0.93 \mathrm{~cm}\left(0.89^{\circ}\right)$ & $0.51 \mathrm{~cm}$ \\
\hline
\end{tabular}

Tabela 6.2: resultados obtidos para cada usuário nas demais execuções do teste, comparando o método de Yoo e Chung com o novo método proposto para estimação das projeções virtuais. Os usuários marcados com $\left(^{*}\right)$ e $(* *)$ utilizavam, respectivamente, lentes de contato e óculos.

\begin{tabular}{|l|c|c|c|c|c|c|}
\hline & \multicolumn{3}{|c|}{ Método Yoo e Chung } & \multicolumn{2}{|c|}{ Método proposto } \\
\hline Usuário & $\alpha_{1}$ & $\alpha_{2}$ & $\alpha_{3}$ & $\alpha_{4}$ & $\alpha$ & diferença angular \\
\hline usuário 1* & 1.07 & 1.03 & 1.17 & 1.05 & 1.13 & $0.82^{\circ}$ \\
\hline usuário 2 & 1.22 & 1.27 & 1.36 & 1.1 & 1.18 & $3.6^{\circ}$ \\
\hline usuário 3** & 1.05 & 1.02 & 0.98 & 1.12 & 1.06 & $1.73^{\circ}$ \\
\hline usuário 4 & 1.13 & 1.13 & 1.41 & 0.91 & 1.18 & $4.6^{\circ}$ \\
\hline usuário 5 & 0.99 & 1.16 & 1.4 & 0.81 & 1.14 & $5.06^{\circ}$ \\
\hline
\end{tabular}

Tabela 6.3: valores dos parâmetros obtidos via calibração para cada usuário e método utilizado para estimação das projeções virtuais. Além disso, para o método proposto, é exibida a diferença angular estimada entre os eixos do olho. Os usuários marcados com $(*)$ e $(* *)$ utilizavam, respectivamente, lentes de contato e óculos.

padrão de $1.0 \mathrm{~cm}$. Na figura 6.3 e na tabela 6.4 podemos observar os resultados individuais para cada usuário.

Podemos observar, através dos experimentos, que o rastreador implementado baseado nos trabalhos de Yoo e Chung [YLC02, YC05] atingiu resultados satisfatórios, com uma precisão em torno de $1^{\circ}$, similar à obtida pelos autores da técnica. Entretanto, tal resultado só foi obtido utilizando um método próprio de calibração e estimação das projeções virtuais dos LEDs que considera a diferença de eixos do olho. Utilizando a implementação original dos autores os resultados obtidos foram consideravelmente piores. Além disso, o rastreador implemen- 

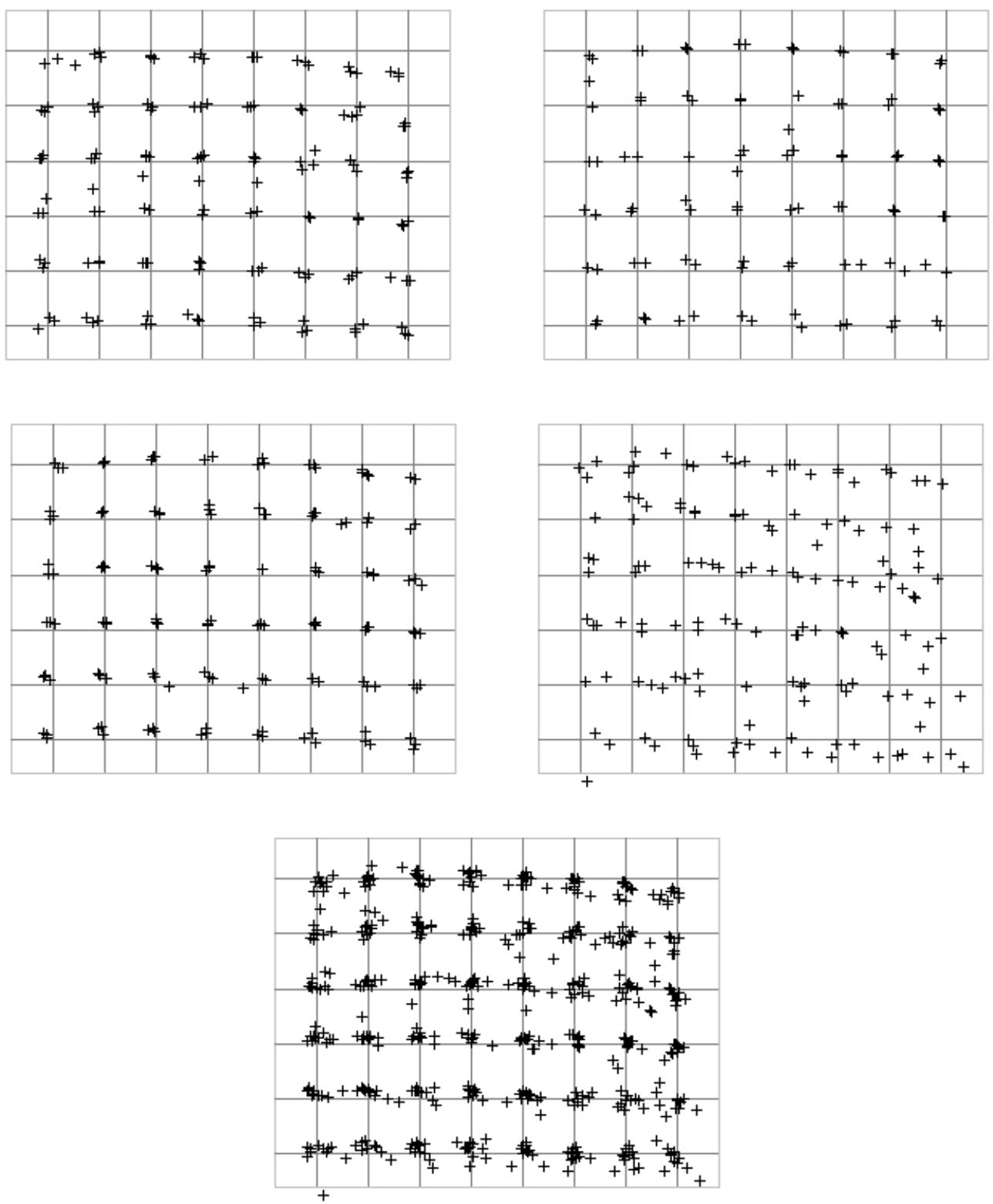

Figura 6.3: resultados obtidos utilizando o método proposto neste trabalho para estimar as projeções virtuais. As cruzes representam os pontos estimados e os cruzamentos das linhas os pontos reais observados. Seguindo da esquerda para a direita e de cima para baixo, as primeiras 4 imagens mostram os resultados individuais para os usuários 6-9 respectivamente. A última imagem reúne os resultados de todos os usuários. 


\begin{tabular}{|l|c|c|c|c|}
\hline & \multicolumn{2}{|c|}{$\mathbf{1}^{\mathbf{0}}$ teste } & \multicolumn{2}{c|}{ Demais testes } \\
\hline Usuário & Erro médio & Desvio padrão & Erro médio & Desvio padrão \\
\hline usuário 6 & $1.2\left(1.15^{\circ}\right) \mathrm{cm}$ & $1.48 \mathrm{~cm}$ & $0.64\left(0.61^{\circ}\right) \mathrm{cm}$ & $0.46 \mathrm{~cm}$ \\
\hline usuário 7 & $0.59\left(0.56^{\circ}\right) \mathrm{cm}$ & $0.37 \mathrm{~cm}$ & $0.78\left(0.75^{\circ}\right) \mathrm{cm}$ & $0.59 \mathrm{~cm}$ \\
\hline usuário 8 & $0.59\left(0.56^{\circ}\right) \mathrm{cm}$ & $0.27 \mathrm{~cm}$ & $0.82\left(0.78^{\circ}\right) \mathrm{cm}$ & $0.9 \mathrm{~cm}$ \\
\hline usuário 9* $^{*} 1.38\left(1.32^{\circ}\right) \mathrm{cm}$ & $1.41 \mathrm{~cm}$ & $1.56\left(1.49^{\circ}\right) \mathrm{cm}$ & $1.16 \mathrm{~cm}$ \\
\hline
\end{tabular}

Tabela 6.4: resultados obtidos para novo teste realizado utilizando apenas o método proposto para estimar as projeções virtuais. Na tabela foram separados os resultados obtidos na primeira e demais execuções do teste. O usuário marcado com $\left(^{*}\right)$ utilizava óculos.

tado se mostrou robusto a movimentações da cabeça, uma vez que os resultados obtidos para cada usuário na primeira execução do teste foram similares aos obtidos nas demais execuções, embora saibamos que o novo método de calibração sugerido é sensível a movimentos de aproximação e afastamento do usuário em relação ao monitor. Entre os usuários que participaram dos testes dois usavam óculos e um lentes de contato. Para essas pessoas, em especial para o usuário com lentes de contato, foi observada uma maior dificuldade para se detectar os reflexos dos LEDs sobre a córnea. Os usuário que usavam óculos precisaram, algumas vezes, procurar novas posições para que reflexos adicionais gerados sobre as lentes não atrapalhassem a detecção dos reflexos sobre a córnea pelo rastreador. Contudo, mesmo para esses usuários (de óculos e lentes), uma vez que os reflexos sobre a córnea foram detectados com sucesso, não foram observadas diferenças significativas nos resultados obtidos. 


\section{Capítulo 7}

\section{Conclusão}

Neste trabalho tratamos do problema do rastreamento (ou estimação) do olhar, que consiste em determinar a direção para onde uma pessoa está olhando. Para isso, fizemos o levantamento bibliográfico de algumas técnicas desenvolvidas para resolver esse problema, passando pelas mais tradicionais, até chegar a técnicas mais recentes. Como nosso foco de uso de rastreadores de olhar está em aplicações para a área de Interação Humano Computador (IHC), técnicas intrusivas, que exigem a utilização de equipamentos em contato com o usuário, e técnicas remotas tradicionais, que não permitem uma grande liberdade de movimentação da cabeça e exigem calibração freqüente, não são muito apropriadas. Algumas técnicas mais recentes estudadas contornam essas limitações através do uso de modelos geométricos mais avançados que apresentam maior robustez a movimentos do usuário. Além disso, a calibração por sessão de uso pode ser substituída por uma calibração feita apenas uma vez, que pode ser armazenada e reutilizada em outras sessões.

Entre as técnicas recentes estudadas, a técnica desenvolvida por Yoo et al. [YLC02, YC05] se mostrou a mais promissora para aplicações em IHC. Ela emprega apenas uma câmera que não precisa ser calibrada e é mais tolerante a movimentos de cabeça. Além disso, não é 
necessário conhecer qualquer informação especial sobre o ambiente cercando o usuário, com exceção das dimensões do monitor. Essa técnica baseia-se no mapeamento de múltiplos reflexos sobre a córnea, gerados por LEDs infravermelhos posicionados nos 4 cantos do monitor. Considera-se a existência de um plano virtual tangente à superfície da córnea onde os pontos correspondentes aos 4 LEDs são projetados. Através da aplicação da razão cruzada a partir desses 4 pontos mais o centro da pupila é possível calcular o ponto observado sobre o monitor.

A fim de avaliar o desempenho dessa técnica, uma série de experimentos utilizando dados sintéticos foram feitos. Em especial foram observadas as influências dos seguintes fatores nos resultados: variações no método para estimar as projeções virtuais dos LEDs, diferença de eixo óptico e eixo visual do olho e tolerância da técnica a movimentos da cabeça. Os resultados experimentais mostraram que o método original, proposto por Yoo e Chung [YC05], para estimação das projeções virtuais apresenta erro maior quando se considera a diferença de eixos do olho, o que nos levou ao desenvolvimento de um novo método. No novo método é feito um processo de calibração que além de calcular o fator de correção $\alpha$ utilizado no cálculo das projeções virtuais, também calcula um vetor deslocamento a ser usado na correção da diferença de eixos do olho. Foram testadas calibrações usando 4 e 9 pontos sendo que com 9 pontos obteve-se melhores resultados (precisão de $0.64^{\circ}$ contra $1.1^{\circ}$ utilizando 4 pontos). Como a diferença de eixos do olho é uma diferença angular mas a compensação que fazemos consiste na soma de um vetor ao ponto estimado, a precisão da técnica utilizando este novo método possui uma certa sensibilidade a movimentos de afastamento e aproximação do olho em relação ao monitor. Mesmo assim, a tolerância a movimentação se mostrou superior à obtida em experimentos similares para a técnica tradicional baseada na detecção da pupila e de um reflexo sobre a córnea.

Uma de nossas maiores contribuições foi a extensão da técnica de múltiplos reflexos considerando um método mais completo do olho, que considera a diferença de eixos óptico e 
visual.

A precisão atingida com nossa implementação foi de aproximadamente $1^{\circ}$, utilizando 9 pontos de calibração. Para fins de comparação, implementamos também o método de estimação das projeções virtuais desenvolvido por Yoo e Chung. Contudo, os resultados obtidos foram piores, com uma precisão em torno de $2.4^{\circ}$. Esse resultado é um pouco estranho uma vez que fizemos a implementação do método deles exatamente como descrito no trabalho original, mas sem obter os mesmos resultados práticos (precisão também em torno de $1^{\circ}$ ). Nós acreditamos que no trabalho deles deve haver uma compensação de translação que de certa forma corrigiria parte dos efeitos da diferença de eixos, mas que não é descrita no artigo.

Entre as razões para não obtenção de um resultado melhor podemos citar: o fato da córnea ser curva que vai contra nossa hipótese de que os LEDs são projetados sobre um plano virtual tangente à córnea; o nosso método de calibração que perde precisão quando o usuário se afasta ou se aproxima do monitor; e por fim a limitação de tamanho das imagens capturadas. Embora a resolução da imagem capturada seja relativamente grande $(768 \times 480$ pixels), o quadrilátero formado pelos reflexos dos LEDs do monitor, na imagem desentrelaçada da pupila escura, apresenta uma dimensão em torno de 40-50 pixels de largura por 15-20 pixels de altura. Dessa forma, um desvio de poucos pixels na detecção dos reflexos ou da pupila pode gerar erros consideráveis na estimativa do olhar.

Como principais contribuições de nosso trabalho podemos citar:

- revisão e síntese da literatura sobre rastreadores de olhar sem calibração e tolerantes a movimentos da cabeça;

- estudo de avaliação de desempenho utilizando um modelo sintético do olho, através do qual podemos medir e comparar o desempenho das técnicas de rastreamento;

- desenvolvimento de uma extensão do trabalho de Yoo et al. [YLC02, YC05], que utiliza 
de um modelo do olho mais completo, capaz de compensar diferenças entre o eixo óptico e o visual;

- desenvolvimento de um sistema de rastreamento de olhar de tempo real, tolerante a movimentação da cabeça, que utiliza uma única câmera e que apresenta precisão comparável a outros sistemas existentes mas conforto muito maior por tolerar movimentos de cabeça;

- avaliação prática do sistema desenvolvido, testando com usuários, e comparando com outros sistemas existentes.

Como trabalhos futuros, uma alternativa para melhorar a perda de precisão devido a movimentos de aproximação e afastamento do monitor por parte do usuário seria calcular a posição do olho em 3D. Combinando o método desenvolvido por Morimoto et al. [MAF02a, MAF02b] com o nosso rastreador seria possível corrigir a diferença de eixos do olho através de um deslocamento proporcional à distância do usuário ao monitor, uma vez que esse vetor deslocamento mantém aproximadamente sua direção e sentido mesmo quando sua magnitude é afetada devido a movimentação do usuário. Outras possibilidades para trabalhos futuros envolvem a elaboração de um processo de detecção de reflexos sobre a córnea mais robusto que consiga compensar a eventual falta de algum deles. Nossa implementação só consegue estimar o olhar se todos os 5 reflexos esperados forem encontrados na imagem. A possibilidade de se compensar a falta de um desses pontos é interessante pois, nos testes práticos, para o nosso posicionamento de câmera e monitor, quando os usuários olhavam para porção inferior da tela, era relativamente freqüente acontecer de um dos 4 reflexos sobre a córnea desaparecer, exigindo que o usuário fizesse pequenos movimentos para procurar uma posição mais adequada. 


\section{Referências Bibliográficas}

[Bar05] T. S. Barcelos. Interfaces prestativas baseadas em visão computacional e informação de contexto. Master's thesis, Departamento de Ciência da Computação do Instituto de Matemática e Estatística, Universidade de São Paulo, Junho 2005. 4,5

[Bar06] R. A. Barbosa. Deteç̧ão e estimação da orientação 3d de faces. Master's thesis, Departamento de Ciência da Computação do Instituto de Matemática e Estatística, Universidade de São Paulo, Agosto 2006. 4

[BF03] David Beymer and Myron Flickner. Eye gaze tracking using an active stereo head. In Proceedings of the IEEE Conference on Computer Vision and Pattern Recognition, volume 2, pages 451-458, 2003. 27, 84

[BP94] Shumeet Baluja and Dean Pomerleau. Non-intrusive gaze tracking using artificial neural networks. Technical Report CMU-CS-94-102, Computer Science Department, Carnegie Mellon University, Pittsburgh, PA, January 1994. 14, 15

[CC73] T. Cornsweet and H. Crane. Accurate two dimensional eye tracker using first and fourth purkinje images. Journal of the optical Society of America, 63:921-928, 1973. 14 
[CMZ05] M. C. Cabral, C. H. Morimoto, and M.K. Zuffo. On the usability of gesture interfaces in virtual reality environments. In CLIHC'05, Conferencia Latinoamericana de Interacion Humano-Computadora, Cuernava, México, October 2005. 4

[Duc02] Andrew T. Duchowski. A breadth-first survey of eye tracking application. ehavior Research Methods, Instruments, and Computers (BRMIC), 34:455-470, 2002. 3

[Duc03] Andrew T. Duchowski. Eye Tracking Methodology: Theory and Practice. Springer Verlag, January 2003. 8

[Ebi95] Yoshinobu Ebisawa. Unconstrained pupil detection technique using two light sources and the image difference method. Visualization and Intelligent Design in engineering and architecture, pages 79-89, 1995. 11

[GEN95] A. Glenstrup and T. Engell-Nielsen. Eye controlled media: Present and future state. Master's thesis, University of Copenhagen DIKU (Institute of Computer Science), Universitetsparken 1 DK-2100 Denmark, June 1995. 8

[GF02] J. N. Van Der Geest and M. A. Frens. Recording eye movements with videooculography and scleral search coils: A direct comparison of two methods. Journal of Neuroscience Methods, 114:185-195, 2002. 12

[GW01] R. C. Gonzalez and R. E. Woods. Digital Image Processing. Prentice Hall, 2001. 77

[HZ00] R. Hartley and A. Zisserman. Multiple View Geometry in Computer Vision. Cambridge University Press, ISBN: 0521623049, 2000. 35 
[KBS93] A. Kaufman, A. Bandopadhay, and B. Shaviv. An eye tracking computer user interface. In Proc. of the research frontier in virtual reallity workshop, pages 7884, 1993. 12

[KR99] Kyung-Nam Kim and R. S. Ramakrishna. Vision-based eye-gaze tracking for human computer interface. In IEEE International Conference on Systems, Man, and Cybernetics, pages 324-329, 1999. 15

[Lon74] R. S. Longhurst. Geometrical and Physical Optics. John Wiley \& Sons, 1974. 10

[MAF02a] Carlos H. Morimoto, Arnon Amir, and Myron Flickner. Free head motion eye gaze tracking without calibration. In CHI 'O2 extended abstracts on Human factors in computing systems, pages 586-587, New York, NY, USA, 2002. ACM Press. 21, 94

[MAF02b] Carlos Hitoshi Morimoto, Arnon Amir, and Myron Flickner. Detecting eye position and gaze from a single camera and 2 light sources. In International Conference on Pattern Recognition, volume 4, pages 314-317, 2002. 21, 94

[MF00] Carlos H. Morimoto and Myron Flickner. Real-time multiple face detection using active illumination. In $F G^{\prime} 00$ : Proceedings of the Fourth IEEE International Conference on Automatic Face and Gesture Recognition, pages 8-13, 2000. 11

[MKAF99] C. H. Morimoto, D. Koons, A. Amir, and M. Flickner. Frame-rate pupil detector and gaze tracker. In Proceedings of the IEEE ICCV'99 Frame-Rate Computer Vision Applications Workshop, 1999. 18, 41, 66

[MKAF00] Carlos Morimoto, Dave Koons, Arnon Amir, and Myron Flickner. Pupil detection and tracking using multiple light sources. Image and vision computing, 18(4):331335, 2000. 11 
[MM05] Carlos H. Morimoto and Marcio R. M. Mimica. Eye gaze tracking techniques for interactive applications. Comput. Vis. Image Underst., 98(1):4-24, 2005. 5, 8, 10, $19,41,43,66$

[NWKF02] Karlene Nguyen, Cindy Wagner, David Koons, and M. Flickner. Differences in the infrared bright pupil response of human eyes. In Proceedings of the symposium on Eye tracking research and applications, pages 133-138, 2002. 11, 74

$\left[\mathrm{RMK}^{+} 88\right]$ J. Ruelen, J. T. Marcus, D. Koops, F. Vries, G. Tiesinga, K. Boshuizen, and J. Bos. Precise recording of eye movement: the iris technique, part 1. Medical \& Biological Engineering \&3 Computing, 26(1):20-26, 1988. 14

[Rob63] D. A. Robinson. A method of measuring eye movements using a scleral search coil in a magnetic field. IEEE Trans. Bio-Med. Electronics, 10:137-145, 1963. 12

[Sel04] T. Selker. Visual attentive interfaces. BT Technology Journal, 22(4):146-150, 2004. 4

[SL04] S. Shih and J. Liu. A novel approach to 3-d gaze tracking using stereo cameras. In IEEE transactions on systems, man, and cybernetics - part B, volume 34, pages 234-245, 2004. 25, 26, 84

[SVS03] Jeffrey S. Shell, Roel Vertegaal, and Alexander W. Skaburskis. Eyepliances: attention-seeking devices that respond to visual attention. In CHI Extended Abstracts, pages 770-771, 2003. 4

[SWL00] S. Shih, Y. Wu, and J. Liu. A calibration-free gaze tracking technique. In Proceedings of the International Conference on Pattern Recognition, volume 4, pages 201-204, 2000. 25, 84 
[SYW97] Rainer Stiefelhagen, Jie Yang, and Alex Waibel. Tracking eyes and monitoring eye gaze. In Workshop on Perceptual User Interfaces, pages 98-100, Banff, Canada, October 1997. 15

[Ver03] Roel Vertegaal. Attentive userinterfaces. Commun. ACM, 46(3):30-33, 2003. 1

[WS82] G. Wyszecki and W. S. Stiles. Color Science: Concepts and Methods, Quantitative Data and Formulae. John Wiley \& Sons, 1982. 8, 9, 42

[WS02] Jian Gang Wang and Eric Sung. Study on eye gaze estimation. IEEE transactions on systems, man, and cybernetics - part B: cybernetics, 32(3):332-350, 2002. 24

[YC05] Dong Hyun Yoo and Myung Jin Chung. A novel non-intrusive eye gaze estimation using cross-ratio under large head motion. Comput. Vis. Image Underst., 98(1):2551, 2005. 28, 30, 45, 53, 54, 55, 56, 57, 58, 61, 88, 91, 92, 93

[YLC02] Dong Hyun Yoo, Bang Rae Lee, and Myoung Jin Chung. Non-contact eye gaze tracking system by mapping of corneal reflections. In FGR '02: Proceedings of the Fifth IEEE International Conference on Automatic Face and Gesture Recognition, pages 101-106, Washington, DC, USA, 2002. IEEE Computer Society. 28, 30, 88, 91,93

[YS75] L. Young and D. Sheena. Methods \& designs: Survey of eye movement recording methods. Behavioral Research Methods \& Instrumentation, 7(5):397-429, 1975. 8, 10

[ZMI99] Shumin Zhai, Carlos Morimoto, and Steven Ihde. Manual and gaze input cascaded (magic) pointing. In $C H I$, pages 246-253, 1999. 4 